Portland State University

PDXScholar

Summer 7-27-2015

\title{
Leadership and Decision-Making Skills of High Poverty Elementary School Principals in an Era of Reduced Resources
}

Kevin Eugene Spooner

Portland State University

Follow this and additional works at: https://pdxscholar.library.pdx.edu/open_access_etds

Part of the Educational Leadership Commons, Elementary and Middle and Secondary Education Administration Commons, and the Finance and Financial Management Commons Let us know how access to this document benefits you.

\section{Recommended Citation}

Spooner, Kevin Eugene, "Leadership and Decision-Making Skills of High Poverty Elementary School Principals in an Era of Reduced Resources" (2015). Dissertations and Theses. Paper 2456.

https://doi.org/10.15760/etd.2454

This Dissertation is brought to you for free and open access. It has been accepted for inclusion in Dissertations and Theses by an authorized administrator of PDXScholar. Please contact us if we can make this document more accessible: pdxscholar@pdx.edu. 
Leadership and Decision-Making Skills of High Poverty Elementary School Principals in an Era of Reduced Resources

by

Kevin Eugene Spooner

A dissertation submitted in partial fulfillment of the requirements for the degree of:

Doctor of Education

in

Educational Leadership: Administration

Dissertation Committee:

Amy Petti, Chair

Samuel Henry

Candace Reynolds

Margarett Everett

Portland State University

2015 
(C) 2015 Kevin Eugene Spooner 


\begin{abstract}
Recently, a great deal of interest has been generated around the role of principal and its effectiveness, especially its impact on improving teacher instruction and student learning. Waters, Marzano, and McNulty (2003) concluded that one quarter of all "school effects" on achievement can be attributed to principals. While there is general agreement on the principal's importance and affect, do we understand how principals have adapted to changes in schools with reduced resources and increased learning needs of students? How have principals made decisions in an environment where resources have been reduced over time? Given the stories of retired principals from high poverty elementary schools, the purpose of this narrative inquiry is to understand how principals made sense of their experience when having to respond to decreasing resources and the need for increased student achievement. Participants in the study included retired principals from high poverty elementary schools who were employed during the time period extending from 2008 through 2014. Findings from the study make sense of the meanings elementary principals have constructed and attached to the phenomena of decision making in times of financial reduction in order to help other principals who have been challenged by similar circumstances. Three categories of leadership styles and seven skill areas emerged in the study. Principals made use of these styles and skills in their responses to the crisis.
\end{abstract}




\section{DEDICATION}

To my father, David Spooner who always told me from a young age that I was a gentleman and a scholar. He left this world too soon at 50 years of age. At the age of 50, as I look back in hindsight, I remember using the phrase often with other young men I have tried to encourage. I hope to keep using it into the future in his memory.

“ The best thing for being sad," replied Merlyn..." is to learn something. That is the only thing that never fails. You may grow old and trembling in your anatomies, you may lie awake at night listening to the disorder of your veins,... you may see the world around you devastated by evil lunatics, or know your honor trampled in the sewers of baser minds. There is only one thing for it then-to learn. Learn why the world wags and what wags it. That is the only thing that the mind can never exhaust, never alienate, never be tortured by, never fear or distrust, and never dream of regretting. Learning is the thing for you."

From The Once and Future King by T.H. White 


\section{ACKNOWLEDGEMENTS}

I would like to acknowledge the support of many colleagues and friends who have helped me along this path toward this point over the last five years.

I am especially grateful to my advisor, Dr. Amy Petti who understands the challenges of doctoral work while carrying the responsibilities of a full time job as an elementary school principal in addition to all of the other important roles in life, especially that of husband and father. Also, I am thankful for the advice and wisdom that came from my committee members including Dr. Samuel Henry, Dr. Candace Reyonolds and Dr. Margrett Everett.

One of my instructors, Dr. Joanne Cooper gave me a metaphor to think about as I worked through this dissertation. She nicknamed me the "bulldozer". She told me that she admired the way that I was pushing and clearing a path for myself through the process to finish much like a bulldozer would do. It was the imagery I needed to finish. Dr. Cooper's advice about writing as well as the camaraderie with other students in her writing classes helped me make it to the finish line.

I would like to thank Stephen Scannell and Alfonso Garcia who were my shadow researchers through much of the research and writing phases of my dissertation work. In addition, I would like to thank all of the students in Dr. Cooper's class for their support and encouragement, especially over the course of this last year. I am cheering for each of you to finish as well. The finish line is just around the corner!

I am most grateful to the participants in this project who agreed to meet with me 
at odd hours to share their stories. Each person was and is a source of inspiration for me and I know that their words as quoted in this work will be inspiring to elementary principals working in similar circumstances.

Finally, I must thank my wife, Maggie who supported me through the ups and downs over the last five years. We celebrated twenty-five years of marriage in 2013 and we're going to spend more time together now that this work is finished. I love you Maggie! 
TABLE OF CONTENTS

Page

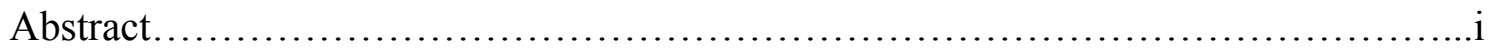

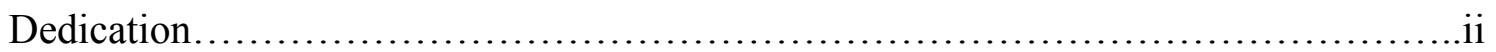

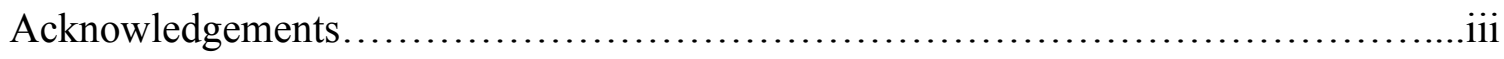

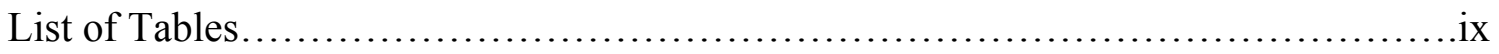

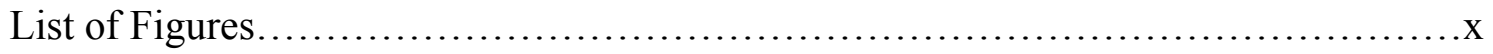

CHAPTER

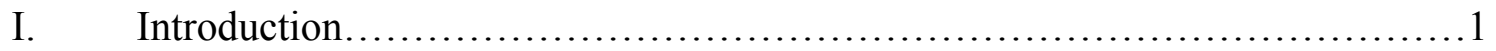

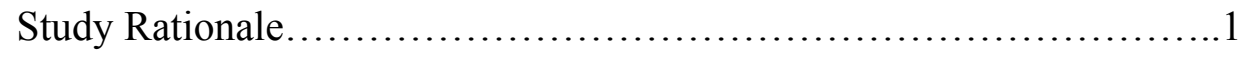

Researcher Interest............................................. 3

Significance........................................................... 4

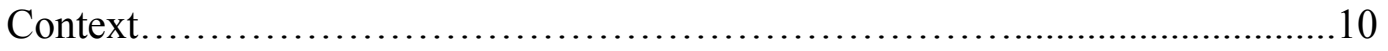

Research Question...................................................14

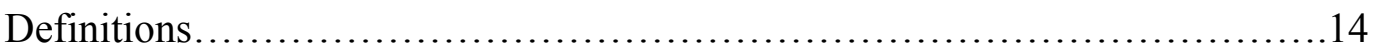

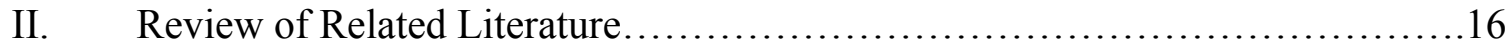

Title 1 or High Poverty Elementary Schools..........................17

Narrative Inquiry Approach......................................18

Roles of Principals in High Poverty Schools ............................ 19

Instructional Leader.........................................19

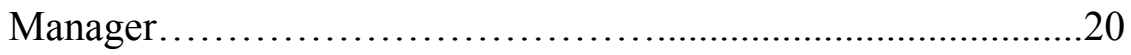


Capacity Builder...........................................21

Monitor and Learner............................................22

Promoter of Social Justice and Equity..........................28

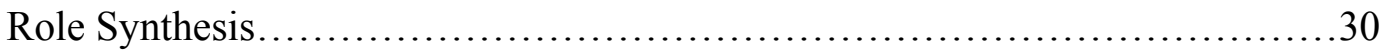

Lived Experiences of Elementary Principals.................................32

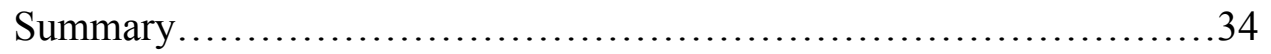

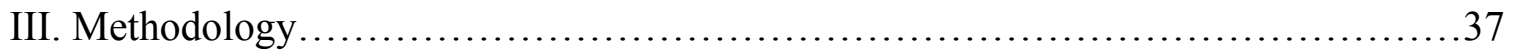

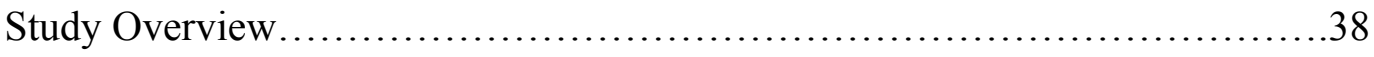

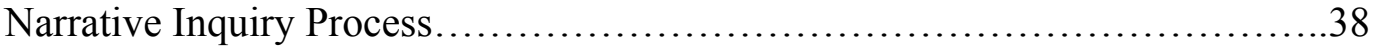

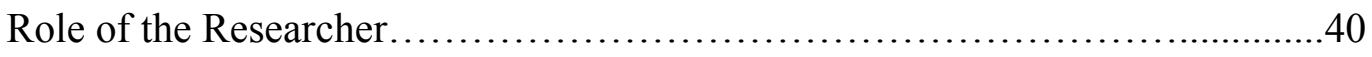

Participants and Recruitment ................................................42

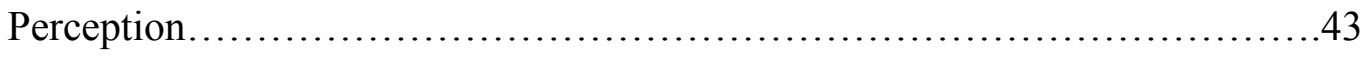

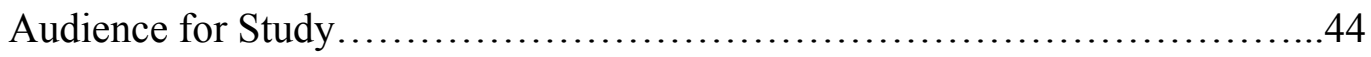

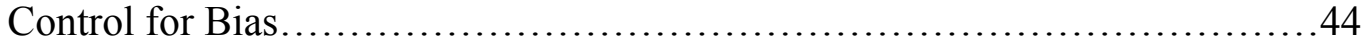

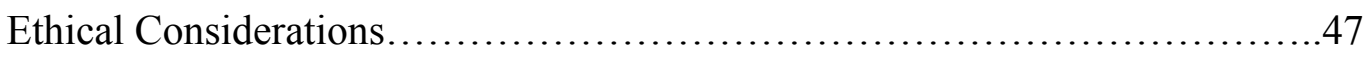

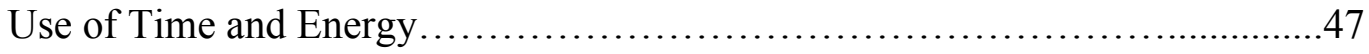

Contrasting Narrative Inquiry and Ethnography Designs......................48

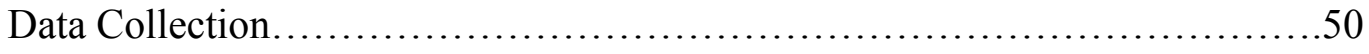

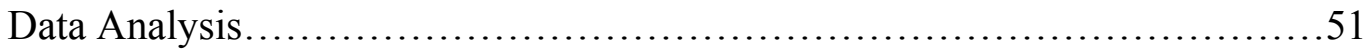

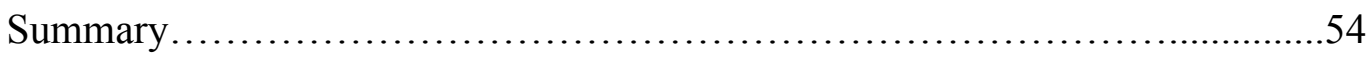

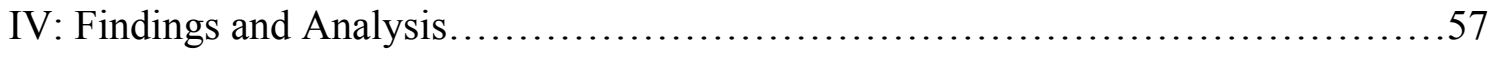

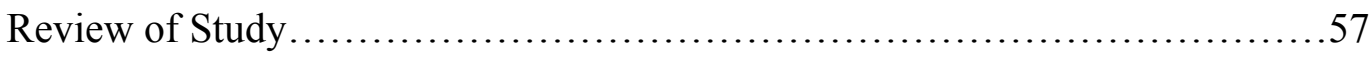


Purpose......................................................... 57

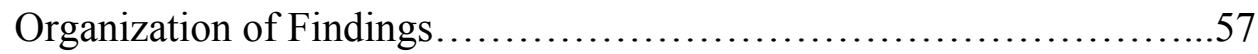

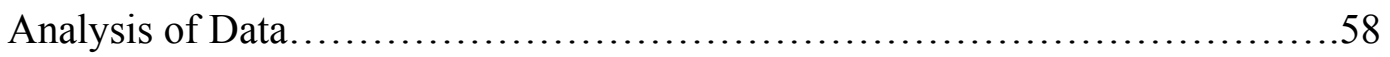

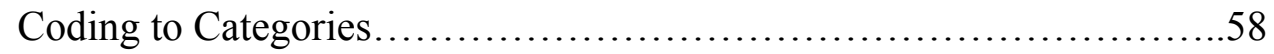

Memos................................................................... 61

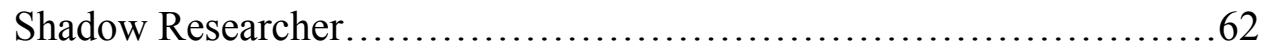

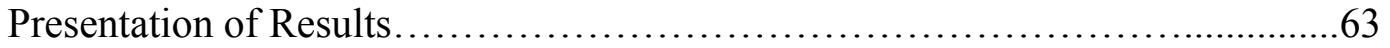

Participant Demographics..........................................64

Interpretation of Findings of participant leadership style................67

Categories of leadership..........................................67

Summary of leadership style .........................................

Participant responses.............................................. 76

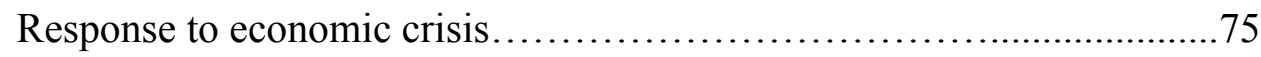

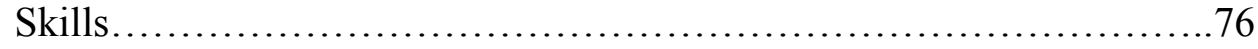

Lessons Learned and Additional Bits of Wisdom.......................82

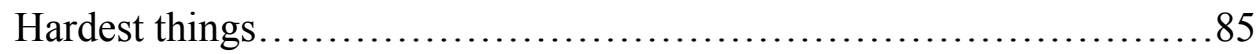

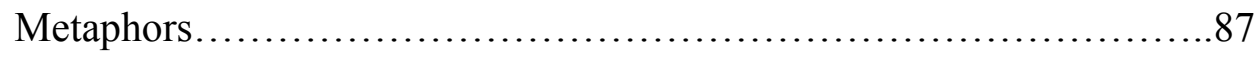

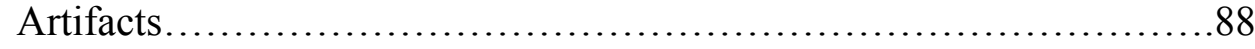

Hindsight........................................................ 91

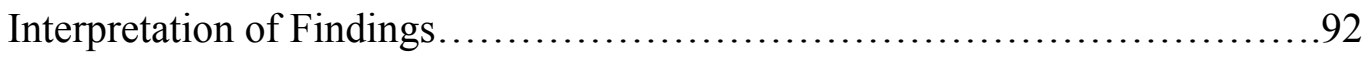

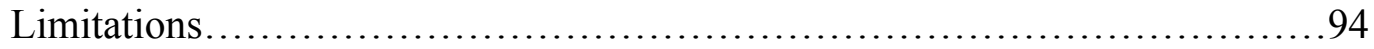

Limitations of narrative research....................................99 


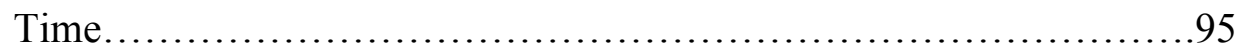

Lack of comprehensiveness.....................................95

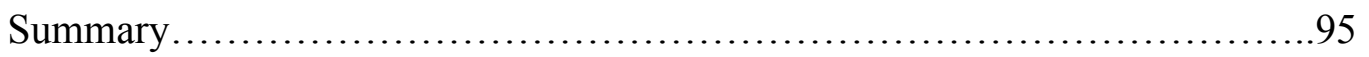

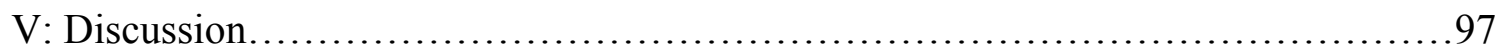

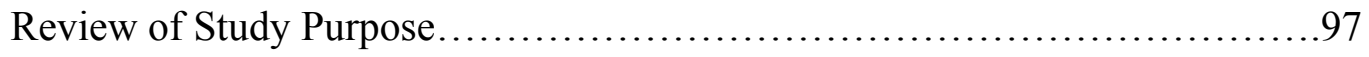

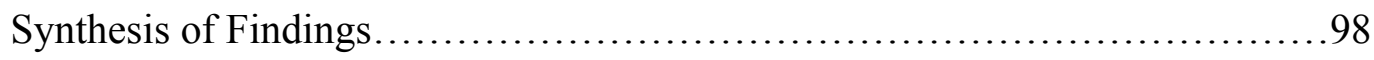

Interpretation of Findings .............................................. 98

Leadership Styles.............................................102

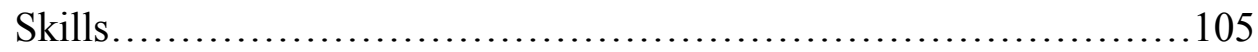

Hidden Bits of Wisdom...........................................113

Larger Context............................................................ 115

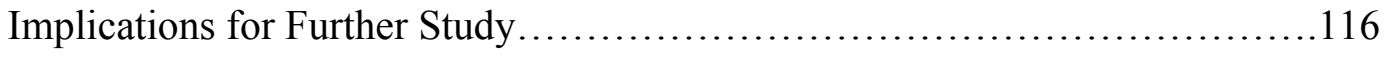

Conclusion.......................................................... 121

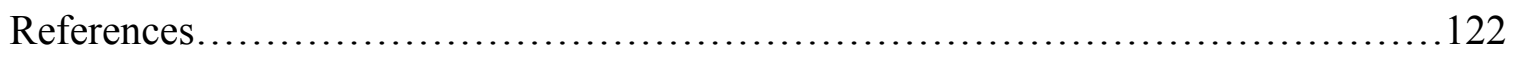

Appendices

A. Budget and Staffing Summary .........................................136

B. IRB Informed Consent Form........................................ 138

C. Sets of Initial Codes................................................ 142

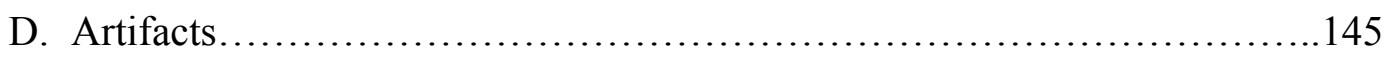

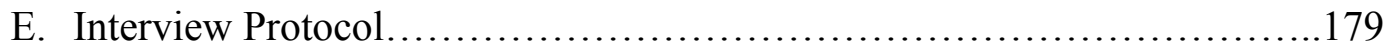

F. Member Checking E-mail Example..................................... 181 


\section{LIST OF TABLES}

Table 1 Valley River School District Leadership Standards......................6

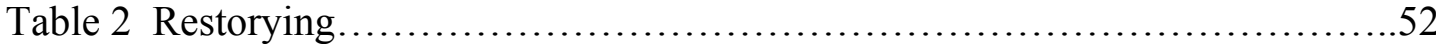

Table 3 Participant Demographics.........................................64

Table 4 Leadership Styles and Supporting Evidence ...........................69

Table 5 Examples of Skills and Leadership Styles Used to Respond to Economic

Crisis.................................................................... 


\section{LIST OF FIGURES}

Figure 2.1 Narrative inquiry approach........................................ 19

Figure 4.1 Code reduction process............................................ 59

Figure 4.2 Steps for analysis................................................60

Figure 4.3 Screen shot of transcript third read...................................61

Figure 4.4 Movement from codes to memos to themes.............................62

Figure 4.5 Screen shot of myself and shadow researcher reviewing my analysis using

Google Hangout TM. 


\section{CHAPTER 1}

\section{Introduction}

\section{Study Rationale}

The roles of the elementary school principal are many and complex. They include instructional leader (Leithwood, Louis, Anderson, and Wahlstrom, 2004), manager (Agnes, 2004), capacity builder (Louis, Leithwood, Wahlstrom and Anderson 2010), monitor and learner (Reeves, 2006), and promoter of social justice (Singleton and Linton, 2006). Recently, a great deal of interest has been generated around the role of principal and its effectiveness, especially its impact on improving teacher instruction and student learning (Leithwood, Louis, Anderson, and Wahlstrom, 2004; Mendels, 2012; NPBEA. 2006; Reeves, 2006; Wallace Foundation, 2013; Waters, T., Marzano, R. J., \& McNulty, B. 2003). Waters, Marzano, and McNulty (2003) concluded that one quarter of all "school effects" on achievement can be attributed to principals. The Wallace Foundation, (2013) found that policies are being enacted to put evaluation procedures in place that will measure principal effectiveness throughout the United States. The National Policy Board for Educational Administration (NPBEA) has adopted standards that are being used by states to develop procedures (NPBEA, 2006). Reeves, (2006) focused on the lead learner role of the principal. Mendels, (2012) identified five important actions of principals that include shaping a vision of academic success for all students, creating a positive climate for all students, cultivating leadership in others, enabling teachers to improve instruction, and managing people, data and processes to foster school 
improvement. Leithwood, Louis, Anderson, and Wahlstrom, (2004) concluded that one quarter of all "school effects" on achievement can be attributed to principals.

While there is general agreement on principal's importance and effect, do we understand how principals have adapted to changes in schools with reduced resources and increased learning needs of students? How have principals made decisions in an environment where resources have been reduced over time? In fact time itself has been reduced in the form of required school days for elementary school students. For the purposes of the study, the name, Valley River School District will be used as a pseudonym for the studied district which is located in a Northwest state in the US . In April of 2011, the Valley River School District negotiated a reduction of six unpaid days with its teacher's union. The reduction resulted in a 168-day school year for students. The decision made national news in a New York Times Newspaper article (Dillon, 2011). Prior to the 2011-2012 school year, the district's budget included significant reductions in staff and school days. In the 2009-10 school year, 108 full time positions including teaching, classified, and administrative positions were reduced. In the 2010-11 school year an additional 106.5 FTE (Full Time Equivalent) made up of the same employee groups were reduced. In addition ten student contact days were eliminated that year. At the beginning of the 2011-12 school year, an additional 149 positions were eliminated along with five student contact days. Two elementary schools were closed and the district re-configured its middle schools from two year programs to three. The reductions mentioned are only a few of the more significant items. A complete summary of the reductions between the 2008-09 and 2013-14 school years can 
be found in the Appendix A, Budget and Staffing Summary 2008/09-2013-14.

Much has been written about leadership and the importance of the elementary school principal's role. (Leithwood, Louis, Anderson, and Wahlstrom, 2004; Mendels, 2012; NPBEA. 2006; Reeves, 2006; Wallace Foundation, 2013; Waters, T., Marzano, R. J., \& McNulty, B. 2003). However, it seems that there are fewer studies that focus on the role of the principal viewed from the their own perspective. The ways in which they changed and adapted to the circumstances of reduced resources in the form of their own personal narrative is what I am curious about. What tools were employed in their response to the situation? Crow, Hausman, and Paredes-Scribner (2002), have suggested that principal perspective should be a focus of future research. More specifically, Beatty (2000) has pointed out that we know very little about the kinds of emotions principals have experienced, especially the cognitive dissonance that comes from the passion they have for their work that is diminished by the frustration of not having the right tools. Given the stories of principals from high poverty elementary schools, the purpose of this narrative inquiry is to understand how principals made sense of their experience when having to respond to decreasing resources and the need for increased student achievement.

Researcher interest. As an educator with twenty-five years of experience in K12 education, I have been fortunate to have gained experience in the field through the lenses of multiple roles including special educator (learning specialist), middle school classroom teacher, teacher on special assignment, district office coordinator (Special Education), assistant principal in a middle school, and elementary school principal. 
Having been an elementary school principal for eight years as of this writing, I have become fascinated with the ways in which the position has changed during my tenure as well as the tenures of my predecessors. I am interested in the ways in which principals have adapted to changing school communities. Communities that at one time were considered suburbs now resemble urban areas with high rates of poverty, increased ethnic diversity, and increasingly diverse student learning needs. I am also interested in the inner voice and dialogue that principals have used to survive in the midst of the changes.

\section{Significance}

This study is significant in four ways. They include professional, district, school, and personal significance.

Significance to the profession. The role of the principal is generally considered the second most important factor in the effort to improve student achievement next to the teacher and classroom instruction (Waters et al., 2003). In a study completed by the Wallace Foundation in 2012 five practices were found to be central to effective school leadership. They include shaping a vision of academic success for all students, creating a positive climate for all students, cultivating leadership in others, enabling teachers to improve instruction, and managing people, data and processes to foster school improvement (Mendels 2012, p. 55, ;Harvey, 2012, p.4,; Porter et al., 2008).

Significance to the district. In all of the states, there is a conscious effort underway to measure school principal effectiveness. Policies are being enacted to put measures in place (Wallace Foundation 2013, p. 3). There is a concern that states and school districts are "operating in the dark" with little data to draw from in terms of 
knowing if principals are prepared, licensed, supported, and evaluated (Briggs, \& Cheney et al, 2013, p. 9). Districts throughout the U.S. have reviewed and revised their existing standards, using the Interstate School Leaders Licensure Consortium (ISLLC) standards and performance indicators that were developed by the Council of Chief State School Officers' State Consortium on Education Leadership. These standards have become the basis for principal training, placement, and evaluation (Wallace Foundation 2013, p. 3).

Valley River's administrator standards are listed in Table 1 below. They resemble the ISLLC standards and indicators., Culture of Teaching and Learning, Management of Learning, Relationships with the Broader Community to Foster Learning, Integrity, Fairness and Ethics in Learning.

These standards and those like them are relevant to the research question because they are expected standards of leadership and practice. During the time period of the economic crisis in which these principals were employed, their responses to the need for increased student achievement while working with reduced resources would have been guided by these standards. 
Table 1

Valley River School District Leadership Standards

\begin{tabular}{|c|c|}
\hline Standard & Definition \\
\hline 1.Vision of Learning & $\begin{array}{l}\text { A school administrator is an educational } \\
\text { leader who promotes the success of all } \\
\text { students by facilitating the development, } \\
\text { articulation, implementation, and } \\
\text { stewardship of a vision of learning that is } \\
\text { shared and supported by the school } \\
\text { community. }\end{array}$ \\
\hline 2. Culture of Teaching and Learning & $\begin{array}{l}\text { A school administrator is an educational } \\
\text { leader who promotes the success of all } \\
\text { students by advocating, nurturing, and } \\
\text { sustaining a school culture and } \\
\text { instructional program conducive to student } \\
\text { learning and professional growth. }\end{array}$ \\
\hline 3. Management of Learning & $\begin{array}{l}\text { A school administrator is an educational } \\
\text { leader who promotes the success of all } \\
\text { students by ensuring management of the } \\
\text { organization, operations, and resources for } \\
\text { a safe, efficient, and effective learning } \\
\text { environment. }\end{array}$ \\
\hline $\begin{array}{l}\text { 4. Relationships with the Broader } \\
\text { Community to Foster Learning }\end{array}$ & $\begin{array}{l}\text { A school administrator is an educational } \\
\text { leader who promotes the success of all } \\
\text { students by collaborating with families and } \\
\text { community members, responding to } \\
\text { diverse community interests and needs, and } \\
\text { mobilizing community resources. }\end{array}$ \\
\hline $\begin{array}{l}\text { 5. Integrity, Fairness and Ethics in } \\
\text { Learning }\end{array}$ & $\begin{array}{l}\text { A school administrator is an educational } \\
\text { leader who promotes the success of all } \\
\text { students by acting with integrity, fairness, } \\
\text { and in an ethical manner. The school } \\
\text { leader is the leader of learning in the school } \\
\text { and conducts himself/herself in this } \\
\text { manner. }\end{array}$ \\
\hline
\end{tabular}


Significance to the school. Wolcott, (1973) in his classic ethnography, The Man in the Principal's $O f f i c{ }_{2}$ questioned whether principals truly understood the system or bureaucracy in which they worked. Wolcott (1973) writes, "They [Principals] would benefit from a better understanding of the anthropologist's distinction between education viewed as cultural process and "schooling" the latter comprising one aspect of the former." (p. 323)

In a "schooling" system, Wolcott (1973) distinguishes between two types of principals, one that works within the system to improve its efficiency to the point where they become part of the system rather than complimenting the system. The second type works to improve the system so that it becomes a catalyst for human development and learning (p. 326). With the distinction between two types of principals, Wolcott illustrates the importance of the principal's role and his or her understanding of that role within the larger system.

Personal significance. This inquiry is particularly significant to me as I've grown up in the public school system. This section explores my personal significance as a student through the lens of my professional experience.

Student experience. My own neighborhood where I grew up was once considered the edge of the urban growth boundary. During the 1960's and 70's I remember growing up in a white middle class neighborhood where the elementary school was located behind my house. I remember participating in many programs that were offered by the school district including instrumental music starting in $4^{\text {th }}$ grade, after school sports, and summer 
recreation programs. The summer recreation program at my elementary school offered arts and crafts classes, an open gym, and a summer baseball team. And if I was tired of those activities, I could get on a shuttle bus that would take me to other schools such as the high school where I could participate in a summer music program that included a concert band and jazz band.

Unfortunately, the programs no longer exist in my old school district. Funding priorities at state and local levels changed. Property tax limitation legislation caused school funding to shift from the local level to the state. The hope was that funding for schools would be more equitable across the state. With its passage in 1990, property taxes were limited to $\$ 5$ per $\$ 1,000$ of real market value over a gradual phase in period. This amendment to the state constitution was blamed for budget cuts in school districts as well as other public services. Proponents of the measure hoped that the public would be more open to passage of a sales tax to support schools in the future. Instead, the opposite occurred. This became the start of a tax revolt in the opposite direction. Further measures were passed including which limited property tax values further. (Wentz, 2000).

The neighborhood has changed also. The middle class culture is less prevalent. The house and the lot where I grew up have been subdivided into multiple lots. Multiple family housing units have been added to the area. Families representing various ethnicities, especially those with ties to Russia and the Ukraine have located there. Changes have increased diversity and raised poverty levels in a short time period while the accountability for academic achievement among minority groups remains high.

Professional experience. Similar changes have taken place in the school 
community where I have worked for the last three years. With the downturn in the national, state and local economies since 2008, increased rates of poverty along with associated problems that impact families have surfaced. The numbers of students receiving free and reduced lunch increased from $65 \%$ to $71 \%$ during the $2012-13$ school year. Problem behavior has increased significantly among students. The number of major office discipline referrals increased by 35\% between the 2011-12 and 2012-13 school years. At the end of the 2010-11 school year, twenty-six staff members including teachers, instructional assistants, and an assistant principal either had positions eliminated or they were asked to transfer to new positions as a result of budget reductions and a decision to move the sixth grade to the middle school. The school experienced the loss of an after school and community education program.

All of the losses occurred simultaneously over a time period in which high stakes accountability measures were put in place as a result of No Child Left Behind (NCLB) legislation. NCLB was the Bush era title for the reauthorization of the Elementary and Secondary Education Act (ESEA). For the remainder of the paper ESEA will be used, as of now, we await the next reauthorization. Since the goal of having $100 \%$ of students either meet or exceed benchmark levels in Reading, Writing, and Math was determined to be untenable many states have been granted a waiver from the US Department of Education. These waivers have several conditions, which include the development of a teacher and principal evaluation system that uses multiple measures including the measurement of each student's learning growth over time.

Currently as a principal in a relatively new school, I am in the position of 
shepherding the school community through a significant amount of change. As a result of the new requirements associated with the ESEA waiver, we will now take significant steps to re-prioritize and establish a new a new mission and vision in our work to educate students.

Walcott (1973) referred to principals who would complement the "schooling" system by focusing on human development. Since becoming a principal, much of my work has been focused on helping faculty adjust to changes in the school system. Human development, learning, and professional growth are some of the most important components of a healthy school community. Walcott suggested that principals "complement" the system. I believe today that principals not only complement the system, but they are responsible for orchestrating it. I have an interest in learning how other principals have responded to the changes while providing the key elements of leadership. Specifically I am interested in studying how principals have provided leadership in an era where resources are being reduced while simultaneously, measures of accountability are increasing, especially in schools where the stakes are the highest. These include schools with populations of students who experience high rates of poverty, learning disabilities, and lack of language proficiency.

\section{Context}

When examining the role of the principal in times of reduction and increased accountability, it is important to understand the context from which my interest surfaced. The context pertinent to the inquiry includes, the historical context of a Title I school, budget reductions, hopes and dreams for the school, and the complexity of poverty as it 
accelerated in the school's neighborhood.

Historical context. Upon entering Sequoia Elementary School as the new principal in the 2010-2011 school year, having had five previous years experience as a principal in a Title 1 school, I was ready to take on the challenges of leading a similar school community of about 450 students with significantly more challenges including a significant caseload of students with disabilities and an increased number of students who were economically disadvantaged. I was looking forward to making use of important additional resources such as an assistant principal, one full time counselor, an additional half-time counselor, an instructional coach, and highly effective teachers who were well known across the district for their collaborative work to improve student achievement. The school had developed a partnership with a local university to start a Professional Development School (PDS) where pre-service teachers would be paired with mentor teachers to complete their training. The PDS format was designed to support professional development for the mentor teachers and pre-service teachers together in a collaborative model that would have mutual benefit to both partners (Petti, 2011).

Budget reductions. At the midpoint of the 2010-2011 school year the school district had to begin to make major budget reductions in response to the economic downturn starting in 2008. The assistant principal was asked to take on additional responsibilities at the district level and her time at Sequoia Elementary was reduced to half time. Sixth grade students were moved to the middle school. Twenty-six staff members including teachers and instructional assistants were either asked to move to different assignments in the district or in some cases, if their seniority was low, they 
moved to lay-off status. Class sizes increased. At Sequoia Elementary some classrooms had as many as thirty-five students in primary grade classrooms. Conditions like increased class size were similar across the district. The superintendent at the time estimated that each employee had taken on an increase of twenty percent in their workloads.

Hopes and dreams. My hopes and dreams as an educational leader were to one day see at least ninety percent or more of our students meet benchmark standards in literacy and mathematics. But over the three years of my time at Sequoia the achievement gaps between white middle class students and other groups including economically disadvantaged, students with disabilities, and English language learners continued to grow. I had much hope for our students and their success, especially because they had highly trained teachers who initially had a strong support system of professional development in place.

Poverty and complexity. Gradually, over time teachers struggled with morale as reduced staffing, increased class sizes, and increased student needs, especially students who were affected by mental illness and trauma were not getting the support they needed. A county funded program to provide mental health treatment to students and their families in the schools free of charge was started. A therapist started his position at halftime, but the number of referrals increased dramatically and within the first year, he was working full time. The skill quality of pre-service teachers coming from the university to participate in the PLLS program was declining and teachers began to perceive the program as a burden. Eventually, because of the poor skill quality and the inability of the 
university to fund their part of the PLLS program, the partnership was sadly discontinued at the end of the 2012-2013 school year. The support system overall appeared to be stretched beyond capacity but teachers continued to adjust and believe in possibilities for their students. Other programs that addressed nutrition, the arts, and afterschool support were either discontinued or were significantly reduced in scope. We took it upon ourselves to advocate for more support from the district level. We met with the superintendent and suggested ways in which we could improve our own professional practice with an increased focus on student engagement. As a faculty, we made a commitment to doing fewer tasks while improving the quality of our instruction with the resources that were available. Having fewer tasks to do didn't necessarily improve morale but it was necessary to bring about a sense of empowerment. At the end of the 2012-2013 school year, I was assigned to a different school in the district where conditions are quite different in terms of student characteristics. The SES status of the community overall is much higher. My hope is to reflect and learn from the last three years as well as learn from the stories of other principals who have experienced similar changes during their tenures.

When considering this context, it is important to understand that high poverty elementary school principals were working with an expectation of increased student achievement and at the same time they were expected to work with fewer resources that included staff and reduced school days. In order to understand their experiences, it will be important to review the research literature that has been written about the roles of principals and the impact these roles have had on student achievement. It will also be 
important to understand the historical context of high poverty or title one schools as well as the literature that has been written about the experiences of principals themselves in high poverty elementary schools.

\section{Research Question}

R 1: How did principals of high poverty elementary schools respond to the phenomena of reduced resources and the expectation of increased student achievement?

\section{Definitions}

The following key terms are defined for clarity through this paper: Principal Leadership (Defined by ISSLC Standards), High Poverty Elementary Schools, Decreasing Resources, Student Achievement, Narrative Inquiry. Principal leadership is a form of school leadership used by elementary school principals as defined by the ISLLC standards listed in Table 1. Researchers (Waters, T., Marzano, R. J., \& McNulty, B. 2003) have pointed out that principal leadership is the second most important factor that can impact student achievement; therefore it is an important concept to consider in relationship to the problem studied. For the purposes of this study, decreasing resources include the reduced number of school days, teachers, classified staff, and time for staff development. Since researchers consider the classroom teacher to be the most important factor impacting student achievement, it should be safe to assume that a reduced number of classroom days with the loss of teachers would be harmful (Waters, T., Marzano, R. J., \& McNulty, B. 2003). High Poverty Elementary Schools are those elementary schools where at least fifty percent of the students receive free or reduced lunch. High poverty 
schools are important to the inquiry as students need highly qualified teachers to meet diverse learning needs.

Title 1 schools are those schools that receive additional federal funds as authorized by the Elementary and Secondary Education Act (ESEA). Elementary schools that have at least $50 \%$ of students that receive free and reduced lunch are eligible to receive these funds. They are commonly called High Poverty Elementary Schools.

Student achievement is defined by measures of accountability such as state test scores and school district assessment data.

A narrative inquiry is “...understood as a spoken or written text giving an account of an event/action or series of events/actions, chronologically connected (Czarniawska, 2004, p. 17). Creswell (2007) writes:

The procedures for implementing this research [narrative inquiry] consist on focusing on studying one or two individuals, gathering data through the collection of their stories, reporting individual experiences, and chronologically ordering (or using life course stages) the meaning of those experiences (p. 54). 


\section{CHAPTER 2}

\section{Literature Review}

This literature review examines the roles of elementary school principals in high poverty schools. In order to review roles, this literature review is divided into three sections. The first part provides a brief history of Title 1, or High Poverty Schools. The second part compares the views of researchers regarding the various roles (instructional leader, manager, capacity builder, monitor and learner, and promoter of social justice). These roles include beliefs about student potential, instructional management, building capacity of the adults in a school and their ability to monitor and reflect on progress or the lack of progress (Chenoweth \& Theokas, 2013). The third examines some of what we know about the lived experiences of principals themselves (Day, Harris, Hatfield, \& Beresford, 2000; Hoppey, 2006; Crow, 2002; Greenfield, 2004).

When it comes to the topic of principal leadership, most of us will readily agree that principals can have a significant impact on student learning (Waters et al., 2003). But is there agreement on how principals impact student learning when resources are significantly reduced (school days and staff reductions)? Whereas some are convinced that there is a defined set of leadership practices that impact student learning (Waters et al., 2003), others maintain that we should be studying the lived experiences of principals themselves (Crow, Hausman, \& Paredes-Scribner, 2000). I believe that the lived experiences of principals (especially during times of economic crises) may reveal new creative leadership practices that have not been discovered in the existing leadership practices research. My own view is that the environment in schools is quite complex, and 
we should be learning from the principals themselves about how they have adapted to reductions in resources and increased accountability.

\section{Title 1, or High Poverty Elementary Schools}

The increased accountability that principals and school districts face has its roots in The Elementary and Secondary Education Act (ESEA) that was passed by Congress in 1965. Title 1, a provision of this legislation, authorized the United States Department of Education to distribute funding to public schools and school districts with a high percentage of low-income families for the purposes of providing additional instructional support in areas of reading and mathematics. Studies since that time have demonstrated a relationship between high poverty and low student achievement (Carmichael, 1997; Reardon, 2013; Stullich, Eisner, McCrary, \& Roney, 2006).

The most recent re-authorization of this act was titled No Child Left Behind (NCLB), and it was passed in 2002 during the George W. Bush era. The re-authorization required greater accountability from teachers and schools to improve student achievement. Teachers and staff were required to have a highly qualified status - in the form of required certifications based on their training in teacher preparation programs at universities. Yearly mandated standardized tests were used to measure Adequate Yearly Progress. If enough students could not reach achievement benchmarks at each grade level, especially those in marginalized groups including students of color, students with disabilities and English language learners, then punitive measures and corrective actions were implemented by states and districts. Schools were required to provide additional staff development to teachers. The lowest performing schools were required to disband 
and re-establish themselves. The lowest performing schools were called Focus and Priority schools. The lowest schools were called Priority. Struggling schools at the next level were labeled Focus, and schools performing at the highest levels were labeled Model schools. Districts often found other placements for poor performing teachers and administrators (Bush, 2001). This step had significant implications especially when districts were trying to improve teacher performance at every school. Some principals may have had a greater burden than others to improve faculty performance simply because they were asked to take a poor performing teacher from another school.

\section{Narrative Inquiry Approach}

For my research I used a narrative inquiry approach in which individuals search for meaning from the world in which they live and work. Creswell (2007) writes that the intent of the researcher in this approach is to collect the stories of participants, report their individual experiences and discover meaning from those experiences. Dewey's (1938/ 2007) philosophy of experience in education provides the basis for this approach. The data for this research consists of the personal experiences of elementary school principals who worked in high poverty schools during an economic crisis with the expectation for increased student achievement. These experiences were shared in the form of stories that constitute the data used for this study. Narrative inquiry is a qualitative method that is best applied when describing the lived experiences of the participants. Figure 2.1 illustrates the narrative inquiry approach. 


\section{Experiences}
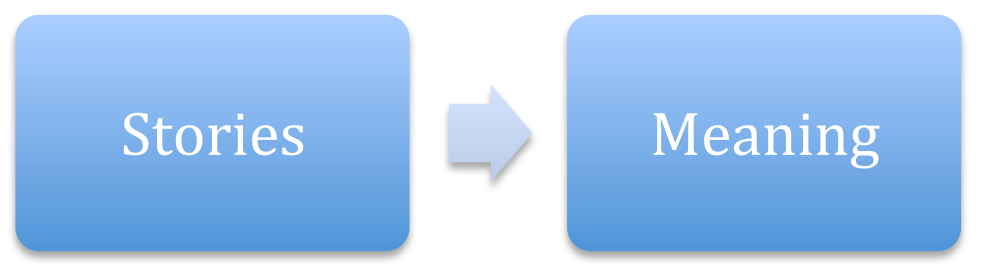

Figure 2.1. Narrative inquiry approach.

My desire was to discover and understand the meanings elementary principals had with the phenomena of decreasing resources and the need for increased student achievement. Therefore narrative inquiry is an appropriate qualitative method for exploratory and descriptictive research.

\section{Roles of Principals in High Poverty Schools}

Elementary principals are often alone in a leadership position and hold multiple responsibilities and roles. Five roles of principals are examined, including that of instructional leader (Leithwood et al., 2004), manager (Sternberg, 2012), capacity builder (Barth, 2013), monitor and learner (Reeves, 2006), and promoter of social justice and equity (Ysseldyke, 2001).

Instructional leader. Studies have concluded that the role of the principal is 
second only to the impact a teacher can have on student achievement. One study has concluded that one quarter of all "school effects" on achievement can be attributed to principals (Leithwood et al., 2004). There are various ways that principals have emphasized instructional leadership. A study was conducted by the Education Trust that sampled twenty-four principals from high-achieving elementary, middle, and high schools, all with high poverty, and located in nineteen different states. The study discovered four qualities they tend to share. First, their beliefs about student potential drive their work. Second, they put instruction at the center of their managerial duties. Third, they focus on building the capacity of all the adults in the building. And fourth, they monitor and evaluate what leads to success and what can be learned from failure (Chenoweth \& Theokas, 2013).

Beliefs. Principals' beliefs about the capacity of students and the expectation that students perform at high levels appear consistently throughout the literature. Research over the last twenty-five years points to the importance of a vision and a set of beliefs that having high expectations for every student is one key to improving achievement among disadvantaged students (Porter et al., 2008).

Reeves (2006) points to several beliefs that are based on research. He points out that leadership, teaching, and adult actions matter more than the demographic variables. Actions that matter, including inquiry, implementation, and monitoring are necessary, and when successful, point to adult causes. He says, "In other words, 'blame the victim [students],' is not morally reprehensible but statistically untrue " (p. xxiii). He concludes that this action will not bring about the improved student achievement that is desired. 
Manager. Sternberg (2012) uses the metaphor of a high wire to illustrate the balancing act that a principal must perform as he or she balances aspects of leadership and management together. He refers to Warren Bennis' definition, which states that leadership is "knowing yourself, having a vision that is well communicated, building trust among colleagues and taking effective action to realize your own leadership potential" (Bennis et al., 2001, p. 45). He then compares Bennis' leadership definition to a definition of management, which is "to control the movement or behavior of" (Agnes, 2004, p. 392). Sternberg elaborates:

The distinct difference between leaders and managers is that leaders deal with the people side of an organization providing inspiration, motivating people and creating opportunities. However, managers deal with the technical side managing day-to-day tasks such as supervising and controlling people by focusing them in the right direction. It is blatantly clear that building principals are both leaders and managers. A too-heavy emphasis on one or the other, and things become unbalanced. (p. 392)

Sternberg's emphasis on balance encourages principals to weigh their actions along a continuum between leadership and management to increase their effectiveness.

Capacity builder. While working toward that balance between leadership and management, one would hope that as the capacity of adults to perform important functions in the school increases, less management would be required. Louis et al. (2010) found that effective leadership from a variety of sources, including principals, teachers, and other staff members, was associated with better student performance on math and reading tests. Encouraging teacher leadership has now become a necessity.

Barth (2013) points to three promising circumstances that will allow teacher leadership to emerge. First, the demands on the principal continue to grow, year after 
year. Principals realize that they can't do all the work on their own. Second, the implementation of the Common Core Standards will provide an opportunity for teachers to share instructional strategies with each other. In the past, teachers may have been told what they needed to teach and how they were going to teach it, but principals aren't in a position to create curriculum and new teaching strategies. Teachers will be asked to take on more responsibilities. Finally, new models of leadership in charter and alternative schools have allowed teachers to take on major decision-making roles, including the hiring of new teachers and evaluating each other.

A specific example of an area where teacher leadership will be needed is in the area of technology use. Murray (2013) states:

Simply put, the best schools are run by administrators that allow teachers to take on leadership roles; not ones that micromanage their every move. It's not feasible for a building administrator to be the expert on every digital tool, system, program, etc. Digital leaders cultivate teacher leadership, abdicate some control, and understand that allowing teachers to lead, mentor and inspire their colleagues will promote positive digital outcomes. (p.1)

From my experience, I can say this quote is accurate. Recently, my building has received an influx of new devices that allow students to have more access to online resources in key content areas such as reading and math. The leadership skills of individual teachers in evaluating and promoting specific online resources have been critical to their meaningful use by our students.

Monitor and learner. Capacity building of teacher leaders is important. In addition, a principal will need to pay attention to his or her own learning. Reeves (2006) points out that characteristics associated with famous leaders, such as sheer guts and determination, ultimately are not the most effective. He points to many 
examples of leaders such as George Washington, Winston Churchill, and Odysseus, who "had extensive experience with the values of waiting, being silent, retreating, and executing circuitous routes to victory" (p. 49).

In terms of daily reflection, Reeves (2006) asks that leaders consider questions in regular journal entries:

-What did you learn today?

- Whom did you nurture today?

- What difficult issue did you confront today?

-What is your most important challenge right now?

- What did you do today to make progress on your most important challenge? (p. 50)

He goes on to say:

Although journaling is, in general, an intensely private activity, the reflective leader knows when personal revelation can have a profound impact. In my own case, some of my toughest leadership decisions have been prompted by a review of journal entries that forced me to recognize that I had attempted the same solution for a particular problem on several occasions, and unsurprisingly, the results did not improve with such a stagnant approach...Reflection forced me to admit that I had been as resistant to change as the others whom I had accused of being resistant and insufficiently enthusiastic to my favored initiatives. Reflection, in brief, forces leaders to climb down from the mythological perch, admit our human foibles, and get real. (p. 51)

Looking back and learning from the past is a critical task for leaders. Having a record of decisions and actions can help leaders recognize their own patterns of decision- making that could be helpful or harmful to the organization.

Promoting a culture of learning. While the focus on his or her own learning is important, the literature refers to the importance of the work a principal does to promote a culture of learning among the staff. Barth (2002) points out that the "underlying culture of a school is learning" (p. 11). One important aspect of the underlying culture is the Professional Learning Community (PLC). Dufour (2013) states: 
Of course, teaching and learning are not divorced from each other. The key to improved student learning is to ensure more good teaching in more classrooms more of the time. The most powerful strategy for improving both teaching and learning, however, is not by micromanaging instruction but by creating the collaborative culture and collective responsibility of a professional learning community (PLC). (p. 37)

Other important practices include classroom walkthroughs and instructional rounds. The practices promote peer collaboration and the principal participates in the activities to promote the culture. The term "walkthrough" refers to a broad range of activities that include classroom observations of teachers at work with students. They are usually conducted by administrators or groups of teachers, to observe teaching practices or the implementation of a curriculum. In their research of classroom walkthroughs, Kachur, Stout, and Edwards (2013) wrote about effective administrators that could promote the process, address teacher concerns, build trust, help schedule time and oversee the follow up to the walkthrough.

Instructional rounds, in a contrast to walkthroughs, are defined by City (2009) in following way:

The rounds process is an explicit practice that is designed to bring discussions of instruction directly into the process of school improvement. By practice, we mean something quite specific. We mean a set of protocols and processes for observing, analyzing, discussing, and understanding instruction that can be used to improve student learning at scale. The practice works because it creates a common discipline and focus among practitioners with a common purpose and set of problems. (p. 3)

City (2013) writes that "real improvements in teaching and learning usually require changing practices and changing what people believe to be possible" (p. 13). In a study of two principals and their use of resources over the span of a year, City found that "no 
amount of time and money spent adding additional coaches or technology made much difference. Students and teachers had to see and believe that something different actually was possible" (p. 13). She went on to describe a situation in which a high school spent over $\$ 125,000$ on instructional coaches. The coaches didn't seem to make much difference in terms of practice. However, one of the coaches promoted a writing contest for students that had a tremendous response. The coach helped students write draft after draft to prepare for it, and small cash prizes were awarded. Teachers were impressed with what they saw and they began to work closely with the coach. Teachers began to believe that change was possible for their students if they changed their own practices. They were able to see the changes happen for students. In her writing about instructional rounds, City (2010) states:

We work with educators on the observation and analysis of teaching practice not because we think it is good for their souls (although it may be), but because we think you cannot change learning and performance at scale without creating a strong, visible, transparent common culture of instructional practice. (p. 32)

In the end, no matter how hard a principal works on his own to help teachers change their practice, it won't happen unless there is a culture in place which will help teachers change their beliefs. City (2013) says, "even thoughtful, hard working leaders who understand how to invest in people, time, and money don't necessarily know how to change practices and beliefs" (p. 13). It is up to the principal to feed and support the culture that brings change. Fullan (2014) goes further to say, "In essence, in dealing with their staffs, principals should shift from focusing on one-to-one work with each individual teacher to leading collaborative work that improves quality throughout the 
faculty"(p. 32).

Knowing the adult learner. Developing a culture of learning, staff development, and training approaches should consider the needs of the adult learner. Trotter (2006) summarized three general themes from the literature on adult learning theory. They included the following:

- Adults use experience and it cannot be ignored.

- Adults need to plan their own educational paths based on their interests and their classrooms.

- The aim of adult education should be to promote individual development by encouraging reflection and inquiry. (p. 12)

Knowles (1973) used the term "neglected species" to describe the adult learner. He wrote that adults are motivated by needs and interests that learning would satisfy, and they have a need to be self-directed in their learning.

Reynolds, Stevens, and West (2013), motivated by the literature that suggests more creativity is needed in the workplace, conducted a study of students in three professional schools at Portland State University that included higher education educational administration, business, and teacher education programs. They studied student responses to assignments that encouraged the use of creativity. Students were able to direct some of their own learning and create projects while being encouraged to take risks, use innovative thinking, synthesize ideas, and make connections across content areas. Examples of projects included writing sonnets to express ideas in a research methods course, and the development of creativity portfolios in a business class. Students 
reported that the activities were worthwhile and furthered their learning of the course content. Encouraging creativity in adult learning is an example of instruction that takes the needs of the adult learner into consideration.

Promoting learning through technology. The culture that brings change is fueled today by the infusion of new technology in schools. Murray (2013) promotes digital leadership among administrators and he encourages actions that can bring innovation and change in a faculty. He lists nine actions leaders can take. They include the following:

1. Foster a culture of innovation and risk taking.

2. Cultivate digital leadership.

3. Utilize technology for improved communication.

4. Communicate your own learning.

5. Invigorate team meetings.

6. Power down to maintain sanity.

7. Utilize technology for improved efficiency.

8. Model expectations for staff.

9. Get connected. (p. 1)

Murray emphasizes the need to participate in a broader learning network. By using digital tools, such as Twitter and Google Plus, administrators can plug into learning networks that provide instant access to resources. He says:

Leaders that model their expectations lead by example and with integrity, help foster environments of innovation and trust. The best digital leaders understand that it's not about the technology. It's about the learning and opportunities that occur through meaningful technology infusion (p. 1).

In terms of leadership, an example of meaningful technology infusion happens on a 
monthly basis, when I meet with a team of principals who give feedback to our director about processes and procedures. Instead of taking a thirty minute drive to the central office, we meet using Google Hangout, a tool that allows individuals to see, talk, and share documents with each other online. The staff in my building can see this is one step that allows me to save up to an hour of time that can now be used to support students and staff in the building.

Promoter of social justice and equity. One of the most important aspects of leadership in schools currently is the concern for equity (Noguera, 2009; Delpit 1995; Ysseldyke, 2001). The pursuit to close the achievement gap between white middle class students and students in marginalized groups — such as students with limited English, students with disabilities, students of color and students impacted by poverty-is a dilemma most $\mathrm{K}-12$ public schools have been facing for some time.

The achievement gap between white, middle class students and marginalized groups defined by the Elementary and Secondary Education Act (ESEA), which is currently referred to as No Child Left Behind (NCLB)—students of color, students eligible for ELD and Special Education services — continues to be a persistent problem in K-12 public education. Since the 1980s, evidence of gaps have shown up in various groups of students at the elementary and secondary levels in periodic reading, science and mathematics tests from the National Assessment of Educational Progress (NAEP, 2005). Chatterji (2006) found, in a study of reading achievement data from 184 U.S. schools as part of the Early Childhood Longitudinal Study (ECLS), that gaps between white and African American children increased from kindergarten entry into first grade. Singleton 
and Linton (2006) use several sets of data to demonstrate the gap, including average SAT and ACT scores from 1998 and the 2003-2004 school year from across the nation. One example demonstrates its existence across income levels of parents ranging from levels below $\$ 20,000$ per year to above $\$ 60,000$. At every income level, Black and Latino students perform ten to fifteen points below whites.

Researchers such as Singleton and Linton (2006) point out that poverty, family support, language, and mobility are not factors that correlate with racial achievement disparities. They believe the factors are wrongly associated with race in causing the gap and they state that teachers usually resort to making inappropriate judgments. Delpit (1995) says:

These adults are not probably are not bad people. They do not wish to damage children; indeed they likely see themselves as wanting to help. Yet they are totally unable to perceive those different from themselves except through their own culturally clouded vision. (p. xiv)

Ysseldyke (2001) points out that in the field of Special Education, professionals are trained to look for deficits, and if they can't find a deficit that fits into a category, they will develop new labels and categories to identify deficits. He says, "The question for assessors is not 'Why isn't Johnny Learning?', but ‘How well did Johnny learn when I $\operatorname{did} \_$_

Instead of accepting perceived conditions as inevitable, Noguera (2011) points out that students from Black and Latino groups need teachers to help them accelerate their learning in order to catch up with their white, middle class peers.

The achievement gap between students of color and their white middle class peers seems daunting. Principals are in the position of having to help teachers 
overcome and unlearn years of cultural practice. In terms of race, a term commonly used to describe the problem is "institutional racism." Principals and teachers are just beginning to come to terms with the dilemma, especially those in high poverty schools.

Schools with high poverty have become increasingly challenged by the widening income gap between high-income and low-income families. Reardon (2013) writes that this gap has increased significantly within the last thirty years, while the achievement gap between White and Black students has grown much smaller. He points to work that was done in the 1960s and 1970s to reduce racial inequality. While both gaps continue to remain large, economic inequality is now greater than racial inequality. He found five social trends that have contributed to the widening income gap in achievement. They include the inability of low-income families to invest in educational resources for their children, more limited upward social mobility, the increased separation between low-skill and high-skill employment, notions of educational success in the form of test scores, and the likelihood that students from high-income families are raised by two parents with college degrees as opposed to a single parent with no college degree (p.13).

\section{Role Synthesis}

Some educators and researchers (Marzano \& McNulty, 2003) would say that we have arrived at a clearer definition of the principal's role by putting student learning in the front and center. Murphy highlighted an important focus of the original ISLLC work group, "The goal has been to generate a critical mass of energy to move school administration out of its 100-year orbit and to reposition the profession around leadership for learning" (as cited in Canole \& Young, 2013, p. 6). 
Walcott (1973) highlighted the problem of role definition for a principal in his famous case study. Ed Bell ${ }^{1}$ the principal studied in Walcott's work, led a conversation in a principals' association committee that met to talk about the role of the principal. Much frustration was shared in the conversation. When it was suggested that the principals talk about upgrading their salaries, one principal responded by saying the following:

Right now, it's a bastard job. Just what are we supposed to do? Is it instructional? I think a better thing for us to look at is the job. How about the new principals - is it a good training they are getting? What do they know? We all came through the old program, but what are these younger fellows getting? I believe now that any school in the state with eight teachers has to have an administrator with a credential. (p. 302)

During the discussions, Walcott was asked about the principal role problem and he shared that he was associated with the Center for the Advanced Study of Educational Administration (CASEA). He said that his study was not a role study, however he did ask the group that if they had the opportunity to get CASEA to do any kind of study, what would they ask for? At about the same time as Wolcott's study was being conducted, CASEA was actually conducting such a study. Becker et al. (1971) concluded in the study that ambiguity about the role of the principal in the educational community was the most critical problem facing the elementary school principal.

The evaluation of a principal must have a clear answer to the question, "Just what are we supposed to do?" I think it would be helpful to point to a paradox that Walcott (1973) and Becker et al. (1971) observed in the role of principal. I hope that an analysis of the standards for evaluation in relationship to the paradox might provide more clarity, or perhaps suggest a need for further research.

\footnotetext{
${ }^{1}$ Ed Bell is a pseudonym for the name of the principal in Walcott's study.
} 
Walcott (1973) stated, "Principals today are bombarded with the notion that they are and ought to be agents of change in the public schools" (p. 307). However, he continues the discussion with a reference to the principal in the study, Ed (pseudonym):

But I did not see any evidence that Ed actually contributed to this foment. The school principal is successful in his work to the extent that he is able to contain and constrain the forces of change with which he must contend as a matter of daily routine; whatever force he exerts on the dynamics of the school contributes to its stability, even when he wants to act, or believes he is acting in a way that will encourage an aura of change. (p. 307)

Wolcott's observation was supported by a quantitative study performed a decade earlier. Griffiths (1963) conducted a study of over 231 elementary school principals from all over the United States. Griffith's research asked principals to respond to typical problems they might face in the simulation of a fictitious school. They found that the principals rarely introduced change into the system. In most cases, principals relied on direction from a superior in the central office.

\section{Lived Experiences of Elementary Principals}

After considering the researchers' views of a principal's roles, it will be important to consider the perspectives of principals themselves. Van Manon (1990) writes that in qualitative studies, researchers study the object or phenomena of lived experiences of the subjects. They strive to find a description of the universal essence, or a "grasp of the very nature of the thing" (p. 163). Moustakas (1994) writes that a researcher tries to find a composite description of the essence that consists of what was experienced and how they experienced it. Crow et al. (2000) conclude that there are fewer studies focusing on the role of the principal viewed from the their own perspective, and that such studies are 
needed. Day (2000) wrote about a study of British head teachers or principals that occurred in 1998. These schools were recognized by the Office for Standards in Education for above average performance, especially in the area of leadership. Interviews of head teachers from twelve schools (including elementary schools) were conducted to collect "educated opinions." Findings from the data suggested consensus among the head teachers and other staff members that the following personal characteristics were important:

- Values led

- $\quad$ People centered

- Achievement oriented

- Inward and Outward Facing

- Able to manage a number of ongoing tensions and dilemmas (p. 1).

In his doctoral dissertation, Hoppey (2006) conducted a case study of an elementary school principal in Florida. The purpose of his study was to revisit the classic study by Harry Wolcott, in The Man in the Principals Office, and to "explore how a principal conceptualizes and enacts his role in an era of high stakes accountability" (p. ix). Hoppey's study used qualitative methods including interviews with the principal. Greenfield (2004) recommended that researchers study and explore the moral aspects of principal leadership by examining their social interactions, as well as their own perspectives in a phenomenological sense. He summarized qualitative studies of principals that were conducted between the years 1979-2003. He writes:

To understand moral leadership requires that one gain an understanding of the perspectives, the lived experiences and the 
subjective meanings of the participants in the leadership relationship. (p. 191)

From his analysis of the research, he made the following recommendations for future study:

1. Study the social relations among school leaders and others, focusing on the activities, interactions, and sentiments characterizing the work of school leaders and teachers and the significance of these in explaining moral leadership.

2. Study the meanings and perspectives underlying what school leaders are doing in their social relations with others, seeking to understand the perspectives of leaders as well as those with whom they interact.

3. Study the nature of the espoused purposes of school leaders' actions and orientations toward others, and the congruence between these, organizational values, and leaders' theories-in-use.

4. Study the authenticity of school leaders in their relations with others.

5. Study the emotional dimensions of being a school leader, including the satisfactions and the disappointments of leading, and feelings of anxiety, frustration, and anger, as well as the feelings of happiness, satisfaction, and pride, among other passions of leadership.

6. Study the basis of the commitments underlying a school leader's purposes, social relations with others, determination to stay the course, and to remain patient in the face of the tremendous pressures school leaders are under to improve schools. (p. 191)

The previous examples and recommendations point to the need for future exploration of the views and perspectives of principals themselves, reporting their own lived experience.

\section{Summary}

This literature review has discussed three major topics including a brief history of Title 1 schools, researchers' views of the principal's role, and a brief review of research speaking to the lived experiences of principals from their points of view. Title 1 schools, or "high poverty schools", were designated to receive additional support 
through an act passed by the U.S. Congress in 1965 entitled the Elementary and Secondary Education Act (ESEA). The most recent re-authorization of this act was titled No Child Left Behind (NCLB), and it was passed in 2002 during the Bush era. The reauthorization required greater accountability from teachers and schools to improve student achievement (Bush, 2001).Since that time, the roles of principals in these schools have been studied. When considering the role of instructional leader, studies have concluded that in terms of impacting student achievement, the role of the principal is secondary to that of the classroom teacher (Leithwood et al., 2004). The role of manager requires a balancing act between providing leadership for instruction and managing the operational details of the school (Sternberg, 2012). The capacity builder strives to help teachers develop their own professional growth as well as teacher leadership (Louis et al., 2010). The monitor and learner role focuses on the ongoing learning that occurs for the principal himself (Reeves, 2006). Most recently, the role of promoter of social justice and equity involves bringing attention to student achievement gaps that are related to race, disability, and economic disadvantage (Singleton \& Linton 2006; Delpit, 1995; Noguera, 2011; Ysseldyke, 2001; Reardon, 2013).

The last section reviewed research that has been done related to the lived experiences of principals themselves. Researchers recommend further study in this area.

Now that a summary of the literature has identified effective practices that are supported by research — as well as the need for further research-I would like to bring the focus to this study's purpose. Much of the research expressed in the first part of the review points to an external analysis of the principal's role. I am curious to know what 
meanings principals themselves have derived from their experiences since 2008 , when we began to experience significant reductions in resources.

With the completion of this review of the literature, I will now move to describe the methods I have used and their rationale for this study. Again, the focus of the study will be framed by the following question: How did principals of high poverty elementary schools respond to the phenomena of reduced resources and the expectation of increased student achievement?

This question informs the qualitative methods of semi-structured interviews and personal narrative employed in the study. 


\section{CHAPTER 3}

\section{Methodology}

\section{Study Overview}

My research posits a narrative inquiry approach by investigating the perspectives of principals and former principals of high poverty elementary schools who have experienced significant reductions of resources, especially staffing, while simultaneously experiencing increased accountability. Given the stories of principals from high poverty elementary schools, the purpose of this narrative inquiry is to understand how principals responded to decreasing resources and the need for increased student achievement.

\section{Methodology Rationale}

The narrative inquiry approach was chosen as a method in order to try to understand a real-life phenomenon, specifically, the lived experiences of elementary principals who have grappled with high poverty, reduced resources, and increased accountability. A narrative inquiry is "understood as a spoken or written text giving an account of an event/action or series of events/actions, chronologically connected" (Czarniawska, 2004, p. 17). Creswell (2007) writes:

The procedures for implementing this research [narrative inquiry] consist of focusing on studying one or two individuals, gathering data through the collection of their stories, reporting individual experiences, and chronologically ordering (or using life course stages) the meaning of those experiences. (p. 54)

The key source of data for analysis was the interview transcripts of principals who were challenged with the circumstances of high poverty, reduced resources, and 
increased accountability. Sources of evidence included interviews of principals, state report card data, class size ratios, and full-time equivalent (FTE) allocations or staffing allocations for full-time employees.

Narrative inquiry process. Clanndinin and Connelly (2000) use a metaphorically three-dimensional narrative inquiry space that includes temporality, personal and social, and place. Temporality refers to time that includes the past, present, and future. They also describe temporality as moving backward and forward. When referring to the personal, they describe a movement inward toward internal conditions, which consist of feelings, hopes, reactions, and moral dispositions. Then, when referring to the social and place dimensions, they describe movement toward the outside or the external environment. Clanndinin and Connelly (1994) write:

Thus, when one is positioned on this two-dimensional space in any particular inquiry, one asks questions, collects field notes, derives interpretations, and writes a research text that addresses both personal and social issues by looking inward and outward, and addresses temporal issues by looking not only to the event but to its past and to its future. (as cited in Clanndinin \& Connelly, 2000, p. 50)

Narrative inquiry was appropriate for this study because principals were asked to look inward as they shared their stories and processed their experiences., During the telling of their stories they discussed their decisions that were made in response to the economic crisis. They looked outward as they retold their interactions that involved staff members and district level supervisors. The temporal component of their narratives involved their retelling of stories by mentioning hindsight or responding to the prompt, "What would you have done differently?" (See Interview protocol question 
Q in Appendix E).

Clanndinin and Connelly (2000) then write:

In this earlier work, we included the dimensions of place within the environment. We now believe it is preferable to see place as a third term, which attends to the specific concrete physical and topological boundaries of inquiry landscapes. (p. 51)

The consideration of place is also important to this methodology. Title 1

elementary schools are a place and distinctly unique because of the student population they serve and the increased expectations for learning growth especially for students in marginalized groups.

Dewey (1938/2007) developed a philosophy of experience and education from which this narrative inquiry approach is based. When describing the relationship of Dewey's philosophy to narrative inquiry, Ollerenshaw and Creswell (2002) write:

This means that to understand people (e.g., teachers, students, and administrators), one examines their personal experiences as well as their interactions with other people. Continuity is related to learning about these experiences, and experiences grow out of other experiences and lead to new experiences. Furthermore, these interactions occur in a place or context such as a school classroom or a teacher's lounge. (p. 339)

I interviewed ten elementary school principals from high poverty elementary

schools. After my interviews, I followed narrative inquiry guidelines to analyze and mediate between the different meanings by using a coding process. Notable proponents of this technique in the field include Strause and Corbin (1998) and Charmaz (2010). Charmaz explains the process in this way:

Coding consists of at least two main phases: an initial phase involving naming each word, line, or segment of data followed by 
a focused, selective phase that uses the most significant or frequent initial codes to sort, synthesize, integrate, and organize large amounts of data. (p. 339)

Charmaz continues to write about the importance of "memoing"-in which the researcher captures comparisons and connections that are made in writing. The memos take the form of conversations that the researcher is having in his or her head as they analyze the coded words or phrases. The memos can be retrieved later or used sooner. They also keep the researcher engaged in the data. This means that to understand people (e.g., teachers, students, and administrators), one examines their personal experiences as well as their interactions with other people. Continuity is related to learning about these experiences, and experiences grow out of other experiences and lead to new experiences. Furthermore, these interactions occur in a place or context such as a school classroom or a teacher's lounge (p. 339).

Charmaz's approach aligns with the social constructivist worldview that is guiding my research.

\section{Role of the Researcher}

Participant Observer. When considering the role of the researcher, Marshall (2011) says, "The researcher is the instrument" (p. 112). In order for the remainder of the section to be more easily read, instead of using third person, I will use first person when I am speaking as a 'participant', and third person when I am distancing myself from the study as the 'researcher'. As the researcher or instrument, I will be inserting myself into the daily lives of the participants. Therefore, it will be important to consider several ethical issues (p. 112). Most importantly, as a researcher I must disclose my personal 
interest in the study, which is to investigate and describe the leadership and decisionmaking skills that principals employed during economic reductions. I have a personal desire to learn what these skills are, not only to answer the research question but also to enhance my personal decision making as a principal. I built enough rapport with the participants that they trusted and believed I was sincerely adding to the knowledge base regarding leadership and decision making. I used a letter to request participation of the principals, which will serve as an entry/informed consent document. These letters are located in Appendix B.

Researcher Bias. Since the study was an inquiry into my own field of work, it was important for me to address my own biases before any data was collected. Patton (2002) provides a series of reflexive questions in the form of an inquiry that I used as a guide (p. 66). The inquiry covers three general areas that include the participants who are studied, myself as the qualitative inquirer, and those receiving the study, or the audience.

Researcher as Qualitative Inquirer. I have had the benefit of ten years of experience as an elementary school principal. Eight of those years included experience at high poverty elementary schools. Within the five-year span of time that I was assigned to one of the schools, we made the transition from a targeted Title I program to school-wide status. My experience in Title I schools continued into my next assignment. With that experience, I can say that I was able to relate to the experiences of the participants. At the same time, I didn't want to assume that these principals approached their work in the same way that I chose to. I also needed to avoid making any judgments about their responses to my questions. I was hopeful that the findings in the study would be as 
objective as possible, so that they would benefit other elementary principals leading high poverty schools.

\section{Participants and Recruitment}

For the purposes of my research, I invited 20 retired principals from seven districts who were leading Title 1 schools during the time period between the 2009-2010 school year and the 2013-14 school year (the most intense budget reduction years). The sample was purposive because I wanted to focus on the experiences of Title 1 principals who were employed during the time of financial crisis.

Recruiting. Retired principals who worked in Title 1 schools between 2008 and 2014 were recruited for the study. All of the principals who participated in the study worked in urban or suburban school districts with high levels of poverty. I took initial steps to recruit by contacting professional organizations who could refer me to potential participants. A representative from one organization referred me to Education Northwest, a non-profit agency in the Northwest that provides leadership training to school leaders. A representative from this agency developed a list of twenty potential participants who fit the criteria for this study and shared their contact information with me. All of the participants were recently retired principals from Title 1 schools who were coaching principals of schools that were designated to receive additional funding and support to improve student achievement outcomes in order to meet requirements established by NCLB and ESEA waivers. I sent an e-mail message out to all twenty of the potential participants with the goal of recruiting ten participants. I selected the first ten who responded if they agreed to the requirements for participation. The requirements 
are listed in the IRB consent form that is located in Appendix B.

\section{Perception}

Researcher's perceptions of participants. The participants in the study were the researcher's peers. These participants were able to lead schools with high poverty that achieved significant results in terms of student achievement while experiencing reductions in staff and school days. I approached the study with some assumptions about what shaped their world views, including the belief that all students can learn despite the circumstances they face in life-including the challenges that come from living in a culture of high poverty. I assumed that the participants had high levels of confidence in their teachers' ability to help students learn.

Participants' perceptions of me. In terms of their perceptions of me, I wondered if they might have thought that I was a little overambitious in taking on the study. I also wondered if they thought that my time could have been spent doing other things, such as spending more time with family outside of work, or at least focusing more on my role as a practitioner as opposed to a researcher. The evidence I had for these assumptions included conversations I had with colleagues in my own school district who questioned why I was taking this project on, when our workloads were increasing without a similar increase in salary or other compensation. These perceptions were important because they could have influenced how I might have interpreted their responses to my questions.

\section{Audience for Study}

Since elementary principals from high poverty schools and potentially those administrators that support them are the intended audience, I hope that they will see me 
as a colleague in the field who is taking significant steps to share his findings about a profession that is challenged by significantly reduced resources. I can imagine that they will bring several perspectives when they review these findings. Perhaps principals from different settings will wonder how the district found itself facing these circumstances, particularly if they are from a different district where the economic conditions and policies were different. My findings will emerge from the research and they will benefit principals in a variety of settings and circumstances, including those who are seeking initial and continuing licensure.

\section{Control for Bias}

I put in controls that helped me to limit my bias when interpreting the data. I planned to use the steps Marshall and Rossman (2011) recommend. They include the following:

- I used a research partner who thoughtfully and gently questions my analysis.

- I built in a time for cross-checking and peer debriefing to search for negative instances.

- My analysis used, but was not limited by previous literature.

- I examined alternative explanations to questions that arose from the data.

- I used a memo taking process that had two sets of notes. One had explicitly descriptive, non-evaluative note taking. The other had tentative categories and personal reactions.

- I kept a running record of the procedures I used throughout my research so that they could be examined externally if necessary. 
Bracketing. One aspect of bias control is having the proper mindset while conducting the research. Creswell (2007) points to the work of Moustaka (1994), who emphasizes the importance of the descriptions of the lived experiences of the participants. The term used to describe the process is called transcendental or psychological phenomenology. An important component to the approach is the action of epoche, or bracketing, in which the researcher must set aside his or her own experiences as much as possible so that they can have a fresh perspective of the phenomenon being studied.

However, the concept of bracketing was important to consider for myself, as my own lived professional experiences might have resembled those of the participants in the study. Edumund Husserl, (as mentioned in LeVasseur, 2003) a philosopher, is considered by many to have introduced the idea of phenomenology. He opposed the idea of naturalism, which says that empirical science is the only way to determine truth. He emphasized the importance of the lived experience of human beings as the source from which science originates (LeVasseur, 2003, p. 410). Husserl used the terms "epoche" and “bracketing” interchangeably (Stewart \& Mickunas, 1990).

New definition of bracketing. LeVasseur (2003) has proposed a new definition of bracketing which was helpful in my research. She writes:

The project of bracketing attempts to get beyond the ordinary assumptions of understanding and stay persistently curious about new phenomena. I believe this provides opportunity for fresh experience and the possibility of new horizons of meaning. (p. 419)

The idea that one's curiosity can help to keep the inquiry fresh by avoiding pre-conceived notions was something I felt I could grasp. I have always had a passionate curiosity to learn about the professional lived experiences of my peers. The drive was 
strong enough to allow the suspension of my beliefs in the search for new perspectives. Creswell (2007) has observed researchers who have dealt with the problem by describing their own experiences with the phenomenon and bracketing out their views before describing the experience of others.

Bracketing technique. I employed the use of a reflective journal. Ahern (1999) recommended the use of a journal to write about instances when the researcher recognizes feelings that could interfere with the researcher's neutrality. The journal can be used to help identify the origins of the feelings. If the origins of the feelings cannot be separated out, then it will be necessary to consult with a colleague to make sure that the data collection and analysis have not been affected. Glen, Mitchinson, Poole, and Wall (2004) demonstrated the use of a reflective journal for the purposes of bracketing in their research, which examined the lived experiences of patients and their partners during the period leading up to their diagnosis of Non-Hodgkins Lymphoma. In their study, researchers took time before their interviews to review those issues of their own that could interfere with the questioning. They would consciously set those aside and use active listening techniques to stay focused on the phenomena being investigated. If a participant brought up a topic that was not relevant to the phenomena and the researcher encouraged the participant to talk more about it, a note would be made in the reflective journal and the researcher would take steps to mentally set it aside before the next interview, committing to stay focused on the phenomena that is being studied.

Learning and growth. With bracketing, my purpose was to learn about and describe leadership skills that were employed in similar circumstances to my own. For 
example, Young (2014) writes about two types of learning growth, longitudinal and exponential. He writes that in the early phases of learning, one will often see growth that steadily improves. Examples include athletic activity, such as running or riding a bike, where the progress is linear.

However, we also experience exponential growth in areas of life that are not as predictable. Long periods of struggle may occur and then all of a sudden quick success is gained. During the struggle, one may experience a large amount of negative feedback about his or her performance and choose to give up. Young says it is important to understand features of the environment, in order to understand whether the growth is linear or exponential. He promotes the idea of looking at how other people have progressed in the field by not looking at their rates of improvement, but by looking at whether growth slows down or speeds up with mastery. This is the kind of insight I was hoping to gain by placing aside my own views, habits, and mindsets, in order to gain a new understanding in my field.

\section{Ethical Considerations}

It was important for me to consider the questions asked by an institutional review board (IRB). These questions addressed attaining access to sites and subjects, providing for informed consent, the kinds of interactions I would have with the subjects, the risks the subjects would take, and how I would reduce those risks (such as using school and personal pseudonyms, reversing gender pronouns) and how I would guard the privacy of data and subjects (Glesne, 2005).

\section{Use of Time and Energy}


Bogdan and Biklen (2006) recommend that qualitative researchers consider boundaries for the use of their time and energy. The timeline needed to be realistic. I completed the research over 16 weeks of time, which included the Fall and Winter terms of 2014-2015. The Spring term was devoted to data analysis and reporting on the findings.

\section{Contrasting Narrative Inquiry and Ethnography Designs}

In the classic case study of one principal, Ed Bell, Walcott (1973) took an ethnographic approach. He wrote:

To describe and analyze the elementary school principalship from a cultural perspective. This study focuses not only on a particular group of people elementary school principals - but on the behavior of one specific elementary school principal during a particular period of time... This study focuses on those human processes in which the principal engaged that were most directly related to his assignment as a principal. However, an ethnographic inquiry into what a principal does as a principal cannot ignore the broader context in which an individual lives and works, and the various ways in which circumstances that appear to be external to his occupational role may actually exert considerable impact. The attention to context and to complex interrelationships in human lives is what makes ethnographic accounts different from accounts written from the perspective of other social sciences. Ethnographic accounts deal with real human beings and actual human behavior, with an emphasis on social, rather than on physiological or psychological, aspects of behavior. (Wolcott, 1973, p. xv)

My study took a different direction, in that the research took the form of a

narrative inquiry as opposed to that of ethnography. In his study, Walcott limited himself

to the "etic stance" of an outside observer. In the etic approach, the observer does not discuss his views with the participants (Creswell, 2007). Hoppey (2006) studied the role of the principal in an era of high stakes accountability using a case study design. In his rationale for the use of a case study, he notes that the participant in 
Walcott's study, Ed Bell, was distraught by Walcott's interpretation of Ed's behavior. Ed felt that he was portrayed as inept. Hoppey writes:

The principal's purpose was to identify, eliminate, and solve issues as they arose. In direct contrast, Wolcott's purpose for being in the school was to uncover how people resolve problems "in an effort to describe and to understand how principals behave" (p. 317). His decision not to personally discuss his observations with his participant played into this mixed reaction from his participant, and limits his case study. Thus, the principal did not envision the finished report the way it turned out because Wolcott did not try to understand the principal's underlying beliefs or values that guided his decision-making and leadership. (p. 44)

Emic stance. In my project, I used an "emic stance," in which the views of the participants are considered (Creswell, 2007). An emic approach, from an anthropological perspective, takes note of the constructs, conceptual themes, and categories expressed by those of the native culture (Lett, 1990). In my case, the participants are the native culture and I am a part of that culture. Researchers who take an emic stance try to put aside existing theories and assumptions to see if new themes or concepts emerge.

Etic stance. On the other hand, Lett (1990) describes the etic stance, in which the researcher starts with an existing theory or assumption from outside of the culture and sees if it applies to the phenomena being studied. In contrasting the two stances, Harris (1976) writes that the difference between the two stances depends on whether the phenomena investigated is occurring in "the heads" of the actors (emic) or in the behavior stream that is being observed (etic) (p. 335). The conception of the two stances came from the linguist Kenneth Pike, who used the suffixes of the words phonetic (etic) and phonemic (emic) to explain observations of language. The phonetic sounds could be observed when looking at the physical ways in which the sounds are produced, such as 
vocalizations. On the other hand, phonemic sounds are the unconscious ways in which sounds are distinguished from each other "in the heads" of the actors (p. 331).

Bracketing was an important process to follow since I took the emic stance. I believe that my curiosity and desire to understand the lived experiences of my professional peers helped. The how and why behind the decisions of elementary principals interests me just as much as their behavior.

\section{Data Collection}

The data collection consisted of in-depth interviews of the participants, as well as a review of budget and staffing documents. The nature of the interviews was open ended and additional artifacts were included. Kvale (1996) wrote that the purpose of interviews is to understand the "life-world" of the participant by attaching meaning to their responses. In order to gain the depth and quality I was seeking, for each participant, I conducted one interview of thirty-to-sixty minutes. Seidman (1991) suggests that the interviewer conduct a first interview to gain the trust of the participant by developing rapport. I did this through an initial meeting, where the participant and I had the opportunity to get to know each other without starting the formal interview. Seidman (1991) suggests that the second interview can explore the experience in depth. As a researcher I "co-composed" (Clanndinin, [2000]) the field texts. These texts are shaped by Clanndinin's notion of three-dimensional inquiry space by using questions or prompts that will guide the participant through the dimensions of temporality, personal and social, and place. Each interview was recorded, transcribed, and then the transcription was sent to the participant for member checking and review. At any time, a participant had the 
opportunity add to their comments via text, telephone, email, or in person. Following Seidman's protocol, I reviewed the transcripts and prepared more focused follow up questions, if necessary, for a second round or clarifying interview.

\section{Data Analysis}

After completing the interviews and reviewing the transcripts with participants, I began the initial analysis by completing a close read of each transcript. Using "Atlas ti" software, I began to create memos for lines and sections in the transcripts - in addition to creating "in vivo codes," or words that were the exact words of the participants. Since I was using a narrative inquiry approach to my analysis, I identified answers to questions that were given to me in narrative or story form. Memos and codes were developed for each of the narratives, including those that had artifacts associated with them. They were then compared with other narratives across all ten transcripts. The "Atlas ti" software helped me to create links between memos and codes to identify patterns. Memos were compared across transcripts to identify themes that were emerging. Those themes became the basis for my findings and conclusions. Throughout the process, a shadow researcher reviewed my analysis to check for biases that might affect my interpretation of the data. The shadow researcher also read journal entries of my own initial reactions after I completed each interview. This feedback also helped me to filter out my personal biases. The role of the shadow researcher and their involvement in the study will be explained further in chapter 4 .

Another aspect of the analysis involved restorying. Ollerensha and Creswell (2002) adapted Clandinin and Connelly's three-dimensional narrative space structure. 
Table 2 functions as a graphic organizer to explain aspects of this structure. The personal and social components are parts of the interaction continuum, while the past, present, and future comprise the continuity continuum. Situation and place are in a category by themselves. This analysis was done after the entire series of interviews were completed.

\section{Table 2}

Restorying

\begin{tabular}{|c|c|c|c|c|c|}
\hline \multicolumn{2}{|c|}{ Interaction---------------- } & \multicolumn{4}{|c|}{ 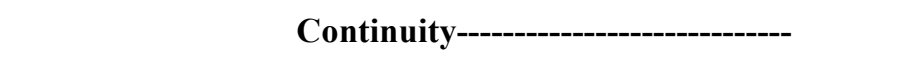 } \\
\hline Personal & Social & Past & Present & Future & Situation/Place \\
\hline
\end{tabular}

In the interaction continuum, the researcher analyzes the personal experiences of the participant who is telling their story. The researcher also looks at the interactions the participant is having with other people.

The researcher analyzed the participant's narrative in terms of the past, present, and future in the continuum.

When considering situation or place, researchers analyzed the physical locations in the narrative, as well as the sequence of the locations in the story.

Themes. After each interview, the data was organized around themes that were generated from the literature review, research questions, interview content, and the purpose for the study. I expected a theme might emerge to align with the standards for principal evaluation that are listed in Table 1. I also focused on key themes in the literature review that are aligned with the principal evaluation standards. One theme I was 
especially interested in was the perceived role of the principal as a learner, as well as his or her ability to promote a culture of learning. More specifically, I was interested in hearing about the ways in which principals addressed barriers. Barriers might have included the following: institutional culture, personal beliefs and motivations, bias, discrimination, and cultural insensitivity (Muhammad \& Hollie, 2012).

Coding. When coding the data, it was important to keep an open mind as I immersed myself in the data. Yin (2003) recommends that the researcher start with a general strategy for analysis. He suggests starting first with a small question from the protocol, draw a tentative conclusion, and then continue to a larger question following the same process. Charmaz (2010) recommends starting with line-by-line coding using the following strategies:

- Breaking data into parts

- Defining actions

- Looking for assumptions

- Interpret actions and meanings

- Comparing data. (p. 50)

She suggests that the researcher shouldn't generate conclusions or theories. Throughout the process, I used constant comparative methods (Glaser \& Strauss, 1967). At first, I compared different sets of data to find similarities and differences. For example, interview statements were compared with other interview statements or incidents that were mentioned. Incidents were compared with other incidents. Charmaz (2010) advises that researchers see their own perspectives as one among many in order to avoid 
prejudgment of what is happening. It will be important to see the world through the participants' eyes.

After initial coding, the researcher moved to focus coding on areas where the significant or most frequently occurring codes were used to sort the large amounts of data. At the next level, axial coding, or finding links between categories was applied. Strauss and Corbin (1998) provide a procedure. Essentially, the procedure results in a potential frame that researchers can apply. The frame could be developed into a theory, but Charmaz (2010) cautions that the codes themselves are not objective criteria. Rather, they should be used to sharpen and focus the analysis. She says that it is important to interrogate one's self.

Memoing. Charmaz (2010) suggests that memo writing be used as a way to analyze the codes and phrases that have been formed. She writes that it is a time for discovery. Rather than advocating a single procedure, she recommends that the researcher use the following components:

- Codes should be defined by analytic properties.

- Processes should be spelled out.

- Comparisons should be made between data, codes, and categories.

- Raw data can be brought into the memo.

- Empirical evidence should be used to support category definitions and analysis.

- List opinions that could be investigated in the field setting.

- Point out gaps in the analysis

- Ask questions of a code or category. (p. 82) 


\section{Summary}

The purpose of this narrative inquiry was to understand the leadership and decision-making skills elementary principals of high poverty elementary schools employed when having to respond to decreasing resources and the need for increased student achievement. A narrative inquiry approach was used to research the lived experiences of the principals. More specifically, the narrative inquiry research was conducted from a social constructivist point of view (Creswell, 2007; Lincoln \& Guba, 1994). Research methods used hermeneutical phenomenology, which is oriented toward the lived experience of principals (Van Manen, 1990).

Consideration of the researcher role as participant observer took into account the researcher's perceptions of the participants, the participants' perceptions of the researcher, as well as the audience for the study (Patton, 2002). Controls for bias included the important step of bracketing to maintain the proper mindset while conducting the research (Creswell, 2007).

Ethical considerations with oversight from the institutional review board (IRB) took into account the potential risks participants might have experienced. An informed consent procedure was used and steps were taken to secure confidential data and participant privacy.

For the purposes of the study, the researcher took an emic stance as opposed to an etic stance. In an emic stance, the researcher does not start with a theory or assumption to guide the research. Rather, the researcher looks for themes and patterns that emerge from the data (Lett, 1990). 
Principals were invited to participate in the study. They included retired principals of Title 1 schools in Northwestern states during the time period from the 2009-2010 through the 2013-2014 school years.

The data collection consisted of at least one in-depth interview per participant, with an open-ended structure. Each interview was audio recorded and transcribed. After the interview was transcribed, it was sent to the participant for member checking.

The data analysis used a narrative inquiry approach that was guided by the recommendations of Strause and Corbin (1998) and Charmaz (2010). 


\section{CHAPTER 4}

\section{Findings and Analysis}

\section{Review of Study}

The research question asks how principals of high poverty elementary schools responded to the phenomena of reduced resources and the expectation of increased student achievement.

Purpose. The purpose of this narrative inquiry was to describe the leadership and decision-making skills elementary principals of high poverty elementary schools employed in response to decreasing resources and the need for increased student achievement.

Research question. How did principals of high poverty elementary schools respond to the phenomena of reduced resources and the expectation of increased student achievement?

\section{Organization of Findings}

Following a narrative inquiry approach, I audio recorded each interview and each interview was transcribed. The narrative transcriptions were coded for significance in relationship to the research question. These codes were then analyzed for patterns or groupings that appeared to be significant. The findings of the study are organized in the following sequence: analysis of data, presentation of results (participant demographics, participant leadership style, and categories of responses to times of economic crisis), as well as lessons learned and additional bits of wisdom. In Chapter Five, I compare my own experiences to those of the participants in this study. 


\section{Analysis of Data}

After completing the interviews and reviewing the transcripts with participants, I completed close reads of each of the transcripts. Atlas.ti ${ }^{\mathbf{T M}}$ software was used to assist with the coding process. The transcript documents were loaded into the software. This allowed me to apply constant comparative analysis to all of the quotes and codes I identified. The software also had tools that allowed me to identify co-occurring codes across all of the transcripts. Since I was using a narrative inquiry approach to my analysis, I identified answers to questions that were given to me in narrative or story form. Memos and codes were written for each of the narratives, including those that had artifacts associated with them. Each participant was asked to bring an artifact that represented his or her career as a title 1 principal. The narratives were then compared with other narratives across all ten transcripts. The Atlas $\mathrm{ti}^{\mathrm{Tm}}$ software helped me to create links between memos and codes, and to identify patterns.

Coding to Categories. I started my first read of the transcripts with line-by-line coding, which consisted of assigning a description to each line of dialogue. Since the rate of progress with this level of analysis was slow, I moved to incident-by-incident coding of the narratives. After completing the first read, I had 539 incidents that were coded. In the Atlas ti ${ }^{\mathrm{TM}}$ software the incidents are considered quotes. In the second read, I began comparing quotes across all ten of the documents. After identifying synonyms and common terminology, I was able to reduce the number of codes to 100 . After working through the third reading of each transcript, I began to notice that the codes could fit into 
broader categories of codes that described styles of leadership (Figure 4.1). One in vivo code inspired by a term from one of the participants, suggested a military theme. The term he used was "loyal lieutenant." I decided to adopt that as one category of leadership style. I will describe the other two categories I was able to identify in the Categories of Leadership section below.

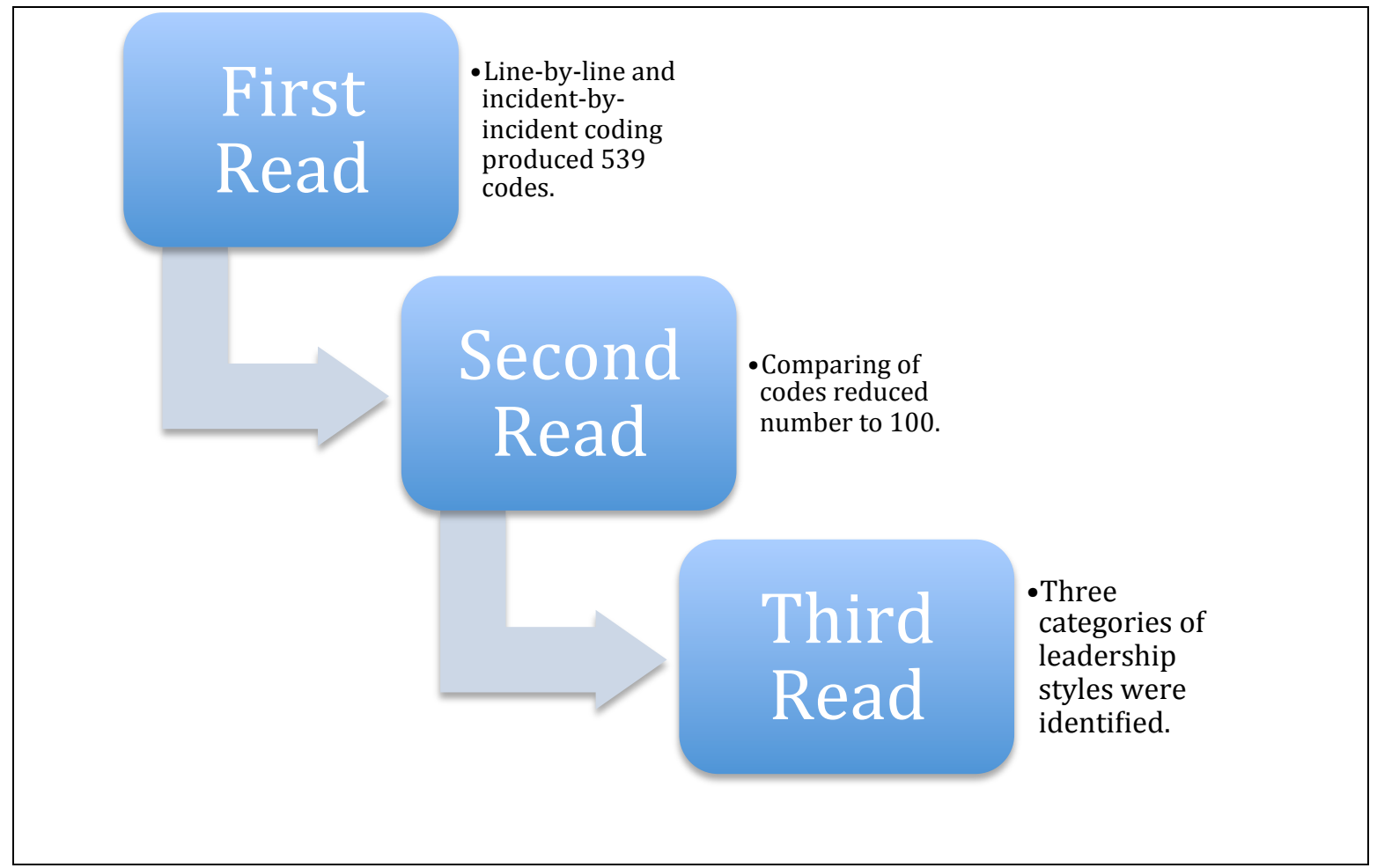

Figure 4.1. Code reduction process.

The categories of leadership were derived from the narratives and initiated by a participant who called himself the "loyal lieutenant. The other categories included “creative captain," and "mission major." Each of these categories is further explained in the "Interpretations of categories of leadership style" section.

Research Procedures. The research procedures included five steps, which are illustrated 
in Figure 4.2. Interviews were initially recorded with a small hand-held digital audio recording device. The audio recordings were digitally sent to a transcript production service. Upon receipt of the transcripts, they were sent to the participants for member checking over e-mail. After participants reviewed the transcripts and made changes, the transcripts were sent back to me so that they could be coded for significance in relationship to the research question.

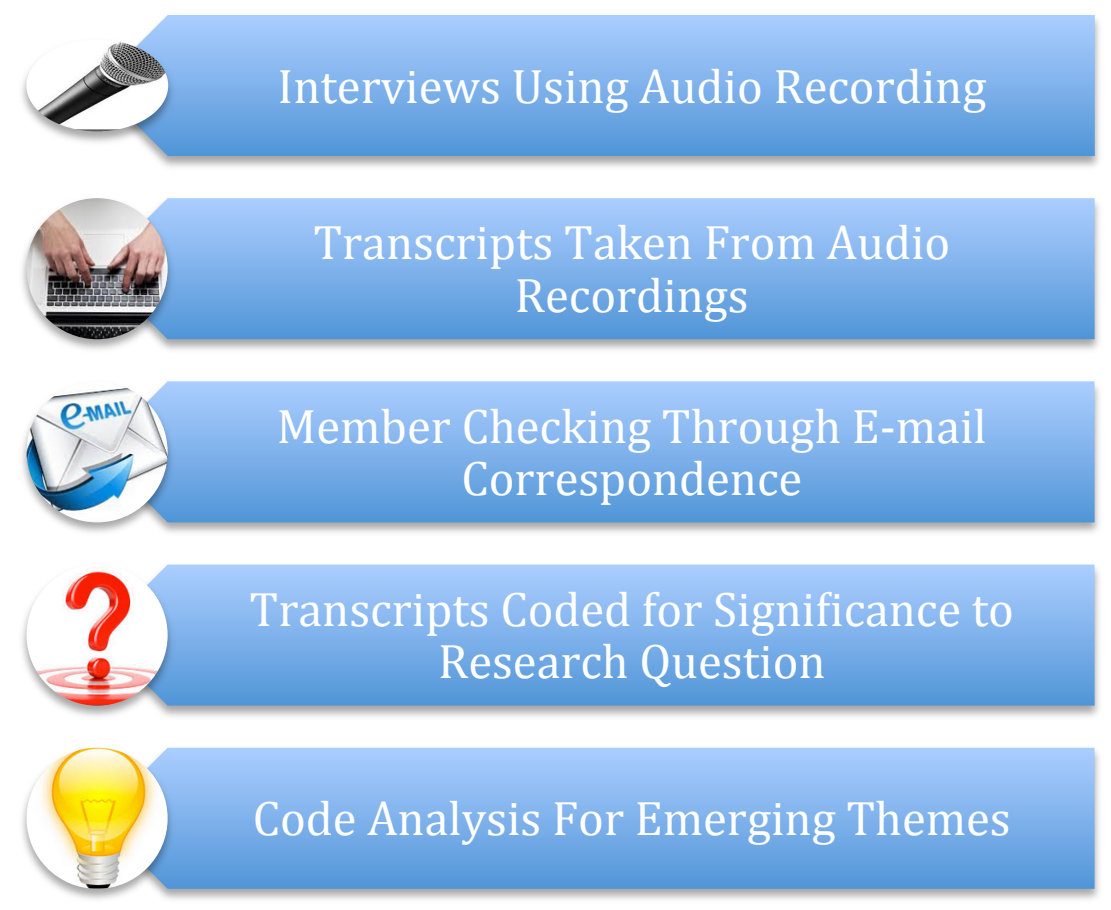

Figure 4.2. Steps for analysis.

Figure 4.3 demonstrates the overall digital process I had used by the time I had reached the third reading of the transcripts. I started with ten transcript documents that were loaded into the software program. Those documents are listed on the $1^{\text {st }}$ left-hand column of the figure. Moving right, the dialogue from the transcripts is located in the next column. The coding of incidents (incidents are coded in blue) occurred in the next 
column, and memos associated with incidents and quotes are listed in the last column.

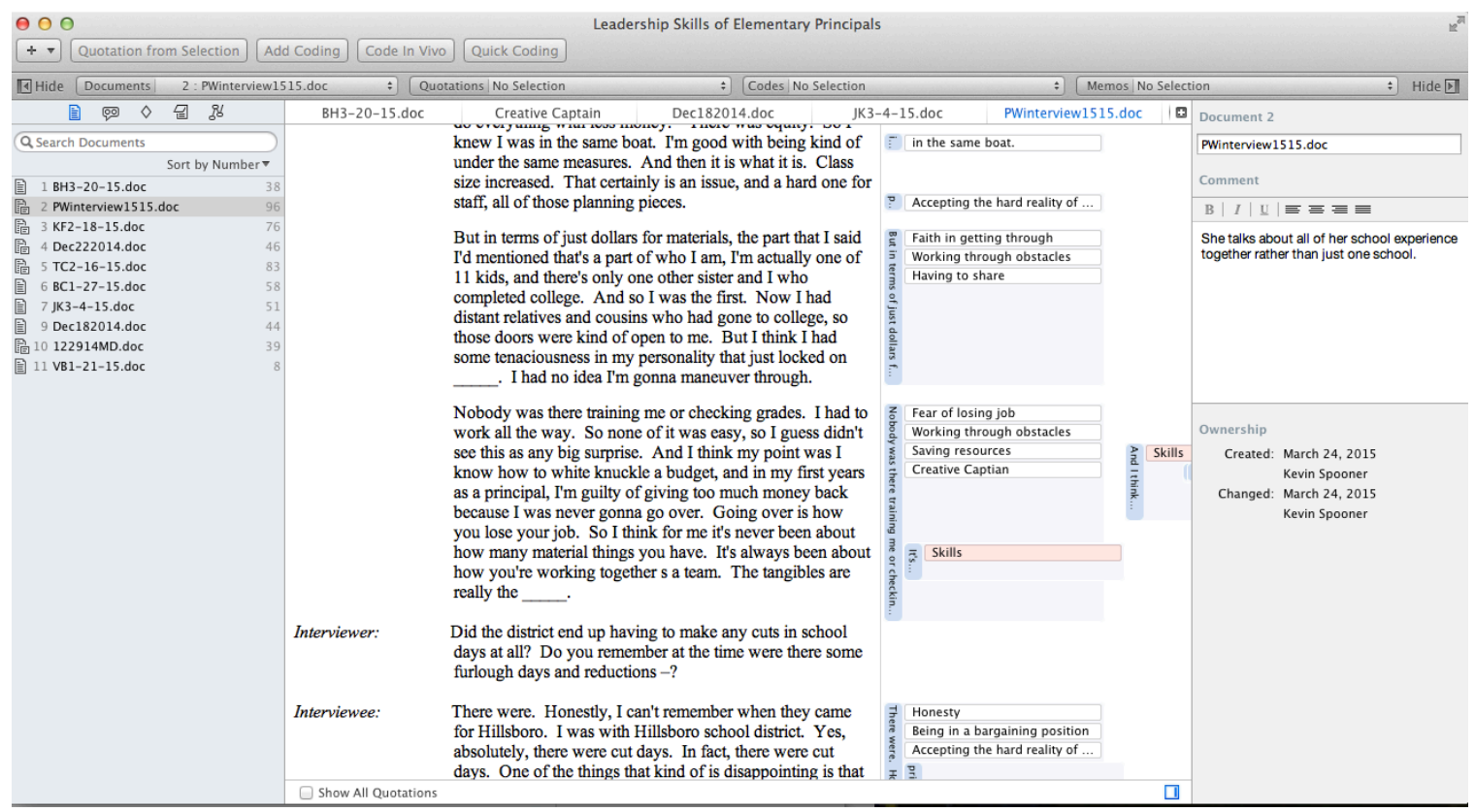

Figure 4.3. Screen shot of transcript third read.

Memos. Memos associated with the incidents and codes were compared across transcripts to look for emerging themes. The memos contained my reactions to quotes from participants, notes about connections to other participant quotes, and notes to self about inquiry directions. The categories of leadership themes emerged from this analysis. Figure 4.4 below illustrates this process. 


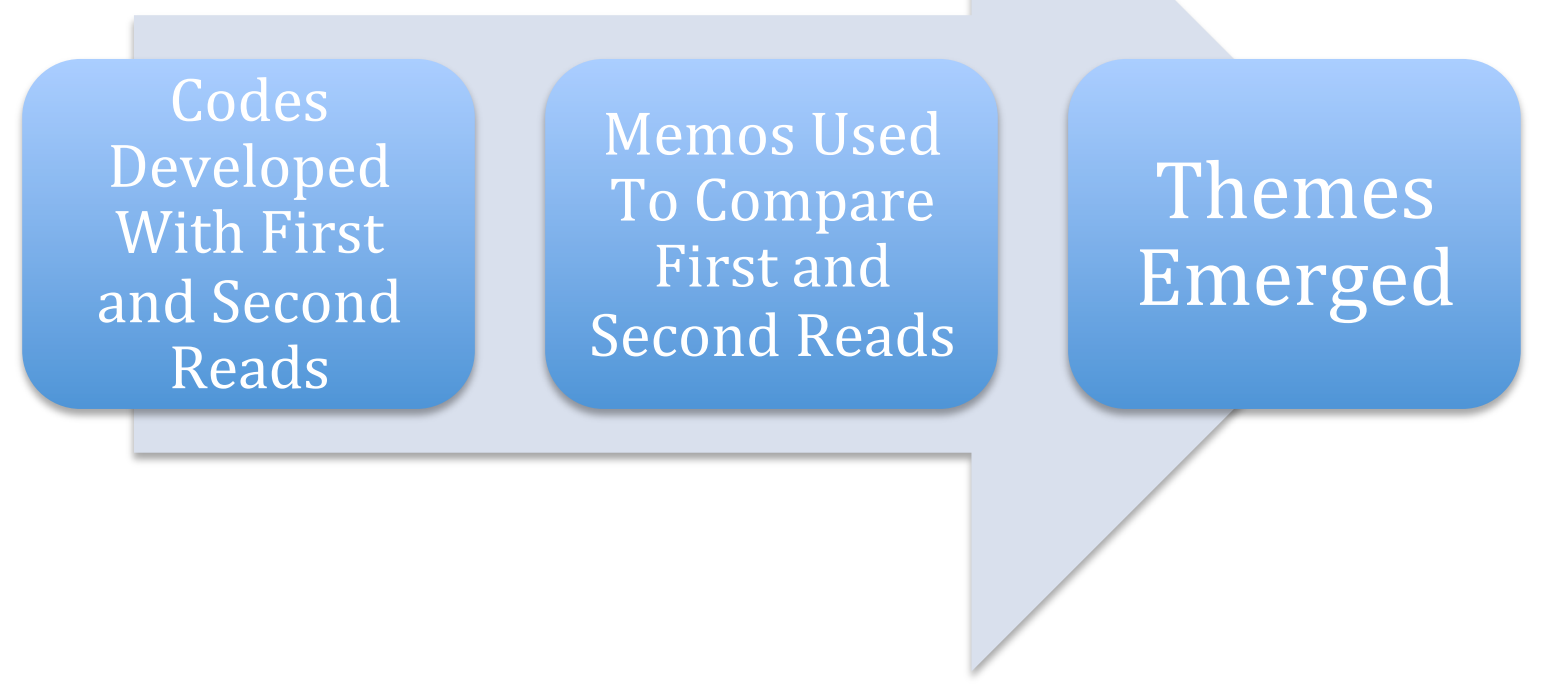

Figure 4.4. Movement from codes to memos to themes.

Shadow researcher. Throughout the process, a shadow researcher reviewed my analysis to check for biases that might affect my interpretation of the data. The shadow researcher also read journal entries of my own initial reactions after I completed each interview. This feedback also helped me to filter out my personal biases. We leveraged Google Hangout technology to create a shared environment for the bias filtering. See Figure 4.5 for a visual representation of this process. 


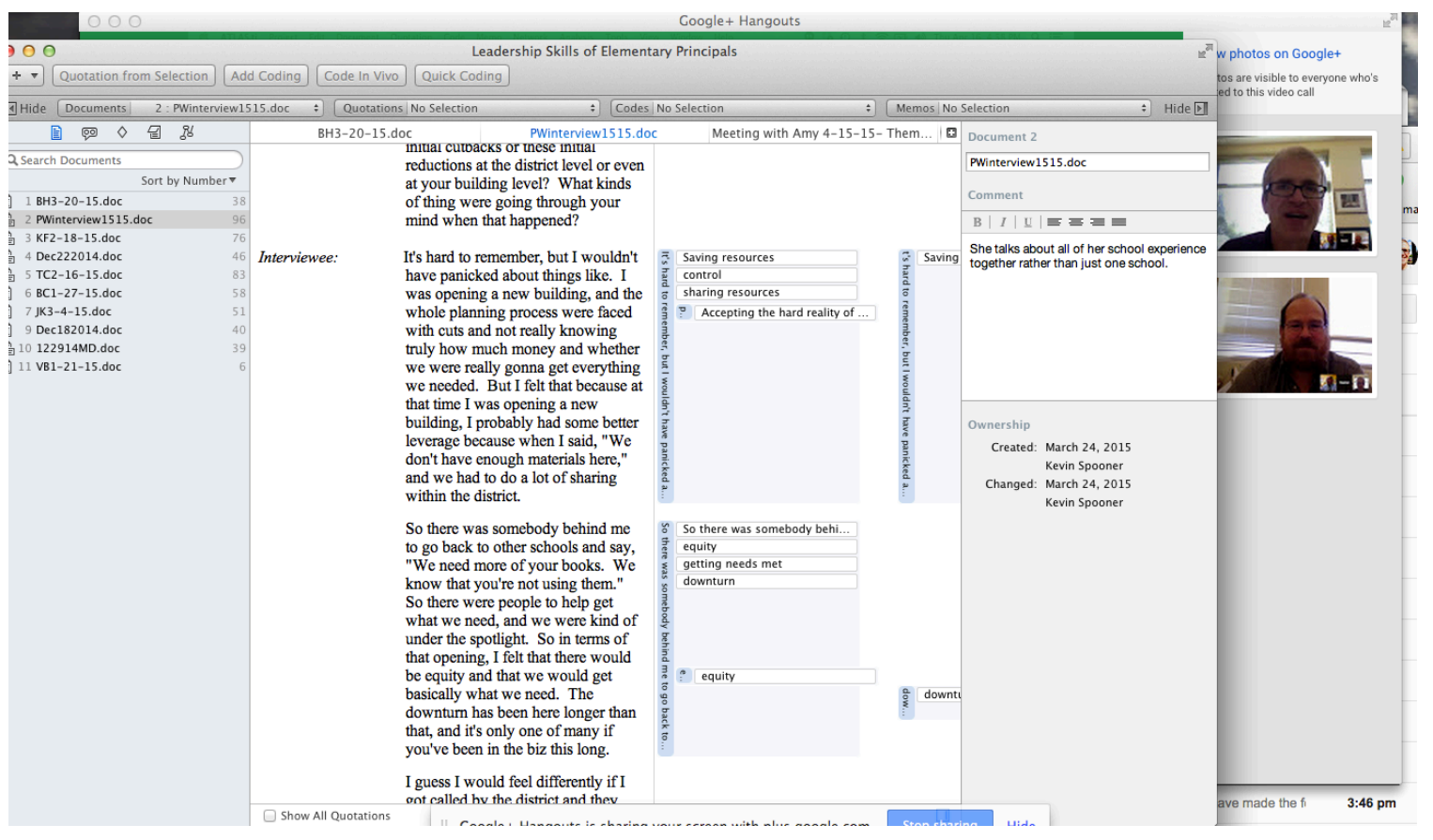

Figure 4.5. Screen shot of myself and shadow researcher reviewing my analysis using

Google Hangout ${ }^{\mathrm{TM}}$.

\section{Presentation of Results}

In this presentation of the results, I will provide an overview of the participant recruiting process, the inquiry process, a summary of participant demographics, interpretation of findings of leadership style, and additional lessons learned with hidden bits of wisdom.

Overview of inquiry process. The inquiry process was semi-structured so that participants could tell their stories. I was able to establish rapport and trust with the participants by sharing the interview questions with them before the interviews. Many participants chose to extend their responses beyond the scope of the initial questions. The 
questions used in the interview are listed in Appendix E. The components of the process are summarized below in Table 3. Most of the principals agreed to meet at convenient locations, such as coffee shops or restaurants. All of the interviews took place in person, and follow up communication — such as member checking-was done through e-mail. An example of an e-mail message is provided in Appendix F.

Participant demographics. Table 3 summarizes demographic information for each participant. All of this data was self-reported by the participants themselves. It is interesting to note that the range of experience in title 1 schools extended from one to twenty-two years. The participants all worked in either urban or sub-urban school districts as opposed to districts located in rural areas.

Table 3

Participant Demographics

\begin{tabular}{|c|c|c|c|c|c|c|c|}
\hline Participant & $\begin{array}{l}\text { Date } \\
\text { Interview } \\
\text { ed }\end{array}$ & Gender & Age & Race & $\begin{array}{l}\text { Years of } \\
\text { Service in } \\
\text { Public } \\
\text { Education }\end{array}$ & $\begin{array}{l}\text { Years of } \\
\text { Service as } \\
\text { a Title } 1 \\
\text { Principal }\end{array}$ & $\begin{array}{l}\text { Experiences } \\
\text { and interests } \\
\text { outside of } \\
\text { Public } \\
\text { Education }\end{array}$ \\
\hline Tricia Firth & $3 / 20 / 15$ & Female & 57 & White & 33 & 8 & $\begin{array}{l}\text { Reading, } \\
\text { crocheting, } \\
\text { hiking and } \\
\text { antique } \\
\text { shopping }\end{array}$ \\
\hline Brenda Scott & $1 / 5 / 15$ & Female & 65 & $\begin{array}{l}\text { White } \\
\text { woman } \\
\text { of } \\
\text { privilege } \\
\text { (her } \\
\text { words) }\end{array}$ & 40 plus & 4 & $\begin{array}{l}\text { Golf and } \\
\text { grandkids }\end{array}$ \\
\hline Patricia Gross & $1 / 27 / 15$ & Female & 62 & $\begin{array}{l}\text { Caucasia } \\
\mathrm{n}\end{array}$ & 40 & 22 & $\begin{array}{l}\text { Gardening, } \\
\text { antiques, } \\
\text { cooking }\end{array}$ \\
\hline
\end{tabular}




\begin{tabular}{|c|c|c|c|c|c|c|c|}
\hline Participant & $\begin{array}{l}\text { Date } \\
\text { Interview } \\
\text { ed }\end{array}$ & Gender & Age & Race & $\begin{array}{l}\text { Years of } \\
\text { Service in } \\
\text { Public }\end{array}$ & $\begin{array}{l}\text { Years of } \\
\text { Service as } \\
\text { a Title } 1\end{array}$ & $\begin{array}{l}\text { Experiences } \\
\text { and interests } \\
\text { outside of } \\
\text { Public } \\
\text { Education }\end{array}$ \\
\hline & & & & & Education & Principal & \\
\hline Ajay Cooke & $3 / 4 / 15$ & Male & 63 & White & 28 & 16 & $\begin{array}{l}\text { Avid handball } \\
\text { player, golf, } \\
\text { softball, } \\
\text { reading }\end{array}$ \\
\hline Alicia Dart & $2 / 16 / 15$ & Female & 61 & White & 32 & 6 & $\begin{array}{l}\text { Reading, } \\
\text { music (guitar } \\
\text { and vocal), } \\
\text { sewing, } \\
\text { gardening }\end{array}$ \\
\hline Peter Epstein & $12 / 29 / 14$ & Male & 63 & White & 31 & 20 & $\begin{array}{l}\text { Sports/Athleti } \\
\text { cs }\end{array}$ \\
\hline Stan Burk & $2 / 18 / 14$ & Male & 66 & $\begin{array}{l}\text { Caucasia } \\
\mathrm{n}\end{array}$ & 24 & 14 & $\begin{array}{l}\text { Sports fan } \\
\text { (golf as a } \\
\text { hobby), } \\
\text { gardening, } \\
\text { cooking, } \\
\text { reading, } \\
\text { marriage team } \\
\text { volunteer } \\
\text { coach }\end{array}$ \\
\hline Becky Durham & $12 / 18 / 14$ & Female & 59 & $\begin{array}{l}\text { Left } \\
\text { Blank }\end{array}$ & 20 & 12 & $\begin{array}{l}\text { Gardening, } \\
\text { sewing, } \\
\text { traveling, } \\
\text { reading and } \\
\text { knitting }\end{array}$ \\
\hline Bob Jones & $12 / 22 / 14$ & Male & 57 & White & 33 & 1 & $\begin{array}{l}\text { Music, } \\
\text { cycling }\end{array}$ \\
\hline Lorrie Smart & $1 / 21 / 15$ & Female & 61 & Asian & 37 & 3 & Baker \\
\hline
\end{tabular}

Findings of self-talk and emotion management. The inner voices of principals, self-talk and emotion management were three areas of overarching findings that emerged in the study. As the researcher, it occurred to me that I was listening to participants have 
conversations with themselves in response to circumstances related to the economic crisis. The questions I asked are listed in Appendix E. The questions were designed to elicit stories of lived experiences from the participants. The responses in many cases referred to conversations principals were having with themselves or their colleagues. In several of these conversations, principals talked about how they managed emotions.

B. Durham's quote below illustrates her management of emotions:

Some of those [verbally abusive interactions] it took a little bit more than self-talk. In fact one [example].... when the person finished with me and left and I went into my counselors office and fell apart. It was like what the person was saying and how they were saying it by the time they finished I believed it. And it really gave me an insight to people that (sic) are verbally abused, and ...I maintained professionalism throughout. But gee, ..., it was pretty bad. She [the counselor] was doing some really positive self-talk with me for quite a while before I could even [function]-yeah, it was awful.

B.Durham (personal communication, December 18, 2014)

In this case, Durham shared how a verbally abusive parent impacted her emotions. She was able to process these emotions with a counselor on her staff after the conversation with the parent. However, I am not sure many principals would feel safe enough to release these kinds of emotions, especially with an employee who they supervise. In a different set of circumstances, another participant in the study, B. Jones talked about his need for a pep talk. He said,

So I got discouraged, I would call her [my supervisor] up and I'd say, 'All right. I need a pep talk. Help me not feel like I am on a sinking damn ship here.' And she would say, 'You are not You are not. You keep doing what you're doing...' and so she would get my head back on straight. But if you don't have that [colleague], that's really tough because then it gets really discouraging when your scores are down and stay down. B. Jones (Personal Communication, December 22, 2014) 
Bob Jones was expressing his frustration and asking for a pep talk from his supervisor in this case in response to the reported student achievement data for his school.

Interpretation of findings of self-talk and emotion management. I believe this finding is critically important and forms the foundation for all of the findings that emerged in the study including the leadership styles and skills that were identified. Evidence of self-talk, emotions and the need to talk about them emerges throughout almost all of the quotes. I will discuss the importance of this finding in chapter 5.

Findings of leadership style. After a third review of the transcripts, three significant codes or categories of leadership emerged. The names for these quotes were inspired by one of the participants who described himself as a "loyal lieutenant." The military metaphor seemed to present itself throughout many of the quotes. In fact, one of the participants shared an artifact that was a speech given on the topic of leadership by a Marine Corps officer.

Categories of leadership. These categories of leadership include the loyal lieutenant, the creative captain, and the mission major. It is important to know that these categories are used to describe general characteristics, rather than one single participant. For purposes of analysis, the categories are defined as follows:

Loyal lieutenant. The loyal lieutenant follows directions from the district level without questioning decisions or pushing back. Research supporting this idea comes from Walcott (1973) and Griffiths (1963), who studied the roles of elementary principals and found that while principals thought that they should be agents of change, the evidence suggested that most of their direction came from the central office and their role was to 
keep the system intact.

Creative captain. The creative captain engineers new systems or procedures in response to resource reductions or demands for increased student achievement accountability. He uses his creativity to engineer new systems and procedures in his building as a response to staff reductions and the expectation for high student achievement. In an ethnographic study of elementary principals in New York, Koyama (2014) found that principals negotiated external accountability and found ways to creatively implement measures. She writes:

In the assemblage, principals negotiate their levels of compliance with NCLB's accountabilities, while maintaining their commitments to the teaching staff, students, students' parentsand their own values. As they selectively appropriate the measures, [they] strategically pick and choose elements to implement and purposefully ignore others. (p. 285)

While creating new ways to implement best instructional practices and deal with reductions in staff and reduced school days, the creative captain keeps his commitment to those practices by negotiating the demands of outside accountability, such as state and federal measures, when possible.

Mission major. A mission major has moral purpose and sticks to the core mission.

Another participant worded it this way:

The shift was once I started realizing that it was more of a permanent thing - and I believe our district leadership started talking that way too because I think we all started to see that, I think it helped me ground myself more strongly in the core mission of supporting the kids and the families and teachers, which is the essence of the principalship. (B. Durham, personal communication, December $18^{\text {th }} 2014$ ) 
This quote reminded me of the importance of moral leadership and having a sense of mission. Greenfield (2004) recommended that researchers study and explore this moral aspect of principal leadership.

While analyzing the quotes in this manner, it seemed as if principals were balancing aspects of management and leadership across their narratives while maintaining a commitment to their mission and core values. Sternberg (2012) uses the metaphor of a high wire walker to describe this balancing act when he encourages principals to weigh their actions along a continuum between leadership and management to increase their effectiveness. Table 4 provides an overview of the emerging leadership styles and the evidence supporting them.

Table 4

Leadership Styles and Supporting Evidence

\begin{tabular}{|l|l|l|}
\hline $\begin{array}{l}\text { Leadership } \\
\text { Styles }\end{array}$ & Characteristics & Supporting Evidence \\
\hline Mission Major & $\begin{array}{l}\text { Has moral purpose and sticks to } \\
\text { the core mission. }\end{array}$ & $\begin{array}{l}\text { "I think it helped me ground myself more } \\
\text { strongly in the core mission of supporting the } \\
\text { kids and the families and teachers, which is } \\
\text { the essence of the principalship." } \\
\text { (Becky Durham, personal communication, } \\
\text { December 18, 2014) }\end{array}$ \\
& $\begin{array}{l}\text { "Which is what is kind of my thing. I am no } \\
\text { longer a religious person, but I try to be a } \\
\text { spiritual person. This is actually from Micah } \\
\text { 6:8. So people might recognize it, but they } \\
\text { might not. But to me this was really the basis } \\
\text { where I needed to come from with my work. } \\
\text { This showed outside my window and this- } \\
\text { the other side showed into my office } \\
\text { sometimes. And sometimes I would put it the } \\
\text { other way. I had it in my windowsill in my } \\
\text { office." } \\
\text { (Alicia Dart, personal communication, } \\
\text { February 16, 2015) }\end{array}$ \\
\hline
\end{tabular}




\begin{tabular}{|c|c|c|}
\hline $\begin{array}{l}\text { Leadership } \\
\text { Styles }\end{array}$ & Characteristics & Supporting Evidence \\
\hline Loyal Lieutenant & $\begin{array}{l}\text { Follows directions from the } \\
\text { district level without questioning } \\
\text { decisions or pushing back. }\end{array}$ & $\begin{array}{l}\text { "Maybe I shoulda complained more. The } \\
\text { whiners and the complainers seem to get } \\
\text { more. That sounds terrible, but I was a pretty } \\
\text { loyal lieutenant. You told me this was the way } \\
\text { it was. I didn't come back to meet with you } \\
\text { and say, 'I can't do that."' } \\
\text { (Ajay Cooke, personal communication, March } \\
4,2015 \text { ) } \\
\text { "When they cut counseling in Blue Creek, } \\
\text { yeah, I had to, yeah. [Laughter] The district } \\
\text { was like, 'You need to spin it,' even though I } \\
\text { vehemently-I told staff, 'Philosophically, } \\
\text { yes, I'm concerned about this, but at the end } \\
\text { of the day, we have } 1.0 \text {. We need to move } \\
\text { forward,' because it got to be where we had } \\
\text { spent all our energy moaning, ... and we're } \\
\text { still in the same boat, so let's focus on rowing } \\
\text { the boat." } \\
\text { (Tricia Firth, personal communication, March } \\
20,2015 \text { ) }\end{array}$ \\
\hline Creative Captain & $\begin{array}{l}\text { Engineers new systems or } \\
\text { procedures in response to } \\
\text { resource reductions or demands } \\
\text { for increased student } \\
\text { achievement accountability. }\end{array}$ & $\begin{array}{l}\text { "When I go into a building, I'm looking. } \\
\text { 'Who are your leaders? Where's some fires } \\
\text { we can build? Let's get this guy outta the } \\
\text { classroom and start giving some coaching } \\
\text { skills,' things like that." } \\
\text { (B.Scott, personal communication, January 5, } \\
\text { 2015) }\end{array}$ \\
\hline
\end{tabular}

Interpretation of leadership style quotes. Each of the participant quotes in Table

6 can be interpreted in the following ways.

Becky Durham. Using the mission major style, Becky chose to focus on what she believed to be the core mission or purpose of her work. This purpose of supporting students, teachers and families was her primary job. By focusing on this kind of thinking, she was able to maintain a moral purpose for her work, as well as help others focus on 
this mission in a time of economic crisis.

Alicia Dart. Also using the major mission style, Alicia found purpose in a social justice frame of thinking based on a verse from the Bible. She described herself as a spiritual person as opposed to a religious person. Here is the quotation she references:

"He has shown you, O mortal, what is good. And what does the Lord require of you? To act justly and to love mercy and to walk humbly with your God" (Micah 6:8, New International Version). Alicia was able to ground herself in this spiritual foundation and share this with her staff at times. She said she would place the nameplate facing outward from her office so that others could see it. She was modeling this for her staff as a reason why this work needed to be done, especially during a time of economic crisis.

Ajay Cooke. Ajay termed the name "loyal lieutenant." Apparently he didn't value whining and complaining at the time, but realized in hindsight that perhaps he should have complained. Ajay maintained that it was important to say to his staff that this was the way it was going to be. He didn't believe he could go back to his superiors and complain.

Tricia Firth. Tricia described having to "spin," or frame, the direction from the district in some way so that it would be acceptable. She acted as a loyal lieutenant, but at the same time she recognized the hardship this direction would cause her staff. She was pointing out the reality of the situation to her staff by saying that energy shouldn't be wasted on something they couldn't control.

S. Burk and B. Scott. Both S. Burk and B. Scott acted as creative captains when they took advantage of the circumstances associated with the economic crises to create 
something new. S. Burk used the metaphor of music creation to describe his work while B. Scott talked about kindling a fire. B. Scott talked about creating new processes and giving staff members' new roles in the school, such as being a coach.

Summary of leadership style. As I have reviewed these quotes several times in my analysis, it has occurred to me how important self-talk can be, particularly in terms of decision making in response to the crisis that is being studied. I was fortunate enough to be able to hear some of the inner dialogue that these principals were having with themselves. I am thinking that these categories of leadership style could serve as a potential framework for a principal's self-reflection. Reeves (2006) writes, "Reflection, in brief, forces leaders to climb down from the mythological perch, admit our human foibles, and get real” (p. 51). Part of getting real as a principal means that one should have a critical distance. Sternberg (2012) writes:

You need to create a critical distance...As an administrator, there is no question that many times a sense of doubt can be a prevalent concept floating in your mind. That sense of doubt can begin to dissipate as you become more and more reflective. The key here is that reflection leads to more reflection. As you get better at the practice, it becomes easier and the pattern that your decision making takes, and the analysis of the results, becomes clean, crisp and clear.

(Chapter 8, section 8, para. 2)

In a time of crisis, self-doubt can have a tendency to infiltrate one's thoughts.

From the "critical distance," it is important to have a healthy dialogue with oneself. The creator of Rational Emotive Therapy, Albert Ellis (2004), writes:

Keep forcefully and persistently disputing your Irrational Beliefs whenever you can see that you are letting them creep back in again. Even when you don't actively hold them, realize that they may arise once more, bring them to 
your consciousness, and preventively_and vigorously!dispute them!

These leadership style categories are examples of rational belief statements that were used in this crisis. These rational belief statements can lay the foundation for effective self-reflection, which can then lead to effective decision making in the future.

Participant responses. The responses to the interview questions were organized into several categories that included many rich narratives, which served to answer the research question in a number of different ways. The response quotes were broken into categories of skills that served to answer the research question. In addition to the responses, I applied leadership styles that seemed appropriate for each quote. They are listed below in Table 5 .

Table 5

Examples of Skills and Leadership Styles Used to Respond to Economic Crisis

\begin{tabular}{|l|l|l|}
\hline Response & Evidence & Leadership Style \\
\hline Team/Relationship & $\begin{array}{l}\text { "So I used my strong relationship with the staff to } \\
\text { maintain that: pay attention to their needs. Those are } \\
\text { strong relational challenges. And maintaining a belief } \\
\text { that we were all in it and we could do this thing. So } \\
\text { it's also an inner optimism that we're going to get } \\
\text { through this." } \\
\text { (P. Epstein, personal communication, December 29, }\end{array}$ & Mission Major \\
2014) & & \\
\hline
\end{tabular}




\begin{tabular}{|c|c|c|}
\hline Response & Evidence & Leadership Style \\
\hline Use of Data & $\begin{array}{l}\text { 'I remember just an anecdotal thing ....And his teacher } \\
\text { goes up to him and says, 'What's wrong?' And he } \\
\text { goes, 'Well I didn't meet.' He goes, 'Yeah, you didn't } \\
\text { meet.' He goes, 'But what was your score last year? } \\
\text { And what was your score this year?' And the teacher } \\
\text { says, 'You stand up proud: that's } 18 \text { points.' [Laughs]. } \\
\text { He goes, 'You lift that head up.' You know, framing it } \\
\text { differently for ourselves and for our kids. It's about-- } \\
\text { it's about growth. It's not about meet. I mean you } \\
\text { know, you do want to meet." } \\
\text { (B. Durham, personal communication, December 18, } \\
\text { 2015) }\end{array}$ & $\begin{array}{l}\text { Creative Captain and Loyal } \\
\text { Lieutenant }\end{array}$ \\
\hline Use of Resources & $\begin{array}{l}\text { "Yes, and some of that-change can always be good, } \\
\text { right? It can be. You're trying to look at it as positive } \\
\text { as you can. I guess the metaphor of who you get on } \\
\text { the bus and what seat you put them on the bus kind of } \\
\text { thing. ... So a lot of people got moved around, and a } \\
\text { lot of people- - not a lot. A lot of the people that were } \\
\text { at our school wanted to be there, but especially some } \\
\text { of the EAs, they didn't. They wanted to be off at a } \\
\text { slow-paced, paper-stapling whatever kind of situation } \\
\text { that was not gonna exist anymore." } \\
\text { (Alicia Dart, personal communication, February } \\
\text { 16, 2015) }\end{array}$ & $\begin{array}{l}\text { Creative Captain and Loyal } \\
\text { Lieutenant }\end{array}$ \\
\hline $\begin{array}{l}\text { Maintaining Hope } \\
\text { and Energy }\end{array}$ & $\begin{array}{l}\text { "These are highly intelligent, committed people that } \\
\text { have made a commitment to kids and want to be } \\
\text { successful, and none of 'em get up in the morning and } \\
\text { say, 'I'm gonna go screw a kid over today.' They may } \\
\text { not have a great day one day, but by and large I was } \\
\text { very blessed. Staffs were committed and wanted to } \\
\text { work together and wanted to work for what was good } \\
\text { for kids. But I think you have to treat them like } \\
\text { professionals and treat them like they deserve to have } \\
\text { the information, and not shut them out of decisions as } \\
\text { much as possible simply because they are part of it. } \\
\text { And I think people, when they feel included, then they } \\
\text { feel like they have a purpose and that what they're } \\
\text { doing-we can get through this together 'cause we're } \\
\text { all on the same boat." } \\
\text { (P. Cross, personal communication, January 27, 2015) }\end{array}$ & $\begin{array}{l}\text { Creative Captain and } \\
\text { Mission Major }\end{array}$ \\
\hline
\end{tabular}




\begin{tabular}{|c|c|c|}
\hline Response & Evidence & Leadership Style \\
\hline $\begin{array}{l}\text { Working with } \\
\text { Perceptions }\end{array}$ & $\begin{array}{l}\text { "People say, 'Oh, it's such and such school. I'd never } \\
\text { want to send my kid there,' or, 'Such and such school.' } \\
\text { Well, have you been in our school? Have you checked } \\
\text { our ratings? Have you walked our halls? Have you } \\
\text { talked to any of our kids? This is a pretty good place to } \\
\text { be, and if you don't like us, go away. We have plenty } \\
\text { of kids who want to be here. } \\
\text { (A. Dart, personal communication, February 16, 2015) }\end{array}$ & Mission Major \\
\hline $\begin{array}{l}\text { Affirming } \\
\text { Teachers }\end{array}$ & $\begin{array}{l}\text { "Okay, so there's a really great book. You know these } \\
\text { books will stick out to you, and it's not a new book. It's } \\
\text { called If You Don't Feed the Teachers They'll Eat the } \\
\text { Children....Stuff like that. A big thing of hummus and } \\
\text { a lot of rice crackers. Everybody's happy 'cause they } \\
\text { got something. Maybe throw some chocolate in there. } \\
\text { And then also just focus on positive things and } \\
\text { successes and call those out. ... So we made up these } \\
\text { things for our staff members, too, I could give it to you } \\
\text { personally. I could put it in your mailbox. It was to so- } \\
\text { and-so, from so-and-so." } \\
\text { (A. Dart, personal communication, February 16, 2015) }\end{array}$ & $\begin{array}{l}\text { Mission Major and Creative } \\
\text { Captain }\end{array}$ \\
\hline Consultation & $\begin{array}{l}\text { 'So I got discouraged, I would call her up and I'd say, } \\
\text { 'All right. I need a pep talk. Help me not feel like I am } \\
\text { on a sinking damn ship here. And she would say, 'You } \\
\text { are not-- no. You are not. You keep doing what you're } \\
\text { doing.' And I'd say, 'Okay, says-' she said, 'Stop now. } \\
\text { Listen to me. You keep doing-' and so she would get } \\
\text { my head back on straight. But if you don't have that, } \\
\text { that's really tough. (B. Jones, personal } \\
\text { communication, December 22, 2014) }\end{array}$ & Loyal Lieutenant \\
\hline
\end{tabular}

\section{Response to economic crisis.}

The participant responses to the economic crisis are organized around seven skill categories. 
Skills. The seven skill categories including use of data, use of resources, team/relationship building, maintaining hope and energy, working with perceptions, affirming teachers, and consultation are all being used to summarize participant answers to the research question - which asks how principals of high poverty elementary schools responded to the phenomena of reduced resources and the expectation of increased student achievement. Participant quotes were placed into each of these categories and an explanation of the associated leadership style is provided.

Use of data. Mendels (2012) wrote about the ways in which principals used data to inform their work in response to high expectations for student achievement. This quote illustrates the creative way this participant was able to frame the use of data for a student.

I remember just an anecdotal thing that there was this one kid who- -he just really wanted to meet. And he had grown so many points and so many points. And then it got to his sixth grade year - must have been fifth - fifth or sixth - anyway. And he didn't meet. And he-just his face went like that. And his teacher goes up to him and says, "What's wrong?" And he goes, "Well I didn't meet." He goes, "Yeah, you didn't meet." He goes, "But what was your score last year? And what was your score this year?" And the teacher says, "You stand up proud: that's 18 points." [Laughs]. He goes, "You lift that head up." You know, framing it differently for ourselves and for our kids. It's about-it's about growth. It's not about meet. I mean you know, you do want to meet. (B. Durham, personal communication, December 18, 2015)

In this quote, B. Durham functions as a creative captain and loyal lieutenant when she refers to the focus on student achievement in her building. This conversation between a student and his teacher illustrates the creative way in which the demand for student achievement can be framed in a way to help the student feel good about his growth 
despite the fact that he did not meet proficiency. As a loyal lieutenant, she is continuing to communicate and emphasize that student achievement is important, as this is an expectation that comes from the school district and her staff. Koyama (2014) wrote about this phenomenon in her ethnographic study of elementary principals in Brooklyn, New York. These principals needed to reframe the perception of high stakes accountability in realistic terms, so that students and teachers could feel like they were making progress.

Use of resources. In the quote below, A. Dart talks about the opportunity that the economic crisis presented to move staff members into positions where they could be more effective. Reeves (2006) wrote about the importance of adult actions in the effort to improve student achievement.

Yes, and some of that - change can always be good, right? It can be. You're trying to look at it as positive as you can. I guess the metaphor of who you get on the bus and what seat you put them on the bus kind of thing. So for staffing I wrote it was a chance for us to get people off the bus that either didn't really want to be on the bus, because when our school opened, three schools - new schools opened that year. Two schools had closed, and there was a redistricting, redrawing of boundaries. So a lot of people got moved around, and a lot of people - not a lot. A lot of the people that were at our school wanted to be there, but especially some of the EAs, they didn't. They wanted to be off at a slow-paced, paper-stapling whatever kind of situation that was not gonna exist anymore. (A. Dart, personal communication, February 16, 2015)

In this quote, A. Dart demonstrates again the leadership styles of the creative captain and the loyal lieutenant when she complies with the school district expectation that staffing numbers be reduced. However, she saw this as an opportunity to place staff members in positions for which they were better suited. She referred to instructional assistants (EAs) who wanted "slow-paced, paper-stapling" positions, and said that these 
positions were not going to exist any longer. She needed assistants who were going to be providing direct instructional support to students. This was an opportunity to move assistants to those positions who were qualified and wanted them, while letting the others go. She refers to the "bus" metaphor used by Collins (2001), who wrote about the importance of placing employees in an organization in the right positions for which they are qualified.

Team/relationship building. Dufour (2013) wrote about the importance of building the capacity of professional learning communities and teams. P. Epstein talked about why this was important:

The skills were real relational. Really my strength is around interpersonal-using my strength finders thing. So I used my strong relationship with the staff to maintain that: pay attention to their needs. Those are strong relational challenges. And maintaining a belief that we were all in it and we could do this thing. So it's also an inner optimism that we're going to get through this. Maybe a denial that we were actually into such a-maybe denial, but basically the glass [was] half full. (P. Epstein, personal communication, December 29, 2014)

P. Epstein exemplifies the mission major style of leadership in this quote when he talks about maintaining a belief system that "we can do this thing." He refers to an inner optimism that "we are going to get through this." He used one of his strengths, relationship building, to pay attention to the needs of his staff. He was able to align his moral purpose of supporting his staff and their collaborative work while keeping them focused on the mission of teaching and learning. He referred to his "Strength finders thing" in this quote. Rath (2007) wrote a book with this title, in which he helps professionals capitalize on the their strengths to solve problems in their work settings. He 
categorizes the strengths into areas such as Achiever, Arranger, and Believer. The book contains a self-assessment the reader can use to identify their strengths and then apply those strengths to solve problems.

Maintaining hope and energy. P. Cross refers to a moral purpose behind her work much like P. Epstein did in the previous example:

These are highly intelligent, committed people that have made a commitment to kids and want to be successful, and none of 'em get up in the morning and say, "I'm gonna go screw a kid over today." They may not have a great day one day, but by and large I was very blessed. Staffs were committed and wanted to work together and wanted to work for what was good for kids. But I think you have to treat them like professionals and treat them like they deserve to have the information, and not shut them out of decisions as much as possible simply because they are part of it. And I think people, when they feel included, then they feel like they have a purpose and that what they're doing-we can get through this together 'cause we're all on the same boat. (P. Cross, personal communication, January 27, 2015)

P. Cross communicated the faith she has in her teachers to work together for the sake of their students. As a mission major in this case, she supports that moral purpose in each of her teachers. She talked about the importance of helping teachers feel included in the decision-making process. As a creative captain, she included her staff members in decision-making processes, as opposed to making decisions by herself. Like P. Epstein, she was focused on helping her staff work together by keeping their attention on the mission at hand.

Working with Perceptions. A. Dart talked about combatting the negative perceptions that existed outside her school. She felt it was her responsibility to confront the negativity by sharing positive narratives about her school.

People say, “Oh, it's such and such school. I'd never want to send my kid 
there," or, "Such and such school." Well, have you been in our school? Have you checked our ratings? Have you walked our halls? Have you talked to any of our kids? This is a pretty good place to be, and if you don't like us, go away. We have plenty of kids who want to be here. (A. Dart, personal communication, Februrary 16, 2015)

This quote is an example of how A. Dart functioned as a creative captain to help frame perceptions about her school. She questioned the rationality of statements made about her school, and encouraged those with negative perceptions to justify their reasoning. She chose to tell the naysayers to stay away so that she could focus on the "kids who want to be here." By doing this, she also took on the role of mission major-validating and supporting the good work being done by communicating with people who had negative things to say about her school community.

This quote also illustrates the process of restorying as defined by Ollerensha and Creswell (2002) who adapted Clandinin and Connelly's (2000) three-dimensional narrative space structure. This structure was explained in Table 2. In this quote, Alicia refers to statements that were made in the past about her school. Restorying involves telling stories along three sets of dimensions that involve interaction, continuity and place. In this quote Alicia was talking in detail about the social interactions she was having related to outside perceptions of her school. This involved personal and social themes. In terms of the continuity dimension she was also focusing on the future when she was thinking about the potential negative impact these statements might have on her students and staff. She was also concerned about the morale of staff and students as part the school 
climate. This concern about school climate also illustrates the importance of place as a dimension of restorying.

Affirming Teachers. In addition to keeping the negativity at bay, A. Dart talked about the importance of affirming the work teachers were doing, even in small ways if she could.

Okay, so there's a really great book. You know these books will stick out to you, and it's not a new book. It's called If You Don't Feed the Teachers They'll Eat the Children....Stuff like that. A big thing of hummus and a lot of rice crackers. Everybody's happy 'cause they got something. (A. Dart, personal communication, February 16, 2015)

In this quote, A. Dart refers to the book, If You Don't Feed the Teachers They Eat the Students!: Guide to Success for Administrators and Teachers. Connors (2000) writes in this book about ways teachers and administrators can affirm and support the work of other teachers in the classroom. He emphasizes that this is an ongoing process that needs to happen, in order to nourish and maintain the positive energy that teachers need to do their work. A. Dart functions as a creative captain as well as a mission major in this case. She affirms the good mission-aligned work her teachers are doing with students in a creative manner.

Consultation. Many of the participants talked about the importance of having a good mentor to confide in. This quote from B. Jones illustrates how much a conversation with a trusted superior or mentor was valued.

Here, again, it's so unique because I would get discouraged. And I tried not to let the staff and community see that, because I wasn't used to these numbers. So what I would do and, here, again, is Quad circumstance, 'cause not everybody's gonna have-I will never have a boss/worker relationship again like I've had with Sue. We go so far back, 20 years. She has been a champion for me like I can't tell you. She is president and CEO 
of the Bob Jones Fan Club. She really is. So I would call her up. She used to be the principal at Holly Creek... She loves that little building. Wanted it healed and likes it just to hang out there. And she didn't have any reason to stop there at all. I'm like, "Isn't there anything you can be doing? Aren't you late for a meeting?" And she would just walk into my office, take off her coat, sit down, and we'd sip whatever and just visit. I'd say, "Was there something?" "No. Nope, I just want to be here. I just wanna hang with you." So I have that kind of relationship with her....So I got discouraged, I would call her up and I'd say, "All right. I need a pep talk. Help me not feel like I am on a sinking damn ship here." And she would say, "You are not—no. You are not. You keep doing what you're doing." And I'd say, "Okay, says-" she said, "Stop now. Listen to me. You keep doing-" and so she would get my head back on straight. But if you don't have that, that's really tough because then it gets really discouraging when your scores are down and stay down. I'm making a whole hell of a lotta difference here, right? (B. Jones, personal communication, December 22, 2014)

Jones in this quote personifies the loyal lieutenant. He clearly wants to meet the expectations the district has for him, but he needs support in doing so. He expressed his appreciation for the support of his superior. Consultation like this was critical to B. Jones, as he needed to know that his leadership and decision-making were both moving in the right direction.

It is interesting to note that the participants referred to best selling books in their quotes as opposed to recognized educational research. These books appeared to provide sources of ideas that confirmed the work they were doing.

Findings of gender differences. After reviewing the quotes of the participants it doesn't appear that patterns of responses aligned themselves in relationship to gender. The categories of styles of leadership as well as skill categories seemed to be used by both male and female participants alike.

\section{Lessons Learned and Additional Bits of Wisdom}


These responses from participants did not answer the research question directly but they are worth noting in order to understand the contexts and circumstances principals faced during the economic crisis. The quotes also offer advice and wisdom to principals who may be faced with similar circumstances in the future. These responses include initial reactions, hardest things, metaphors, artifacts and hindsight.

Initial reactions. The first set of narratives I collected from the participant interview data were responses to my question about their initial reactions to budget reductions that were announced by their school districts.

Here we go again. [Laughs] I started with Measure 5, so I started with sitting in a lot of budget meetings and sitting in at Dutch Creek at that time, we were one of the most well endowed districts in the state. That's not hyperbole. But the way Measure 5 worked is [that] it kept property taxes to five percent. We were one of those districts that had one of the most severe hits. (A. Cooke, personal communication, March 4, 2015)

In this narrative, Ajay, a participant from a school district in the mid-Willamette Valley area, looked to the past. As discussed in Chapter 1, with Measure 5's passage in 1990 , property taxes were limited to $\$ 5$ per $\$ 1,000$ of real market value over a gradual phase in period. This amendment to the state constitution was blamed for budget cuts in school districts, as well as other public services. In the effort to compensate for the loss of revenue from local property taxes, the state became responsible for distributing funding to districts across the state in an equitable manner. Funding was allocated based on the numbers of students, as well as the needs of students who were eligible for Special Education and English Language Development services. Unfortunately, before Measure 5 , inequities in school funding existed across the state. 
Ajay referred to a not too distant past, in which he experienced significant reductions in school district spending. As a result of the equalization in funding, his district had to make significant reductions at the time, since funding was based on an amount per student that was determined by the state rather than by local taxes. Ajay shared that his local district was "one of the most well endowed in the state." His narrative looked to the past, such that he was able to use this experience to inform his leadership and decision-making in the present. This experience may have played a factor in his school's future success.

Tricia Firth's quote below refers to the frustration some principals were experiencing when having to work with reduced staffing resources:

So and with the school in Cherrie Heights, the poverty level and the home life that students were coming from, we-every student was fed breakfast and lunch. They just came with a host of issues, yet not enough counselors, and at Cherrie Heights, I had one and a half counselors, but that wasn't enough for all of the issues, because, I mean, kids were going home to what they call the Loft, which was off of 6th and Main. The apartment complex was Broadfoot Terrace. They'd come to school, like the night before being woken up by gunfire. (T. Firth, personal communication, March 20, 2015)

Tricia was serving as a temporary principal in a district with one of the highest poverty levels. Her experience was not unlike my own, in terms of the poverty and the lack of resources to support the needs of students who were dealing with factors related to food safety and violence outside of school. Reardon (2013) has studied the impact of poverty on student achievement. He writes that the gap in student achievement between high-income and low-income families has increased significantly within the last thirty 
years. He also writes that the gap is now larger than the gap between white and black students, although both gaps continue to be large. Tricia's description of these circumstances illustrates the kinds of resources that were being reduced in the face of increasing student need.

Hardest things. Participants were asked to share some of the hardest circumstances they had to work with. Smart summarized what most participants explained, that it hurt to layoff people, or reduce their working hours, but it hurt more to see the stress that staff underwent with the pending reductions: "I think that the hardest things that I dealt with involve[d] staff's personal lives and people getting sick, and one of my teachers passed away in the middle of the year" (L. Smart, personal communication, January 21, 2015)

Several of participants mentioned that supporting staff members through trials and circumstances in their personal lives seemed to be the most challenging. Many participants said that instances like this kept them awake at night.

Other participants shared some of the emotions they were experiencing with their

work. B. Durham's quote below is an example:

Some of those it took a little bit more than self-talk. In fact, one-of course maybe this is getting too personal-but one of them, one of the scenarios, when the person finished with me and left and I went into my counselors office and fell apart it was like what the person was saying and how they were saying it, by the time they finished I was believing it. And it really gave me an insight to people that are verbally abused, and howbecause mine was-I was just maintaining a professional, "Well, that's your point of view. I look at it a little bit differently than that." And so I maintained professionalism throughout. But gee, it was pretty bad. She was doing some really positive self-talk with me for quite a while before I could even-yeah, it was awful. (A. Durham, personal communication, December 18, 2014) 
Greenfield (2004) wrote about the need for further study of how principals

process emotions. He wrote:

Study the emotional dimensions of being a school leader, including the satisfactions and the disappointments of leading, and feelings of anxiety, frustration, and anger, as well as the feelings of happiness, satisfaction, and pride, among other passions of leadership. (p. 191)

Durham's quote above reveals some of this dimension of moral leadership. Beatty (2000) studied and wrote about leaders in education, and their reluctance to talk about emotions at work. She writes:

For the leaders in this study, the freedom to communicate openly at work about their own emotions had been all but eliminated, replaced by a repertoire of more emotionally managed techniques. This was a matter of reluctant resignation for some and lamentation for others, but ultimately it was accepted by all participants as the way power and control is traditionally maintained. Distributed leadership and letting go of control came only with experience, deliberate effort and initial stress. But in these cases, the leaders' efforts were rewarded with reduced anxiety through a shared burden of responsibility and the mutual joy of success. Early experiences of letting go of control did not come easily, and maintaining strict emotional management of the self and of others remained, for a long time, central to the work. However, some of the leaders thrived on experiencing 'flow' through their own empowerment and collaboration with others. They needed emotional support and the affirmation of being known, which boosted their confidence. (p. 355)

Many of the quotes from my interviews referred to the work principals were doing to build relationships and support team building. B. Durham's ability to confide in the counselor shows she is willing to risk being vulnerable with her, in order to share some burdens of responsibility with the counselor. 
Metaphor. Principals were asked to share metaphors that represented their work as elementary school principals. Here are a few selected quotes.

In this first quote, L. Smart emphasizes the importance of building trust with her teachers, so that when it was necessary to take some drastic action, it would be accepted by her staff:

I guess think of myself sometimes as Mary Poppins. And you know in every element, let's say in every chore to be done, there is an element of fun. That's one piece and I think a spoonful of sugar helps the medicine go down. I think that I generally didn't get into each trouble with teachers when I did things like change grade levels for-change teams. And I think that a spoonful of sugar was big. (L. Smart, personal communications, January 21, 2015)

The sugar in L. Smart's quote would be the trust she establishes with her teachers so that they can accept her reasons for making necessary changes.

T. Firth was not the only participant to use this metaphor. The boat metaphor was used frequently throughout many quotes:

It's like rowing a boat. You've got everybody in this boat, and you've got to get them from point A to point B intact, and you don't know what's going to-what the weather's going to do. (T. Firth, personal communication, March 20, 2015)

Many of the participants talked about having to deal with many unknowns in their response to the economic crisis. Despite the unknowns, they knew that they had to lead their teachers from point A to point B.

In the quote below, B. Durham illustrates the difficulty of managing many tasks at one time by comparing her work to making tapioca pudding:

Have you made tapioca pudding? Okay, so you're in your kitchen, you're making tapioca but you're also cooking dinner. You're making tapioca, which needs to be constantly stirred. But you're also making dinner too. 
Yeah, trying to do two things that really cannot be done at the same time really well. Because it's going to come to a boil, and you've got to be stirring it. And then it thickens. But you don't want it to burn. So it's got to be hot enough for the milk to come to a boil with the tapioca, but you can't let it burn. And I guess-I think about student discipline. I don't know if student discipline is the dinner or if it's the tapioca. But it's just-and maybe it's not like that at every school. But you have your core mission and then you have what happens every day. So maybe that tapioca is the stuff that happens. It doesn't even have to be student stuff but it's happening all day. You're trying to run this school, make dinner. But at the same time there's all these things. (B. Durham, personal communication, December 18, 2014)

When responding to the economic crisis, B. Durham continues to emphasize the importance of staying with the core mission (her mission major leadership style), despite all of the other things that have to happen surrounding that core mission. Sternberg (2012) writes about the importance of balancing management and leadership tasks. The leadership tasks help to keep her staff focused on the core mission, while the management tasks, though necessary, can at times get in the way.

Artifacts. Participants were asked to bring artifacts that helped to explain their work. In addition to the quotes below, pictures of the artifacts are located in Appendix D. P. Cross referred to an article that focuses on the topic of leadership. Athens (2008) gave the speech, "What's Love Got To Do With IT". In the speech, this military professor of leadership at the U.S. Naval Academy talks about the importance of love and compassion in the work of leadership:

I did a presentation at a press conference one time and that was the theme of it. I was shocked how many people came. But what I found interesting, there's a lot of, lot of good science books written about what we already do, but there aren't as many that are written about the other side of it, and one of the most amazing speakers I ever heard-actually two of them- 
talked about that side of leadership. One was a Marine Corps colonel, retired. He teaches at Annapolis. He was an amazing speaker. I should send you his speech...It's just, it's a great - it's called "What's Love Got to Do with It," and here's this guy who was a big-time Marine colonel really talking about leadership from the heart, and he is absolutely amazing. (P. Cross, personal communication, January 27, 2015)

This is further evidence of the importance of emotion in principal leadership, particularly in a period of economic crisis. Greenfield (2004) and Beatty (2000) emphasize that emotions like love and compassion need further study within the context of school leadership.

In this next quote, B. Jones talks about a picture that was given to him as a gift from his staff:

Then Principal's Week of that first grade year. Teachers assignment on the board was, "Mr. Long is..." and then kids were then to fill out on theand these will be compiled and bound in a book for Mr. Long on Boss' Week. I shoulda brought it with me. I've got it home somewhere. "Mr.Jones is nice and he is_-" I don't remember what the other descriptor words were. They were all good. And then the second row says, "And he helped people be good, like Jesus," with the J inverted. And then illustration at the bottom was her standing here, the little boy lying on the ground. She had illustrated this with stick figures. And me standing here, and an arrow drawn over here, making a direct parallel with the little boy standing up, she standing up, me standing here and then Jesus. And there's a crown and so it was direct correlation. Now the $\mathrm{J}$ is inverted, which makes it even cuter, and this is in first grade manuscript. My staff howled. I got this at the staff meeting. I said, "Now I knew I was good, but I didn't know I was at this level. This takes it to a different level." (B. Jones, personal communication, December 22, 2014)

This quote illustrates the importance of moral leadership in a humorous way. While this quote didn't refer to an event that occurred during the time period being studied, it does show the value B. Jones placed on moral lessons learned by students.

In this quote, L. Smart referred to an artifact that represents a topic I thought 
would be mentioned more often by participants. "This is something I really use probably in the second half of my career and it's very - there is a book called Courageous Conversations About Race” (L. Smart, personal communication, January 21, 2015). Networks of schools and districts have been working together to build awareness of social justice issues and equity. Specifically, schools are building awareness about equity and race in relationship to student achievement. Singleton and Linton (2006) wrote the book L. Smart is referring to. This book encourages school leaders to become more conscious of race and equity and its impact on student achievement. These researchers and others, including Noguera (2009) and Delpit (1995), write about the achievement gap that exists between white students and students of color. They call for systemic change that will not happen unless school leaders take action. L. Smart talked about how important this emphasis was during the second half of her career.

The sharing of artifacts and metaphors allowed the participants to use more creative means to tell their stories. Researchers point out that images can be used to communicate messages that cannot be expressed in words. Weber (2008) writes that images "discover what we didn't know we knew, or to see what we never noticed before" (p. 41). Barone (1995) explains that art can help narrative researchers "create space where the experience can be vicariously lived" (p. 169). When considering the use of metaphors, Sfard (1998) writes:

Indeed, metaphors are the most primitive, most elusive, and yet amazingly informative objects of analysis. Their special power stems from the fact that they often cross borders between the spontaneous and the scientific, between the intuitive and the formal. (p. 4) 
The responses in the forms of artifacts and metaphors helped to expand my approach to getting participants to share the full extent of their lived experiences as title one elementary principals in a time of economic crisis. I was also able to gain a deep understanding of those experiences that took me beyond direct answers to the interview questions.

Hindsight. Looking back, principals were also asked to share anything they would have done differently in their careers. In the quote below, P. Cross shares some wisdom she gained looking back over her career:

I wouldn't have been in such a big hurry all the time. I was always in a hurry. Even when I was out and about, my brain was always thinking three steps ahead and I didn't really appreciate the time that I had at the moment I had it. Sometimes I want to get through those situations, but I think if I could do it over I would look at.... Well, you know it when your kids are growing up. You know it about things like that, but what-when you begin to think about this is the last time I will do this or the last experience I will have exactly like this, you really begin, at least for me, to look at it through a different set of eyes....And that's when I think I began to realize what I should have done- that maybe I should have slowed down. My mom always said I was in too big of a hurry. (P. Cross, personal communication, January 27, 2015)

The hindsight quotes illustrate part of the interaction continuum that Ollerensha and Creswell (2002) adapted from Clandinin and Connelly's three dimensional narrative space structure. Table 2 in Chapter 3 was used as a graphic organizer to explain aspects of this structure. Looking toward the past is an important part of their continuity continuum. 


\section{Interpretation of Findings}

The research question asks how principals of high poverty elementary schools responded to the phenomena of reduced resources and the expectation of increased student achievement. Their answers were categorized in quotes that were shared in the response to economic crisis section. Many technical ideas and responses were shared, but throughout almost every quote, whether it was a direct response to the research question or in additional shared bits of wisdom, I detected some evidence of emotions that were expressed by the participants, as well as the desire to find ways to manage their emotions. They also talked about sensitivity to the emotions of their staff members. I believe this was especially true in the leadership style categories of loyal lieutenant, mission major, and creative captain that were identified.

For the purposes of research, this project was called a narrative inquiry. For the participants, this was an extensive opportunity for self-reflection. Having the opportunity to listen and inquire into the lived experiences of the participants while they were selfreflecting gave me the opportunity to get a glimpse into their decision making while they were under the outside pressure of having to respond to increased accountability with reduced resources.

The three leadership styles that emerged from the quotes could also be called "inner voices of leadership," used by the leaders themselves to respond to the crisis, and perhaps to manage their emotions while also helping influence the healthy management of emotions on the part of their teachers and staff members.

The leadership styles and skills can be intertwined in this effort. For example, the 
loyal lieutenant is communicating the direction coming from the central office without pushing back too much. In this loyal lieutenant thinking, he or she is resisting the urge to express too much frustration when he knows this direction will not be well received by his staff.

He then puts on his creative captain hat and takes steps to re-frame this communication about the directions coming from the district because he anticipates anger and frustration coming from his staff members. He also communicates a vision of possibilities, and talks about his belief that students will continue to grow in their learning, even when teachers are facing high-stakes expectations from outside the school.

He still works to maintain the integrity of the message without changing it when he takes on the mission major role. After reframing the direction message from the district, he is able to remind teachers and staff that this direction is in line with our mission to teach and support the learning of students. As a mission major he affirms, encourages, and celebrates the good work teachers are doing in response to the directions from the district, thereby fueling emotions of hope and enthusiasm for teachers' work despite the circumstances. He or she listens and acknowledges the frustration of staff members and encourages healthy responses to these emotions, such as taking time to detach and de-stress with support from resources outside of work such as family, friends, and perhaps counseling. He may use some of his team-building skills to build a resilient climate of mutual support throughout professional learning communities in the school.

The styles of leadership worked together to frame how the identified skills were used in response to the demands for increased student achievement with reduced 
resources.

\section{Limitations}

This study had several limitations, which include general limitations of narrative research in general, time considerations, and lack of comprehensiveness.

Limitations of narrative research. Cresswell (2007) writes that narrative research can be quite challenging. He points out that the researcher needs to collect extensive research about the participant and have a "clear understanding of the context of the individual's life" (p. 57). In this study, the majority of the data collected came in the form of interview transcript data and field notes. Limited information was collected from other sources such as school district documents. Collecting extensive research and background about each participant was a challenge in this study.

Pinnegar and Daynes (2006) raise important questions about how the researcher "restories" the accounts of the participants. They ask important questions that include the following:

- Who owns the story?

- Who can tell it?

- Who can change it?

This study intended to give full ownership of the stories to the participants themselves, however it seems that because the story is shared in the telling of it, the researcher receives some ownership of the story for his purposes, which were to explore the lived experiences of elementary school principals in title 1 schools. The participants are 
trusting that these stories will be used for that purpose only.

Time. This study was conducted over a limited time period of nine months. While there was adequate time to recruit participants and collect data, the time to analyze the data became limited due to the researcher's own professional responsibilities. In addition, participants were required to recall events that occurred several years ago. Memories may have faded, but big ideas seemed to have remained in their minds beyond the immediate crisis they faced.

Lack of comprehensiveness. While the narratives gathered for this study were rich and informative, there seems to be more layers left to discover in the lived experiences of each participant. Edel (1984) writes about the importance of uncovering the "figure under the carpet" that explains the full context of a life. This study by no means captured the full context of each participant's experience, but I believe it did reveal important answers to the research question. Important leadership and decisionmaking skills were discovered through this project.

\section{Summary}

The findings that emerged from this study included three categories of styles of leadership that included the loyal lieutenant, the creative captain, and the mission major. The loyal lieutenant follows directions from the district level without questioning decisions or pushing back. The creative captain engineers new systems or procedures in response to resource reductions or demands for increased student achievement accountability. The mission major has moral purpose and sticks to the core mission. 
Seven skill areas were identified as responses to the economic crisis by the participants. The three leadership styles were used in combination with these skills. The skills included use of data, use of resources, team/relationship building, maintaining hope and energy, working with perceptions, affirming teachers, and consultation.

Participants contributed metaphors and artifacts to the study. These elements allowed the researcher to gain responses from participants that they may not have been able to express in words.

At the end of their interviews, participants were asked to share anything they would have done differently in their careers, now that they were looking back in hindsight. 


\section{CHAPTER 5}

\section{Discussion}

\section{Review of Study Purpose}

The purpose of this study was to learn how principals of high poverty elementary schools responded to the phenomena of reduced resources and the expectation of increased student achievement. More specifically, this study asked how principals have adapted to changes in schools with reduced resources and increased learning needs of students. It asked how principals made decisions in an environment where resources were reduced over time and the need for increased student achievement increased. This study was situated in the time period from 2008-2014 and it captured principal narratives of the problems principals faced during that period. Schools in the Northwest have faced a series of economic downturns historically and this study focused on one of those downturns.

\section{Synthesis of Findings}

This study produced an overarching finding that self-reflection is critically important to the work of the principal. In this study, I had the opportunity to hear principals talk about the conversations they were having with themselves in response to the circumstances of economic crisis. Three main areas of findings within this selfreflection umbrella emerged in this study. They included categories of leadership styles, leadership skills, and hidden bits of wisdom. The styles and skills areas were directly related to the research question, while the hidden bits of wisdom were unexpected but 
important to consider. One process observed in the hidden bits of wisdom, the inner voice, emerged as an important consideration. All three of these areas are interrelated and they serve to provide a picture of the responses of principals to the phenomena of economic crisis.

\section{Interpretation of Findings}

At this point, I will take the opportunity to interpret the findings in relationship to the existing research and the research question which asked how principals have adapted to changes in schools with reduced resources and increased learning needs of students.

\section{Importance of self-reflection.}

As I synthesized the findings, I concurred with Creswell (2007) who proposed researchers who are close to the participants needed to describe their own experiences with the phenomenon and bracket them out. I needed to suspend my beliefs about those experiences before describing the experiences of others. As I wrote in Chapter 3, I have always had a passionate curiosity to learn about the professional lived experiences of my peers. This drive was strong enough to allow the suspension of my beliefs in the search for new perspectives. LeVasseur (2003) proposed that a researcher could stay "persistently curious about the new phenomena" and have the "opportunity for fresh experience and the possibility of new horizons of meaning."

However, at certain points, it was necessary for me to examine my own lived experiences and stories in relationship to my peers in order to make sense of the narratives that were shared with me. Clandinin \& Connelly (1995) as well as Huber and Whelan (1999) write about how the storyteller is influenced by the act of storytelling. 
They write that the researcher can gain insight into her or his own life through

storytelling. I know that I gained new insights about my work and life experience as an elementary school principal while conducting this study.

Research supporting self reflection. Reeves (2006) writes about journaling and the importance of reflection:

Although journaling is, in general, an intensely private activity, the reflective leader knows when personal revelation can have a profound impact. In my own case, some of my toughest leadership decisions have been prompted by a review of journal entries that forced me to recognize that I had attempted the same solution for a particular problem on several occasions, and unsurprisingly, the results did not improve with such a stagnant approach... Reflection forced me to admit that I had been as resistant to change as the others whom I had accused of being resistant and insufficiently enthusiastic to my favored initiatives. Reflection, in brief, forces leaders to climb down from the mythological perch, admit our human foibles, and get real (p. 51)

This inquiry gave me this opportunity to step down from my "mythological perch", admit my "foibles and get real." Trotter (2006) and Sternberg (2012) write about the importance of self-reflection also.

Inner voice. As part of the reflection process, I was particularly interested in studying the inner voices of the participants in this study to learn and understand their responses to the economic crisis. Leithwood et al. (1995) argued that school leaders and those that are coaching them should understand these inner voices when he wrote this, .....they need a better understanding of principals' internal mental processes and states: the rational aspects of these processes, such as the content and organization of knowledge structures, as well as non-rational elements as beliefs, attitudes and values, (p. 27).

Beatty (2000) and Greenfield (2004) wrote about the importance of studying the 
emotions of principals in the context of their work. They both pointed out that there is little research that studies this phenomena.

Findings from Beatty's (2000) qualitative study of educational administration doctoral students who were in the middle years of their professional lives, showed that the freedom to talk about emotions at work was generally not possible. The participants in the study had to rely on their own management techniques to work through the emotions they experienced. The leaders in the study, including one elementary school principal found that the use of distributed leadership and letting go of some control allowed for reduced anxiety through shared responsibility and the celebration of mutual success. Those leaders that focused on maintaining strict control without sharing leadership responsibility were impacted by the emotions of others. They tended to experience anxiety and disillusionment (Beatty, 2000).

Hochschild (1993) wrote about the concept of emotional labor in an article about the airline industry where employees were expected to maintain a positive outward appearance at all times. She says,

Emotional labor is the silent work of evoking and suppressing feeling- in ourselves and in others. When you drive a truck or swing a hammer for a living, you give the company your time and sweat. But you don't relinquish your way of seeing things. You don't give the company your face or your feelings. (p. 333)

Becky Durham (personal communication, December 18, 2015) in her quote talked about maintaining a professional appearance and the need to suppress her feelings at least temporarily. She also talked about how difficult it was to do this. Bob Jones (Personal Communication, December 22, 2014) talked about his need for a 
"pep talk" and how he appreciated the encouragement he received from his supervisor when he was discouraged. Hochschild (1993) points out that in our modern economy, the ability to deal with people, relationships and feelings will matter relatively more than making things for a living. The quotes from Durham and Jones illustrate the importance of this emotional labor and its impact on the inner voice.

Through the study of these inner voices, I believe I was able to capture some of the emotions principals were experiencing and how they were managing them in response to external demands in a time of economic crisis.

Loader (2002) wrote a book about his experience as a principal by studying the inner

person. I can identify with his experience when he wrote,

Amongst my friends there have been those who have counseled me against going ahead with the publication of this book, arguing: 'It could do you professional harm because it is so personal.'; 'You may limit your future options by settling down the sort of person you now see yourself to be.'; 'Why wear your heart on your sleeve?'; 'People will be able to take advantage of you because you have revealed so much of your self.' I will have to wait and see if these are the outcomes.

I have a different point of view. I think that it is important that books like this are written so that we, the readers, obtain a more balanced view of leadership. Leadership has its highs and lows, its successes and failures. Principals cry, laugh, dream and become suspicious. There are times when principals do want the fairy godmother to come and save them. While leadership is about courage, about creating the tomorrow of our choice, heroism does not come easily and this book is a case in point. My hope is that this is the first of a series of books that will come from many authors and that these books will inform and sustain those of us who attempt leadership. We are not looking for war stories but personal tales of everyday events. Their publication will make accessible craft knowledge, will facilitate personal insight, stimulate good discussion and lead to the establishment of better schools (p. 2-3). 
Self-reflection and inner-voice are key components to this study. The examples and quotes that have been studied illustrate Loader's point that we need a more balanced view of leadership that includes the inner voices of principals. It seems interesting now to contrast this view with Wolcott's (1973) approach which emphasized an etic stance or outside view which meant that he didn't discuss his beliefs with the participant . Hoppey (2006) pointed out that Wolcott's ethnographic study did not try to understand the principal's underlying beliefs or values that guided his decision-making and leadership. I wonder what kinds of findings Wolcott would have reached had he asked his participant questions about his beliefs, feelings and emotions in addition to the reasons for his decisions and actions.

Leadership styles. In his quote above, Loader (2002) wrote that researchers should be looking for the stories of everyday events rather than war stories. In a sense, the narratives I have collected may resemble war stories since the terms used to describe the categories come from the military. The terms I used to describe the leadership styles including loyal lieutenant, creative captain and mission major were an attempt to categorize these stories in terms that were inspired by the narratives of principals themselves. As reported earlier, Ajay, actually used the term, loyal lieutenant in his narrative. This term inspired the use of the other terms to describe the leadership styles I observed in the data. I don't believe I was looking for war stories if that is what the reader would like to call them. However, the research question asks principals to talk about their responses to an economic crisis. In this case, I believe a researcher should expect to hear some war stories if the question refers to a crisis. 


\section{Research supporting leadership styles.}

The loyal lieutenant style is supported by research from Walcott (1973) and Griffiths (1963) who studied the roles of elementary principals. They found that while principals thought that they should be agents of change, the evidence suggested that most of their direction came from the central office and their role was to keep the system intact. The creative captain style is supported by the work of Koyama (2014) who wrote about the ways in which principals negotiated the demands of outside accountability such as state and federal measures when that was possible. In some cases principals were able to convince their superiors to create new polices regarding accountability measures as a result of their work. Senge (1990) emphasizes this leadership style when he wrote about creative tension:

His relentless commitment to the truth and to inquiry into the forces underlying the current reality continually highlight the gaps between reality and the vision. Leaders generate and manage this creative tensionnot just in themselves but in an entire organization. This is how they energize an organization. That is their basic job. That is why they exist. (p. 357).

The principal who uses the creative captain style works in the midst of this creative tension to lead the organization, especially during times of economic crises.

Greenfield's (2004) research supported the mission major style when he emphasized the need for more study of the moral aspects of educational leadership. Senge's (1990) quote also supports the mission major style when he refers to the leader's "relentless commitment to the truth" by keeping the learning organization focused on the idea that we can learn together to get the results we want to see in the end. 
Senge (1990) wrote about his trip to South Africa in February of 1990. President De Klerk had announced the lifting of bans on black political groups and Nelson Mandela, soon to be the future president of a new democratic government in South Africa was scheduled to be released from prison. Senge was invited to come as part of an initiative to promote the development of learning organizations and learning communities with a new generation of black and white leaders who had promised to work together in the formation of a new democratic society.

Senge's trip caused me to remember my own travels to South Africa in July of 1995, a year after Nelson Mandela was elected. I had the opportunity to travel with twelve teachers from the state as part of a Fulbright exchange trip to the country. Our purpose was to learn and witness how schools and society were changing and transforming as a result of the change in government. I visited schools in Kwazulu Natal where the only books students had in their library were a set of comics that were donated by a school in the U.S. I taught in classrooms where three students shared a desk and they had to copy all of the learning content into their notebooks (if they had them) because there was no such thing as a copy machine anywhere to be found within miles of the school. Contrasted with the other extreme, I also visited schools in white areas of South Africa where students could have more access to the internet than I could as a teacher back in the United States. The reader should keep in mind that the internet was just beginning to have a presence in schools at this time. These students also participated in a sky diving club that was sponsored by the school. Thinking back to this experience, I can only imagine the kinds of creative captions, mission majors, and loyal lieutenants 
that were running these schools. Imagine the creative tension involved when school teachers and leaders would be welcoming new students into their classrooms who may have had little or no access to a quality education because of their race. Imagine the deeply embedded belief systems and the resistance of the local communities including the teachers themselves when they were being asked to suspend those beliefs for the greater good. My experience as an elementary school principal in this economic crisis between 2008-2014 pales in comparison.

Skills. The seven skill areas researched in this study include use of data, use of resources, team/relationship building, maintaining hope and energy, working with perceptions, affirming teachers and consultation. In the interviews each participant was asked questions in relationship to these skill areas. These areas were identified from research on the roles of principals that were summarized in the literature review.

Team/relationship building. Peter Epstein's quote also reminded me of Senge's (1990) work that focused on the learning organization. Peter's report of his work to support relationships, keep his team together, and build confidence that they could do this work together exemplified this particular skill. Peter was demonstrating his role as an instructional leader in this quote. Leithwood, et. al, (2004) wrote about the importance of this role and its impact on student achievement. His quote also suggested that he was building the capacity of his teachers by encouraging them to take on leadership roles among their peers. Louis, et. al (2010) found that building teacher capacity and leadership was associated with improved student achievement in math and reading. I can say that I too have witnessed the importance of this skill. In three of the buildings where 
I have been an elementary school principal, I can say that I have had the pleasure of working with strong teams of teachers who enjoy working with each other to impact student learning. Several of these teams have asked me to promise that I will never break them apart. I have to say that the teams who have asked me to make this promise have had seen outstanding student achievement results over the last several years. Although I am no longer a principal at this school, a team I worked with went on to be one of the moving forces behind large achievement gains in math and reading on the part of students in their school. This resulted in a model school rating by the just this last year.

Use of data. Barth (2002) and Dufour (2013) write about the importance of the learning culture in a building. The learning culture relies on the effective use of data to make decisions about instruction for students. City (2009) has developed and studied a number of protocols to be used for the objective observation of instruction as well as data. Becky Durham's quote where she talked about a teacher's use of data shows how important it is to frame the conversation:

And his teacher goes up to him and says, "What's wrong?" And he goes, "Well I didn't meet." He goes, "Yeah, you didn't meet." He goes, "But what was your score last year? And what was your score this year?" And the teacher says, "You stand up proud: that's 18 points." [Laughs]. He goes, "You lift that head up." You know, framing it differently for ourselves and for our kids. It's about -- it's about growth. It's not about meet. I mean you know, you do want to meet.

B. Durham (personal communication, December 18, 2015)

Becky's quote illustrates the importance of talking about data in terms of a growth mindset. Dweck (2007) has introduced and studied this concept that promotes growth in learning through embracing challenges and failures as learning opportunities. Increased 
attention is placed on student effort as opposed to talent and frequent success. Her work has influenced teachers in school districts all over the country as well as other areas outside of education including business and interpersonal relationships. I have found recently that framing conversations around data in terms of a growth mindset for both students and adults, particularly teachers is extremely important especially during times of economic crisis where there is a need for educators to embrace difficult problems. Students and teachers in my current school talk about not being able to learn a concept "yet" as opposed to saying, "This is so hard, I am never going to learn this."

Durham's quote also points to the use of growth measurement in terms of accountability to state and federal guidelines. States now use growth percentile data among other measures to determine whether students in schools are making adequate gains in their learning.

Use of resources. Alicia Dart in her interview said, "Yes, and some of that change can always be good, right? I guess the metaphor of who you get on the bus and what seat you put them on the bus kind of thing." A. Dart (personal communication, February 16, 2015)

As a principal during this time period (2008-2014), I found that I was able to move some people to better seats on the bus by moving them to positions that were better suited for them and most importantly better for students and their learning. However, other movements were not good for students. We lost many strong, energetic, new teachers due to reductions that were determined by seniority or length of service according to the collective bargaining agreement between teachers and the school district. 
Increased class sizes also resulted when these moves occurred. Some teacher movements to classrooms were even more troubling when teachers who were having performance issues were placed there.

Maintaining hope and energy. Patricia Cross's quote related to this skill recognizes the investment and energy teachers put in to their work each day. She said,

These are highly intelligent, committed people that have made a commitment to kids and want to be successful, and none of 'em get up in the morning and say, "I'm gonna go screw a kid over today."... And I think people, when they feel included, then they feel like they have a purpose and that what they're doing - we can get through this together 'cause we're all on the same boat.

P. Cross (personal communication, January $27^{\text {th }}, 2015$ )

Reeves (2006) points out that adult actions matter in schools. He writes that it is absolutely unacceptable for a teacher, principal or any staff member to place the blame for poor learning performance on the students themselves. I believe that it is important to help teachers maintain a sense of purpose for their work. Patricia does this. This purpose also creates a sense of hope. Teachers get up to go to work each day to teach students with the hope that they will learn. This is part of the mission major leadership style in keeping the focus on the purpose and mission. The failures on the part of students become opportunities for learning and it becomes the job of the teacher with the principal's support to help students see their failures in this way. At another level, it becomes the job of the principal to help teachers see student failure as an opportunity for professional growth and improved practice. Dweck's (2007) growth mindset ideas are so important in framing this skill of maintaining hope and energy. The hope comes from the maintenance of this growth mindset. 
Working with perceptions. Alicia Dart's quote is an example of the work principals do to manage outside perceptions of the school. She said,

People say, "Oh, it's such and such school. I'd never want to send my kid there," or, "Such and such school." Well, have you been in our school? Have you checked our ratings? Have you walked our halls? Have you talked to any of our kids? This is a pretty good place to be, and if you don't like us, go away. We have plenty of kids who want to be here.

A. Dart (personal communication, February 16, 2015)

The questions Alicia fired back in response to the question I asked might suggest that she is a little defensive. On the other hand, I believe her point was to make sure that her voice was heard in the narrative about her school.

Alicia's questions also make sense and are supported by recent research. Zeehandelaar \& Northern (2013) conducted a study in conjunction with a marketresearch firm, Harris Interactive for the Thomas B. Fordham Institute. The study found agreement about the core attributes parents want to see in their children's schools. Two thousand parents of children in public and private schools from a broad range of backgrounds were surveyed. When forced to choose among several attributes, nearly all of the parents prioritized a solid core curriculum in reading, math, and science along with strong critical thinking skills. However, some of the parents preferred specializations that are only possible in a system that allows school choice. I believe Alicia was responding to the increased demand for school choice. I don't believe she would have told a parent to simply go away, but I do believe that she recognized that parents have options for school choice. I believe she also had a strong sense of the characteristics of her student population and the preferences of the parents. Many districts now have open-enrollment 
policies which allow parents to request to enroll a student in a school that is outside of their district and attendance area, provided that they are willing to provide transportation to that school. The laws state that once students are accepted into a school district, they will be allowed to stay enrolled in that school district until they graduate from high school. Parents can continue to apply to have their students attend in other districts using the inter-district transfer process as well. However this process requires that parents reapply for transfer each school year.

The open-enrollment process also has implications for district revenue. Bamesberger (2014) summarized one school district's response to this dilemma. The district discovered that it would be losing significant revenue to support all of its schools if parents continued to enroll their children outside of the district. When parents choose to enroll their children in another district, the revenue from the state follows them to the new district. Districts are now having to grapple with this phenomena and it is becoming increasingly important that principals are conscious of the perceptions parents have of their school, especially if they are deciding to enroll their child elsewhere.

In this time of economic crisis, Alicia's quote is an example of the work principals had to do to influence the narrative about their schools. Parents now have more options to consider when thinking about where their children attend schools.

Affirming teachers. Alicia Dart also spoke to the importance of affirming teachers in their work. She said,

We had a thing in our school - well, we were a PBIS school, obviously, so we had our positives that we gave to kids. So we made up these things for our staff members, too, and they were called - I don't remember what they were called, but I probably have a copy on my computer. But they were a thing where you - I would give one to you as a staff member, adult 
to adult, in the school. It was a real quick thing. I could give it to you personally.

A. Dart (personal communication, Februrary 16, 2015)

Alicia's referred to PBIS (Positive Behavior Interventions and Support) in this quote. Many schools in use this program to monitor behavioral referrals and track systems at a school-wide level to help maintain a positive school climate. In this instant she is using her creative captain hat to recognize and affirm the good work her teachers are doing. This particular approach of putting a system in place which allows teachers to recognize each other for their good work was inspired by acknowledgement systems in PBIS schools that recognize students for their work to meet school-wide expectations such as be safe, be respectful, and be responsible. In this case, teachers are merely affirming and recognizing the good work they see other teachers doing. City (2013) and Fullan (2014) wrote about the need for principals to create a culture where faculty members support each other. They both emphasized the point that principals won't be able to have this impact by working one to one with teachers alone. They wrote that a culture needs to be established for this, meaning that teachers need to support each other. Alicia's quote above provides an example of one simple way to impact a school culture and help it to feed itself.

Consultation. Stan Burk, in this quote referred to the consultation skill and his need for it. He said,

So I made a lot of alliances on people that could help us, but Debby was probably as far as a peer, one that we would wrestle with each other about how to deal with stuff that we didn't think was right or whatever, or if we had an employee issue, or how to build master schedules, on and on and on.... So we had - it was sort of it went from sort of a mentorship to a peer/consultive kind of thing that really - that was are helpful to me. 
'Cause we know the jobs can be just so isolating.

Stan Burk (Personal Communication February 18, 2015)

Principals need to have consultation with mentors or their superiors. Several of the participants mentioned a mentor or supervisor that they were able to confide in.

Leithwood et al. (1995) referred to the need for coaches and supervisors of principals to have this understanding. Again this points to what I believe is the importance of the principal's inner voice, particularly in a time of economic crisis. This voice is ultimately going to be working through the decision-making process. Consultation with a trusted supervisor or mentor who understands the conditions a principal works under is an important skill. I believe that a principal needs to seek out this consultation. It isn't going to just simply arrive when it is needed. Stan Burk asked for it. He would "wrestle" with his colleague about an employee issue, or how to build a master schedule. He was using his creative captain style of leadership by working with a trusted ally to engineer new systems or procedures such as a master schedule. He also may have talked through an employee issue in order to get the right people "on the bus" while reducing staff and continuing to respond to the need for increased student achievement.

\section{The Leadership Style that Leads to Improved Student Achievement}

While all of the leadership styles impact student achievement in some way, I believe there is enough evidence to suggest that the creative captain style of leadership has the most impact. After reviewing and interpreting the transcript data, the creative captain style was tied to the leadership skills more frequently than other styles. This style was associated with several of the skills that emerged including the use of data, use of resources, maintaining hope and energy and affirming teachers. In 
addition, researchers including Koyama (2014), Louis et al (2010), and Leithwood et al (2004) wrote about the innovative actions principals took in their response to the demand for increased student achievement. Senge (1990) wrote about the need for leaders of organizations to work with the creative tension between the vision for success and the current reality both in their own thinking and in the management of their organizations. The creative captain style was used more frequently and consistently by the leaders in this study to work through this creative tension between the increased demand for student achievement and the reality of reduced resources to meet the demand.

\section{Hidden bits of Wisdom}

The metaphors and artifacts collected in this inquiry may be worthy of further study. All of them are summarized in Appendix D. These elements of the study allowed me to venture beyond the direct answers to the interview questions. Weber (2008), Barone (1995), and Sfard (1998) wrote about the importance of studying both metaphors and artifacts. There is yet so much interpretation that cold be done with these pieces. Perhaps there is some material here for further study.

I wanted to highlight one artifact in particular because it speaks to a topic I thought I would hear more about in my interviews with the participants. Lorrie Smart, one of the participants said, "This is something I really used probably in the second half of my career and it's very - there is a book called Courageous Conversations About Race." L. Smart (personal communication, January 21, 2015)

Singleton and Linton (2006), Delpit (1995), Noguera, (2009), Ysseldyke (2001) and Reardon (2013) all wrote about the importance of social justice and equity in 
schools. In the literature review, I summarized much of their research that focused on the achievement gaps between students of privilege and other students in marginalized groups categorized by race, disability and economic status. Singleton and Linton (2006) wrote the book that Lorrie Smart referred to. When talking about an era of economic crisis and the need for improved student achievement, I thought I would have heard more from the participants about the ways in which they addressed these gaps. I was at least hoping to hear some discussion of achievement gap issues. I believe principals provided examples of actions they were taking to build capacity among teachers when they referred to concerns they had about test score gaps between groups of students, but I didn't hear very much about their beliefs on this subject. Lorrie Smart talked about her passion to address issues of social justice. She said,

And I had this hanging by my phone [picture of the book, Courageous Conversations] and really tried to attend to these when I had conversations with parents..... So I could look and keep reminded about why did we make that decision.

L. Smart (personal communication, January 21, 2015)

Lorrie intentionally set up a way to remind herself about this important work, especially when she was talking with parents about her decision-making process. Her approach here is an answer to the research question I was thinking I might have heard from other principals. As I thought about this surprise further, I looked at the demographic chart in chapter 4 of this study and realized that all of the participants were white. Lorrie was the only participant who referred to herself as non-white or Asian. I am wondering if her consciousness of equity had some relationship to her own racial identity and cultural background. This observation to me seems significant because I know that the school 
districts where the participants worked were all active participants in organizations that provide training and coaching to help principals address equity issues.

The other artifact I thought was worth highlighting came from Patricia Cross.

She said,

I did a presentation at a press conference one time and that was the theme of it. I was shocked how many people came. But what I found interesting, there's a lot of, lot of good science books written about what we already do, but there aren't as many that are written about the other side of it, and one of the most amazing speakers I ever heard - actually two of them - talked about that side of leadership. One was a Marine Corps colonel, retired. He teaches at Annapolis. He was an amazing speaker. I should send you his speech..... It's just, it's a great - it's called "What's Love Got to Do with It," and here's this guy who was a big-time Marine colonel really talking about leadership from the heart, and he is absolutely amazing.

P. Cross (personal communication, January 27, 2015)

Patricia's artifact is an example that to some degree represents all of the other artifacts.

The participants were asked to share an artifact that represented their careers. Patricia's

artifact focused on a side of leadership that I believe gets taken for granted much too

often. All of the leaders interviewed in this study shared something from their hearts

even if they couldn't do so in words. Evidence of this can be seen in Appendix D. I

believe the topic of leading from the heart, especially in an era of economic crisis would be worthy of further study.

\section{Larger Context}

In this study, I used a social constructivist paradigm or worldview in which individuals search for meaning from the world in which they live and work. Meanings are subjective and they are formed through their interactions with others. Creswell, 
(2007) and Lincoln \& Guba (1994) wrote about the intent of the researcher to make sense of the meanings others have. The narrative inquiry approach was chosen as a method in order to try to understand a real-life phenomenon, specifically, the lived experiences of elementary principals who have grappled with high poverty, reduced resources, and increased accountability. Van Manon, (1990) and Moustakas, (1994) wrote about the use of narrative inquiry to discover the "essence" of lived experience. Crow, Hausman, and Paredes-Scribner, (2000) conclude there are fewer studies that focus on the role of the principal viewed from the their own perspective and that such studies are needed. More understanding of the lived experiences of principals is needed.

My desire and purpose was to make sense of the meanings elementary principals have constructed by asking them to reflect about their lived experiences of the phenomena of decreased resources and the need for increased student achievement in an era of reduced resources.

This study found that self-reflection is critically important to the work of the principal. In this study, I had the opportunity to hear some of the reflections in the form of self-conversations principals had. Three main areas of findings within these self conversations were the emergence of leadership styles, leadership skills, and hidden bits of wisdom. The skill areas were related to research from the literature review and the hidden bits of wisdom emerged from the requested metaphors and artifacts.

\section{Implications For Further Study}

This study only begins to scratch the surface of the meanings principals attached to the phenomena of reduced resources and the increased need for student achievement. It 
seems that the Northwest is fertile ground for studies like this due to the continuous cycles of economic downturn and reduced funding for public schools. Linhares (2011) chronicled the history of one state's tax system and its impact on K-12 schools. I believe that as long as this cycle continues, principals and the district leaders that support them will need to learn how to cope with the reality of uncertain funding resources. They will also need to understand how to prepare for such cycles during times of relative economic prosperity. More study of the time period between 2008-2014 in the form of qualitative and perhaps quantitative studies of principal responses to the phenomena of reduced resources and increased demand for student achievement is needed.

Study of the inner voices of principals. I believe some principals have some answers to the research question that are worthy of attention. They have been summarized in this study. The roles of principals in response to an economic crisis are important and have not been clearly established. The research I summarized in the literature review only refers to the roles principals play in their impact on student achievement and the learning culture of a school. This study focused on the selfreflection of principals in response to the crisis. Perhaps these self-reflections could serve as a starting point for more focused research in the roles principals play in response to an economic crisis. For example, if a principal talked about their work to affirm teachers or build capacity of teachers, what methodology or practices in these areas could be studied further? And what about the process of self-reflection itself? Principals are now required to self-reflect as part of their own evaluations. What are the best ways for principals to self-reflect? I believe more study of this phenomena from an emic stance 
will be helpful to future principals who need to respond to an economic crisis. Perhaps a study as ambitious and extensive as Walcott's (1973) work is necessary. Only this time an anthropological approach considering constructs, conceptual themes, and categories expressed by those of the native culture (Lett, 1990) or principals themselves would be initiated.

Social Justice Promotion. One of the roles of principals I wrote about in the literature review referred to social justice promotion. While the evidence I have uncovered in this study is limited, I believe more study of this role is needed. The racial background of each of the participants in this study was white except for one principal who placed themselves in the Asian category. How can we continue to expect increased student achievement and a closing of racial achievement gaps when the majority of the leaders in the state are white? Portland State University (PSU) is one of several institutions that will be providing training for future leaders that include both teachers and administrators. Kapoor \& Williams (2003), faculty members at PSU wrote,

As teachers. we must give varied formats a chance to develop students' abilities and decenter inflexible teaching practices that prevent students from interacting gainfully in a pluralistic world. For instance. when we place students in nonprofit, service-based organizations, they confront the their racial and class positioning in a way they rarely have previously. ( $\mathrm{p}$. 74)

This quote serves as some evidence we are moving forward in the effort to train future leaders how to address social justice and equity issues. More focused work is especially needed to address student achievement gaps.

What hiring policies will need to be changed so that more people of color will take on leadership roles in schools? Their perspectives are needed in the effort to 
improve the response to the need for increased student achievement, especially during times of economic crisis. White principals and leaders who have the authority now will have to usher in new leadership. Perhaps a study of the steps they are taking would be worthwhile.

Principal Evaluation. Legislation in states established new administrator evaluation frameworks in 2011. The Valley River Administrator Standards summarized in Table 1 were developed to comply with this legislation. How should principals be evaluated during an era of economic crisis? Does this framework account for the skills principals need in order to respond to the cycle of economic crisis that seem to happen in the Northwest? I would suggest that this could be a future topic of study.

Principal Coaching. Most of the principals in this study worked for the organization, Education Northwest which is responsible for providing coaching and training to principals throughout the Northwestern United States. At the time of this study, these principals were actively coaching principals of schools that were rated in the focus and priority categories in terms of student achievement outcomes on state tests. A study of their work, specifically their coaching to help principals respond to the need for increased student achievement with reduced resources would be most helpful. In terms of policy, perhaps the role of Education Northwest could be expanded to provide coaching to all principals of Title 1 schools because of the continuous downward economic cycles they face.

Emotions. The study of emotion management would be worthy of future study. How do principals manage their emotions in the face of increased demands for student 
achievement and reduced resources? Also, how do they help teachers and others manage their emotions? Is this a role they should play in terms of building teacher capacity? Beatty (2000), Greenfield (2004), Leithwood et al. (1995), Hochschild (1993) and Loader (2002) wrote about the need to understand how principals manage their emotions but they didn't focus on the this topic in terms of the research question in this study.

Coaching and Emotions. In terms of emotions, mentoring and coaching for principals, I believe Loader (2002) has an excellent suggestion that should be explored further. He writes,

Maybe as principals we should be looking to create some supervision structure in which we can be nurtured. Maybe it is something that Associations of Principals could initiate. It is not quite the confessional of the Catholic Church although I know that to be useful and positive. Identifying personal loneliness is not the same as being preoccupied or excessively introspective.... Rather admitting to loneliness can lead us to talk to others, to enter into relationship whether inside our outside our community. That is the generative spirit I am seeking, from sadness to action and then to community. (p. 39)

I wonder how many principals of title one schools have battled through loneliness, broken spirits, and frustration in response to the economic crisis. This study provided just a glimpse. Could the response to emotions be a focus of coaching and mentoring for principals in the future? Perhaps the act of responding to emotions needs to be recognized as a legitimate professional task first. Principal decision-making in a time of economic crisis will involve emotions. How do we move from "sadness to action and then to community" as Loader suggested? Can enough trust get built in an organization to allow principals to feel safe enough to share how they are processing their own emotions and the emotions of those they supervise in response to circumstances during 
this time of economic crisis?

\section{Conclusion}

This study produced an overarching finding that self-reflection is critically important to the work of the principal. Categories of leadership styles, leadership skills, and hidden bits of wisdom emerged from the self-reflections of principals. The styles and skills areas were directly related to the research question, while the hidden bits of wisdom were unexpected but important to consider. All three of these areas are interrelated and they served to provide a picture of the responses of principals to the phenomena of economic crisis. Further suggested areas of study include principal evaluation standards, inner voices of principals, the role of the principal in promoting social justice, principal coaching, and emotion management on the part of principals. 


\section{References}

Achilles, C., \& Price, W. J. (2001). What is missing in the current debate about educational administration? The AASA Professor, 24, 8-13.

Adams, J. E., \& Copland, M. A. (2005). When learning counts: Rethinking licenses for school leaders. Seattle, WA: Center on Reinventing Public Education.

Administrative Assessment and Evaluation Rubric. (2013). Retrieved from http://www.nclack.k12.or.us/cms/lib6/OR01000992/Centricity/domain/273/ talented_perform_files/Administrative_Rubric.pdf.

Agnes, M. E. (2004). Websters new world dictionary. (4 ${ }^{\text {th }}$ ed.). Hoboken, NJ: John Wiley \& Sons.

Ahern, K. J. (1999). Tips for reflective bracketing. Qualitative Health Research, 9(3), $407-411$.

Athens, A. (2008). “Leadership: What's Love Got to Do With It?”. I/C Capstone Seminar. U.S. Naval Academy. Annapolis, Maryland. January, 2008. Presentation.

Bamesberger, M. (2014, February 17). North Clackamas Schools to Pursue "Aggressive" Open Enrollment. Oregonlive.com. Retrieved from http://www.oregonlive.com/.

Barone, T. (1995). The purpose of arts-based educational research. International Journal of Educational Research, 32(2), 169-180.

Barth, R. S. (2002). The culture builder. Educational Leadership, 59(8), 6.

Barth, R. S. (2013). The time Is ripe (again). Educational Leadership, 71(2), 10. 
Becker, G., Withycombe, R., Doyle F., Miller E., Morgan C., Deloretto, L.,...

Goldhammer, K. (1971). Elementary school principals and their schoolsbeacons of brilliance \& potholes of pestilence. (CASEA-Monogr-23 BR-5-0217). Eugene, OR: University of Oregon, Center for Advanced Study of Educational Administration.

Bennis, W., Cummings, T. G., \& Spreitzer, G. M. (2001). The future of leadership. San Francisco, CA: John Wiley \& Sons, Inc.

Beatty, B. R. (2000). The emotions of educational leadership: Breaking the silence. International Journal of Leadership in Education, 3(4), 331-357.

Bogdan, R. C., \& Biklen, S. K. (2006). Qualitative research for education: An introduction to theory and methods (5th ed.). Boston: Allyn \& Bacon.

Briggs, K., Cheney, R., \& G. R., Davis, J., \& Moll, K.(2013). Operating in the Dark: What Outdated State Policies and Data Gaps Mean for Effective School Leadership. Retrieved from http://www.edweek.org/media/gwbi20principals.pdf.

Bush, G. W. (2001). No Child Left Behind. Retrieved from http://eric.ed.gov/?id=ED447608

Clandinin, D. J., \& Connelly, F. M. (1994). Personal experience methods. In N. K. Denzin and Y. Lincoln (Eds.), Handbook of qualitative research. (pp. 413-437). Thousand Oaks, California: Sage.

Clandinin, D. J., Connelly, F. M., \& Craig, C. (1995). Teachers' professional knowledge landscapes (Vol. 15). New York: Teachers College Press. 
Clandinin, D. J., \& Connelly, F. M. (2000). Narrative inquiry: Experience and story in qualitative research. San Francisco: Josey-Bass.

Connors, N. A. (2000). If you don't feed the teachers they eat the students!: Guide to success for administrators and teachers. (J. Streams, Ed.) (Edition Unstated edition). Nashville: Incentive Publications.

Czarniawska, B. (2004). Narratives in social science research. London: Sage.

Chenoweth, K., \& Theokas, C. (2013). How high poverty schools are getting it done, $70(7), 56-59$.

Canole, M., \& Young, M. (2013). Standards for Educational Leaders: An Analysis. Retrieved from http://www.ccsso.org.

Chatterji, M. (2006). Reading achievement gaps, correlates, and moderators of early reading achievement: Evidence from the early childhood longitudinal study (ECLS) Kindergarten to First Grade Sample. Journal of educational psychology (0022-0663), 98, 489.

City, E. A. (2013). Leadership in challenging times. Educational Leadership, 70(7), $11-13$

City, E. A., Elmore R. F., Fiarman, S. E., \& Teitel, L. (2009). Instructional rounds in education. Cambridge, MA: Harvard Education Press.

Collins, J. C. (2001). Good to great: Why some companies make the leap--and others don't. CITY: Random House.

Creswell, J. W. (2012). Qualitative inquiry and research design: Choosing among five 
approaches. Thousand Oaks, CA: Sage.

Crow, G. M., Hausman, C. S., \& Scribner, J. P. (2002). Reshaping the role of the school principal. Yearbook of the National Society for the Study of Education, 101(1), $189-210$.

Davis, S., Darling-Hammond, L., LaPointe, M., \& Meyerson, D. (2005). Review of leadership: School leadership study_Developing successful principals. Stanford, CA: Stanford Educational Leadership Institute.

Day, C., Harris, A., Hatfield, M. T., \& Beresford, J. (2000). Leading schools in times of change. Buckingham: McGraw-Hill International.

Delpit, L. D. (1995). Other people's children: Cultural conflict in the classroom. New York: New Press.

Dewey, J. (1938/2007). Experience and education. Simon and Schuster. Retrieved from http://books.google.com.proxy.lib.pdx.edu/books?hl=en\&lr=\&id=JhjPK4FKpCc C\&oi=fnd\&pg=PA14\&dq=John+Dewey\&ots=D9tEnHIG9\&sig=yWRfJqi7Bnng m3CfsawKliKNBbE (Original work published 1938).

Dillon, S. (2011). As budgets are trimmed, time in class is shortened. The New York Times, p. A14.

DuFour, R. (2013). How do principals really improve schools? Educational Leadership, 70(7), 34-40.

Dweck, C. (2007). Mindset: The new psychology of success (Reprint edition). New York: Ballantine Books.

Edel, L. (1984). Writing lives: Principal biographica. New York: Norton. 
Elmore, R. F. (2007). School reform from the inside out: Policy, practice, and performance. Cambridge, MA: Harvard Education Press.

Ellis, A. (2004). Rational emotive behavior therapy: it works for me-it can work for you. Amherst, NY: Prometheus Books.

English, F. (2003). Cookie-cutter leaders for cookie-cutter schools: The teleology of standardization and the delegitimization of the university in educational leadership preparation. Leadership and Policy in Schools, 2(1), 27-47.

Fullan, M. (2010). The moral imperative realized. Thousand Oaks, CA: Corwin Press.

Fullan, M. (2014). The principal: three keys to maximizing impact. San Francisco, CA: Jossey-Bass.

Glaser, B. G., \& Strauss. (1967). The discovery of grounded theory. Chicago: Aldine.

Glen, S., Mitchison, S., Poole, H., \& Wall, C. (2004). Using a reflective diary to develop bracketing skills during a phenomenological investigation. Nurse Researcher, 11(4), 20.

Glesne, C., \& Peshkin, A. (2005). Becoming qualitative researchers: An introduction $\left(3^{\text {rd }}\right.$ ed.). White Plains, NY: Longman.

Greenfield, Jr., W. D. (2004). Moral leadership in schools. Journal of Educational Administration, 42(2), 174-196.

Griffiths, D. E. (1963). The elementary-school principal and change in the school system. Theory into practice, 2(5), 278-284.

Gronn, P. (2003). The new work of educational leaders: Changing leadership practice in 
an era of school reform. Thousand Oakes, CA: Sage.

Harvey, J., \& Holland, H. (2012). The school principal as leader: Guiding schools to better teaching and learning. Retrieved from http://www.wallacefoundation.org.

Harris, M. (1976). History and significance of the emic/etic distinction. Annual Review of Anthropology, 329-350.

Hattie, J. (2009). Visible Learning: A synthesis of over 800 meta-analyses relating to student achievement. New York: Routledge.

Hess, F.M. (2003). A license to lead? A new leadership agenda for America's schools. Washington, DC: Progressive Policy Institute.

Hirsh, S., \& Killion, J. (2009). When educators learn, students learn. Phi Delta Kappan, 90(7), 464-469.

Hochschild, A. R. (2003). The managed heart: Commercialization of human feeling, With a new afterword. Berkely, CA: Univ of California Press.

Hoppey, D. T. (2006). The man in the principal's office: Revisiting Harry Wolcott's research during an era of increased complexity and high stakes accountability (Doctoral dissertation, University of Florida). Retrieved from http://www.proquest.com.

Huber, J., \& Whelan, K. (1999). A marginal story as a place of possibility: negotiating self on the professional knowledge landscape. Teaching and Teacher Education, 15(4), 381-396. http://doi.org/10.1016/S0742-051X(98)00048-1.

Kachur, D. S., Stout, J. A., \& Edwards, C. L. (2013). Engaging teachers in classroom walkthroughs. Alexandria, VA: ASCD. 
Kapoor, P., \& Williams, D. R. (2003). Higher education's imperative: Rising to the challenge of educating citizens. Michigan Journal of Community Service Learning, 10(1), 70 .

Keeler, C. M. (2002). Exploring the validity of standards for school administration preparation. Journal of School Leadership, 12(5), 579-602.

Knowles, M. (1973). The adult learner: A neglected species. Retrieved from http://files.eric.ed.gov/fulltext/ED084368.pdf

J Kolama. (2014). Principals as bricoleurs making sense and making do in an era of accountability. Educational Administration Quarterly: EAQ., 50(2), 279. http://doi.org/10.1177/0013161X13492796

Kvale, S. (1996). InterViews: An introduction to qualitative research interviewing. Thousand Oaks: Sage.

LeVasseur, J. J. (2003). The problem of bracketing in phenomenology. Qualitative health research, 13(3), 408-420.

Leithwood, K. A., Louis, K. S., Anderson, S., \& Wahlstrom, K. (2004). Review of research: How leadership influences student learning. Toronto: University of Minnesota.

Leithwood, K., \& Steinbach, R. (2005). Toward a second generation of school leadership standards. In P. Hallinger (Ed.), Global trends in school leadership preparation. ([insert page \#s of chapter]). Netherlands: Swets \& Zeitlinger.

Leithwood, K., Begley, P. T., \& Cousins, J. B. (2005). Developing expert leadership for future schools. London: Routledge. 
Lett, J. (1990). Emics and etics: Notes on the epistemology of anthropology. In T. N. Headland, K. L. Pike, \& M. Harris (Eds.), Emics and etics: The insider/outsider debate. Frontiers of anthropology, 7. (pp. 127-142). Newbury Park, Calif: Sage Publications.

Linn, R. (2002). Accountability systems: Implications of requirements of the no child left behind act of 2001. Educational Researcher : A Publication of the American Educational Research Association., 31(6), 3.

http://doi.org/10.3102/0013189X031006003

Lincoln, Y. S., \& Guba, G. E. (1994). RSVP: We are pleased to accept your invitation. American Journal of Evaluation. 15(179), 179-192.

Linhares, T (2011). Recent history of Oregon's property tax system. Retrieved from http://www.lanecounty.org/departments/assessmentandtaxation/documents/recent _history_nov_2011.pdf

Loader, D. (2002). The inner principal. London:Routledge.

Louis, K. S., Leithwood, K., Wahlstrom, K., \& Anderson, S. (2010). Investigating the links to improved student learning: Final report of research findings. New York: The Wallace Foundation.

Lyons, N. \& LaBoskey, V.K. (2002). Narrative inquiry in practice: Advancing the knowledge of teaching. New York: Teachers College Press.

Marshall, C., \& Rossman, G. B. (2011). Designing qualitative research. Thousand Oaks, CA: Sage.

Mendels, Pamela (2012). The Effective Principal. Retrieved from 
http://www.wallacefoundation.org/knowledge-center/school-leadership/effectiveprincipal-leadership/Documents/The-Effective-Principal.pdf

Metlife. (2013). The Metlife survey of the American teacher: Challenges for school leadership. New York: Author. Retrieved from www.metlife.com/assets/cao/foundation/MetLife-Teacher-Survey-2012.pdf.

Moustakas, C. (1994). Phenomenological research methods. Thousand Oaks, CA: Sage.

Muhammad, A., \& Hollie, S. (2012). The will to lead and the skill to teach: transforming schools at every level. Bloomington, IN: Solution Tree.

Murray, T. (2013, Sept 18). Digital leadership for administrators. Retrieved from https://smartblogs.com/education/2013/09/18/digital-leadership-foradministrators/.

Myers, M. D., \& Newman, M. (2007). The qualitative interview in IS research: Examining the craft. Information and organization, 17(1), 2-26.

National Assessment of Educational Progress (NAEP). (2005). The Nation's Report Card. Washington, D.C: U.S. Department of Education.

Noguera, P. A. (2009). Crossing borders, breaking barriers: How teachers can transcend race, class and cultural differences to promote academic achievement and engagement for all. Ethnicity and Race In a Changing World, $1(2), 50-52$.

NPBEA. (2006). Updating educational leadership professional standards in a changing public education environment. Washington, DC: Council of the Chief State School Officers. 
Ollerenshaw, J. A., \& Creswell, J. W. (2002). Narrative research: A comparison of two restorying data analysis approaches. Qualitative Inquiry, 8(3), 329-347.

Oregon Department of Education. (2011). HB 3681 Frequently Asked Questions. (MEMORANDUM NO. 002-2011-12 -HB 3681). Retrieved from http://www.ode.state.or.us/.

Oregon Departement of Education. (2014). Oregon Framework for Teacher and Administrator Evaluation and Support Systems. Retrieved from http://www.ode.state.or.us/.

Patton, M. Q. (2002). Qualitative research and evaluation methods $\left(3^{\text {rd }}\right.$ ed.). Thousand Oaks, CA: Sage.

Petti, A. (2011). Seeking mutual benefit: University and districts partners in preparation. Paper presented at National Council for Professors of Educational Administration annual conference, 08/04/11. Portland, OR.

Pinnegar, S. \& Daynes, J. (2006). Locating narrative inquiry historically: Thematics in the turn to narrative. In D.J. Clanndinin (Ed.), Handbook of narrative inquiry. Thousand Oaks, CA: Sage.

Pitre, P., \& Smith, W. (2004). ISLLC standards and school leadership: Who's leading this band? Teachers College Record. Retrieved from www.tcrecord.org.

Polikoff, M. (2013). The waive of the future. School accountability in the waiver era. Educational Researcher: A Publication of the American Educational Research Association., 43(1), 45. http://doi.org/10.3102/0013189X13517137 
Polkinghorne, D. E. (2005). Language and meaning: Data collection in qualitative research. Journal of counseling psychology, 52(2), 137.

Portin, B., Schneider, P., DeArmond, M., \& Gundlach, L. (2003). Making sense of leading schools: A study of the school principalship. Retrieved from http://www.crpe.org/pubs/pdf/MakingSense_PortinWeb.pdf.

Porter, A. C., Murphy, J., Goldring, E., Elliott, S. N., Polikoff, M. S., \& May, H. (2008). Vanderbilt assessment of leadership in education: Technical manual, version 1.0. New York: The Wallace Foundation. Retrieved from www.wallacefoundation.org/knowledge-center/school-leadership/principalevaluation/Pages/Vanderbilt-Assessment-of-Leadership-in-Education-TechnicalManual-1.aspx.

Potter, W. J. (1996). An analysis of thinking and research about qualitative methods. London: Routledge.

Reardon, S. F. (2013). The widening income achievement gap. Educational Leadership, $70(8), 10$.

Rath, T. (2007). Strengths finder 2.0. Washington, DC: Gallup Press.

Reeves, D. B. (2006). The learning leader. Alexandria, Virginia: Association for Supervision and Curriculum Development.

Reynolds, C., Stevens, D. D., \& West, E. (2013). "I'm in a Professional School! Why Are You Making Me Do This?” A Cross-Disciplinary Study of the Use of Creative Classroom Projects on Student Learning. College Teaching, 61(2), 51-59.

Rossman, G. B., \& Wilson, B. L. (1994). Numbers and words revisited: Being 
shamelessly eclectic. Quality and Quantity, 28, 315-327.

Salem's Education Leaders On Teacher Layoffs. (n.d.). Retrieved (03/18/15) from http://www.wweek.com/portland/blog-26754salems_education_leaders_on_teacher_layoffs.html

Seidman, I. E. (1991). Interviewing as qualitative research. New York: Teachers College Press.

Senge, P. (1990). The fifth discipline: the art \& practice of the learning organization. New York: Currency Doubleday

Sfard, A. (1998). On two metaphors for learning and the dangers of choosing just one. Educational Researcher : A Publication of the American Educational Research Association., 27(2), 4. http://doi.org/10.3102/0013189X027002004

Singleton, G. E., \& Linton, C. (2006). Courageous Conversations. Thousand Oaks, CA: Corwin Press.

Spiers, J. A. (2008). Tech tips: Using video management/analysis technology in qualitative research. International Journal of Qualitative Methods, 3(1), 57-61.

Spooner, K. (2015). Leadership and Decision-Making Skills of High Poverty Elementary School Principals in an Era of Reduced Resources. (Unpublished Doctoral Dissertation). Portland State University, Portland, Oregon.

Sternberg, D. (2012). The principal: Traversing the high-wire with no net below- 79 places where the high-wire can be greasy. Pittsburgh, PA: Rose Dog Books. Kindle Version.

Stewart, D., \& Mickunas, A. (1990). Exploring phenomenology: A guide to the field and 
its related literature. Athens: Ohio University Press.

Strauss, A., \& Corbin, J. (1998). Basics of qualitative research: Grounded theory procedures and techniques ( $2^{\text {nd }}$ ed.). Thousand Oaks, CA: Sage.

Trotter, Y. D. (2006). Adult learning theories: Impacting professional development programs. Delta Kappa Gamma Bulletin, 72(2), 8.

Van Manen, M. (1990). Researching lived experience: Human science for an action sensitive pedagogy. Ontario, Canada: The University of Western Ontario.

Valley River School District (2013). Administrative Assessment and Evaluation Rubric. Walcott, H. F. (1973). The man in the principal's office: An ethnography. Walnut Creek, California: Altimira press.

Wallace Foundation (2013). Recent leader standards from six principal pipeline districts: 2013. Retrieved from_http://www.wallacefoundation.org/knowledgecenter/school-leadership/principal-training/Documents/Recent-LeaderStandards.pdf.

Waters, T., \& Grubb, S. (2004). The leadership we need: Using research to strengthen the use of standards for administrator preparation and licensure programs. Aurora, CO: McREL.

Waters, T., Marzano, R. J., \& McNulty, B. (2003). Balanced Leadership: What 30 Years of Research Tells Us about the Effect of Leadership on Student Achievement: A Working Paper. Aurora, CO: McREL.

Weber, S. (2008). Visual images in research. In J. G. Knowles \& A. L. Cole 
(Eds.), Handbook of the arts in qualitative research (pp. 41-51). Thousand Oaks, CA: Sage.

Wentz, P. (2000, May). The Ballot Measure That Ate Oregon. Willamette Week. Retrieved from http://wweek.com/__ALL_OLD_HTML/25-1990.html\#ballot.

Yin, R. K. (2009). Case study research: Design and methods. Retrieved from Amazon.com.

Young, M. D., \& Mawhinney, H. (Eds.). (2012). The research base supporting the ELCC standards. Charlottesville,VA: UCEA.

Young, S. (2013, February 5). Two types of growth. (Blog Entry). Retrieved from http://www.scotthyoung.com/blog/2013/02/05/two-types-of-growth.

Ysseldyke, J. (2001). Reflections on a research career: Generalization from 25 years of research on assessment. Exceptional Children, 67(3), 295.

Zeehandelaar, D., \& Northern, A. (2013). What Do Parents Want? Education Preferences and Trade-Offs. Retrieved from http://edex.s3-us-west2.amazonaws.com/publication/pdfs/20130827 What Parents Want In Education Preferences and Trade Offs FINAL.pdf. 


\section{Appendix A}

\section{Budget Summary 2008-14}

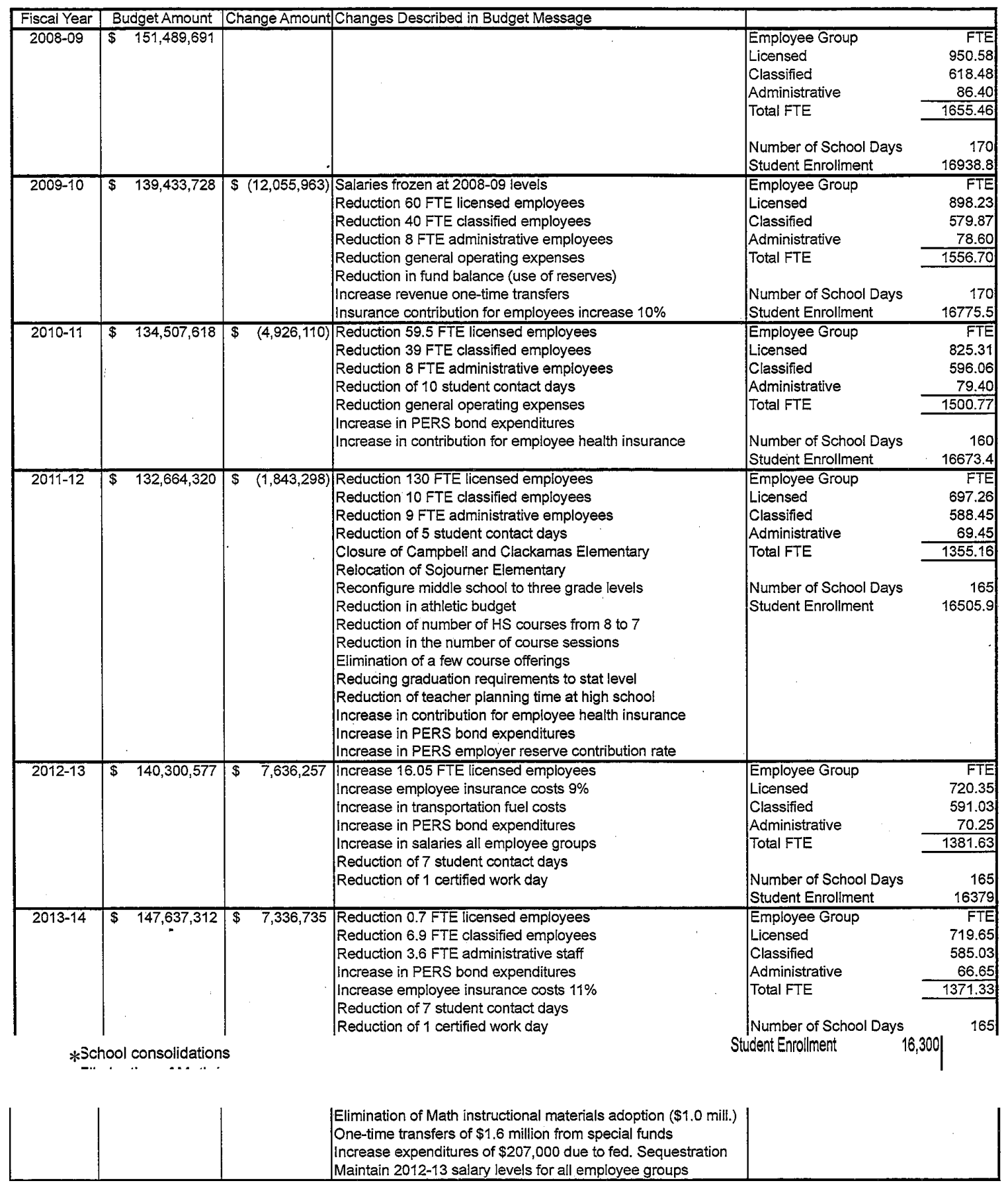


Staffing Summary from 2008-2014:

Licensed: $-24.4 \%$

Classified: $-5.6 \%$

Administrative: $-23 \%$

Total Staff Reduction: $-17.16 \%$

*School names and acronyms were removed from this item in order to

preserve confidentiality. 


\section{Appendix B}

\section{The Portland State University}

\section{Consent to Participate in Research}

\section{Leadership and Decision-Making Skills of High Poverty Elementary School Principals in an Era of Reduced Resources}

October 13,2014

\section{Introduction}

You are being asked to participate in a research study that is being done by Kevin Spooner who is the Principal Investigator from the Department of Educational Leadership at Portland State University in Portland, Oregon. This research is studying leadership and decision-making skills elementary principals of high poverty elementary schools employed when having to respond to decreasing resources and the need for increased student achievement during the time period extending from 2008-2014.

You are being asked to participate in this study because you are a retired elementary school principal with experience in high poverty (Title 1) elementary schools during the time period mentioned above.

This form will explain the research study, and will also explain the possible risks as well as the possible benefits to you. We encourage you to talk with your family and friends before you decide to take part in this research study. If you have any questions, please ask one of the study investigators.

\section{What will happen if I decide to participate?}

If you agree to participate, the following things will happen:

Your participation will include being interviewed one time for 30 minutes to an hour with the possibility of a follow up interview to clarify remarks. The interview will be audio- recorded and transcribed. The audio recording will be destroyed when the transcriptions are finished.

You may be vulnerable to someone's determining who you are and what you have said, but I will protect you from this possibility as much as possible by using pseudonyms for your name, the name of the school, and the name of the district. I will give you a hard copy of the transcript for each interview. You will be able to make any changes you want.

This study will be shared with the dissertation committee and other appropriate members of the Portland State community. The dissertation that results from this work will be published in hard copy and digital form which will be housed in the library at Portland State University. 
How long will I be in this study?

Participation in this study will take a total of 30 minutes to an hour with a potential follow- up interview to clarify remarks.

\section{What are the risks or side effects of being in this study?}

There are risks of stress, emotional distress, inconvenience and possible loss of privacy and confidentiality associated with participating in a research study.

You may be vulnerable to someone's determining who you are and what you have said, but I will protect you from this possibility as much as possible by using pseudonyms for your name, the name of the school, and the name of the district. I will give you a hard copy of the transcript for each interview. You will be able to make any changes you want. You have the right to withdraw from the study anytime you want up until March 1, 2015. At that point, I will be in the final stages of the writing process and will not be able to remove quotations from the document.

For more information about risks and discomforts, ask the investigator.

What are the benefits to being in this study?

Findings from the study will be used to help other principals who have been challenged by similar circumstances.

\section{How will my information be kept confidential?}

We will take measures to protect the security of all your personal information, but we cannot guarantee confidentiality of all study data. Pseudonyms will be used for your name, the name of the school, and the name of the district. I will give you a hard copy of the transcript for each interview. You will be able to make any changes you want.

Information contained in your study records is used by study staff. The Portland State University Institutional Review Board (IRB) that oversees human subject research and/or other entities may be permitted to access your records, and there may be times when we are required by law to share your information. It is the investigator's legal obligation to report child abuse, child neglect, elder abuse, harm to self or others or any life-threatening situation to the appropriate authorities, and; therefore, your confidentiality will not be maintained.

Your name will not be used in any published reports about this study. 
Will I be paid for taking part in this study?

\section{Can I stop being in the study once I begin?}

Your participation in this study is completely voluntary. You have the right to choose not to participate or to withdraw your participation at any point in this study without penalty or loss of benefits to which you are otherwise entitled.

\section{Whom can I call with questions or complaints about this study?}

If you have any questions, concerns or complaints at any time about the research study, Dr. Amy Petti or his/her associates will be glad to answer them at 503.680 .1623

If you need to contact someone after business hours or on weekends, please call 503 351-0857 and ask for Kevin Spooner.

\section{Whom can I call with questions about my rights as a research participant?}

If you have questions regarding your rights as a research participant, you may call the PSU Office for Research Integrity at (503) 725-2227 or 1(877) 480-4400. The ORI is the office that supports the PSU Institutional Review Board (IRB). The IRB is a group of people from PSU and the community who provide independent oversight of safety and ethical issues related to research involving human participants. For more information, you may also access the IRB website at https://sites.google.com/a/pdx.edu/research/integrity.

\section{CONSENT}

You are making a decision whether to participate in this study. Your signature below indicates that you have read the information provided (or the information was read to you). By signing this consent form, you are not waiving any of your legal rights as a research participant.

You have had an opportunity to ask questions and all questions have been answered to your satisfaction. By signing this consent form, you agree to participate in this study. A copy of this consent form will be provided to you.

Name of Adult Subject (print) Signature of Adult Subject Date

\section{INVESTIGATOR SIGNATURE}

This research study has been explained to the participant and all of his/her questions have been answered. The participant understands the information described in this consent form and freely consents to participate. 
Name of Investigator/ Research Team Member (type or print)

(Signature of Investigator/ Research Team Member) Date 


\section{Appendix C}

\section{Sets of Initial Codes}

\begin{tabular}{|c|c|}
\hline Codes & \\
\hline Accepting the hard reality of the situation & $\bullet$ \\
\hline Artifacts & $\bullet$ \\
\hline Banding together & - \\
\hline Being grateful for anything we get & $\bullet$ \\
\hline Being in a bargaining position & $\bullet$ \\
\hline Being matter of fact & $\bullet$ \\
\hline COSA & $\bullet$ \\
\hline CRAP. & $\bullet$ \\
\hline Casualties & $\bullet$ \\
\hline Change & $\bullet$ \\
\hline Coaches in title schools & $\bullet$ \\
\hline Concern that funds would be wasted & $\bullet$ \\
\hline Conditions in and outside of school & $\bullet$ \\
\hline Creative Captian & $\bullet$ \\
\hline Cutting staff & $\bullet$ \\
\hline Decisions & $\bullet$ \\
\hline Decisions to support teams & $\bullet$ \\
\hline Don't plan without the team involved & $\bullet$ \\
\hline ELD & $\bullet$ \\
\hline Faith in getting through & $\bullet$ \\
\hline Fear of losing job & $\bullet$ \\
\hline Feeding students & $\bullet$ \\
\hline Finding best practices & $\bullet$ \\
\hline Future & $\bullet$ \\
\hline Getting resources & $\bullet$ \\
\hline Having to do triage & $\bullet$ \\
\hline Having to share & $\bullet$ \\
\hline Highly organized & $\bullet$ \\
\hline Honesty & $\bullet$ \\
\hline Hope & $\bullet$ \\
\hline IAs & $\bullet$ \\
\hline Leadership for instruction & $\bullet$ \\
\hline Leadership skills & $\bullet$ \\
\hline Listening and learning about best practices & $\bullet$ \\
\hline Losing days of instruction & $\bullet$ \\
\hline Lost literacy experiences & $\bullet$ \\
\hline Measure 5 & $\bullet$ \\
\hline
\end{tabular}




\begin{tabular}{|c|c|}
\hline Metaphor & $\bullet$ \\
\hline Narratives & $\bullet$ \\
\hline No Child Left Behind & $\bullet$ \\
\hline PBIS s & $\bullet$ \\
\hline Priorities in decision making & $\bullet$ \\
\hline Problem solving & $\bullet$ \\
\hline RTI SWAT & $\bullet$ \\
\hline Reading First, & $\bullet$ \\
\hline SIP, & $\bullet$ \\
\hline SPED & $\bullet$ \\
\hline Safety & $\bullet$ \\
\hline $\begin{array}{l}\text { Saving energy rather than complaining about something we don't have } \\
\text { control over }\end{array}$ & $\bullet$ \\
\hline Saving resources & $\bullet$ \\
\hline Servant Leadership & $\bullet$ \\
\hline Setting up a system & $\bullet$ \\
\hline Shortfall & - \\
\hline Site Council- Not having faith in it? & $\bullet$ \\
\hline Situation/Place & $\bullet$ \\
\hline Skills & $\bullet$ \\
\hline $\begin{array}{l}\text { So there was somebody behind me to go back to other schools and say, } \\
\text { "We need more of your books. We know that you're not using them." } \\
\text { So there were people to help get what we need, and we were kind }\end{array}$ & $\bullet$ \\
\hline Social & $\bullet$ \\
\hline Spending tied to goals & - \\
\hline Supporting instruction in the classroom & $\bullet$ \\
\hline Survive & $\bullet$ \\
\hline Teams & $\bullet$ \\
\hline That's now how I want to die, what hill I want to be on. & $\bullet$ \\
\hline Thrive & $\bullet$ \\
\hline Values & $\bullet$ \\
\hline Working through obstacles & $\bullet$ \\
\hline balance literacy. & $\bullet$ \\
\hline bible & $\bullet$ \\
\hline bus & $\bullet$ \\
\hline common core & $\bullet$ \\
\hline control & $\bullet$ \\
\hline downturn & $\bullet$ \\
\hline equity & $\bullet$ \\
\hline flywheel & $\bullet$ \\
\hline focus school. & $\bullet$ \\
\hline get on the bus & $\bullet$ \\
\hline
\end{tabular}




\begin{tabular}{l} 
getting needs met \\
gnashing of teeth \\
in the same boat. \\
ladder, \\
lock and load, \\
loyal lieutenant. \\
mama bear" \\
my albatros \\
old boys \\
sharing resources \\
sky was falling. \\
\hline using good sense \\
white knuckle \\
who's on fire?
\end{tabular}

\section{Appendix D}




\section{Artifacts}

\section{A. These photos of artifacts were taken at the time of each participant's}

interview.

\section{Quotes accompany each photo.}

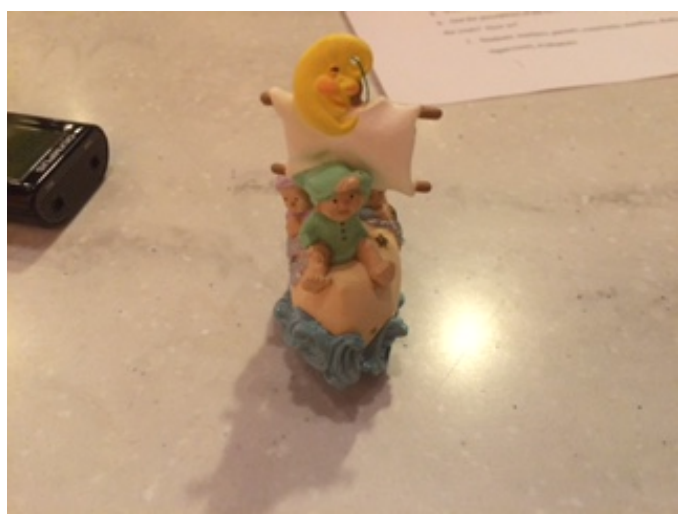

This is a -- it's an ornament. It's Winken, Blinken and Nod. And it's important because the person who gave it to me -- it was a parent, and it was in maybe my second year. And this was kind of all she had to give. She had -- and I'm not sure about the details of it but it ended up -- I think she was being abused by her husband, but the way it unfolded was that she hit him, he called the police, she was arrested, DHS got involved, she was taken away from the kids. She had no money; everything was in his name. And so I was helping her.

And it was one of those gut things -- it must have been my first or my second year, and it was just -- it was like --

I And this went on for a few months. It was later that she came in -- and she said, she goes, "This is one of my most treasured possessions." And she gave it to me.

B. Durham (personal communication December 18, 2014) 


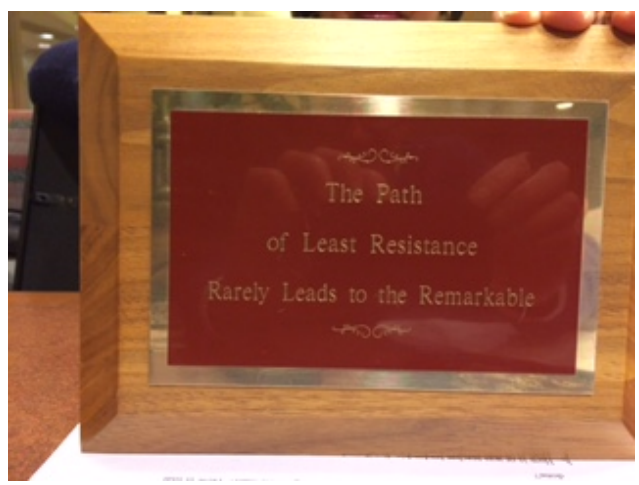

(The plaque says- The path of Least Resistance Rarely Leads to the Remarkable) I had this on my door when I - my first year of being a principal and I had a student teacher in my building that made this for me.

He was a second career person.

He had a very, very, very successful career.

He drove a Ferrari to school...

But it was my first year of being a principal and I was leading the staff through studying the idea of mixed age, multi-age grouping.

And it was hard and it was exciting but $\mathrm{I}-$ at the end of the year he gave this to me.

L. Smart (personal communication, January 21, 2015)

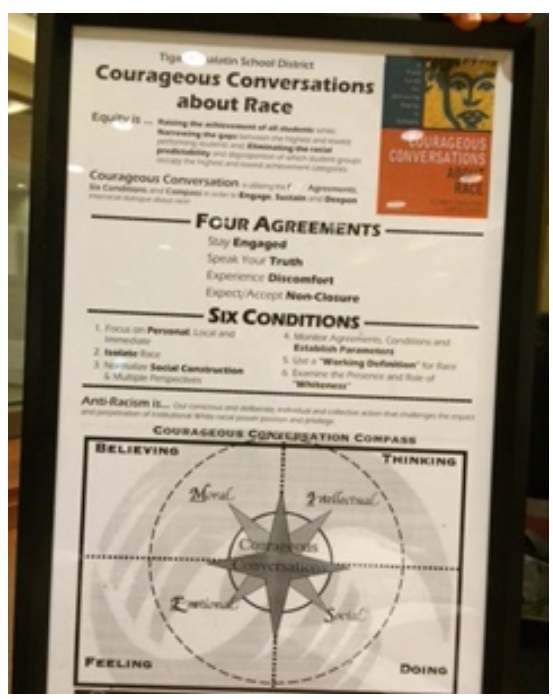

This is something I really use probably in the second half of my career and it's very there is a book called Courageous Conversations About Race. 
And I had this hanging by my phone and really tried to attend to these when I had conversations with parents.

L. Smart (personal communication, January 21, 2015)

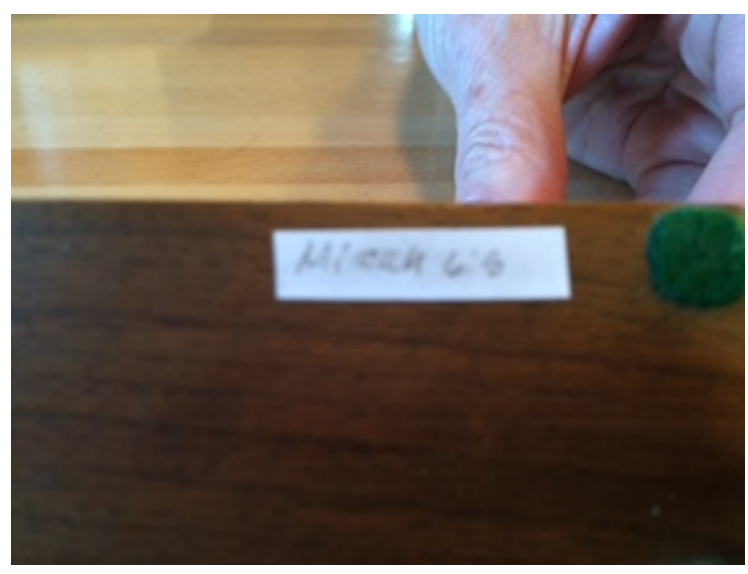

"Which is what is kind of my thing. I am no longer a religious person, but I try to be a spiritual person. This is actually from Micah 6:8. So people might recognize it, but they might not. But to me this was really the basis where I needed to come from with my work. This showed outside my window and this - the other side showed into my office sometimes. And sometimes I would put it the other way. I had it in my windowsill in my office."

Alicia Dart (personal communication, February 16, 2015)

\section{B. This artifact was contributed by Patricia Gross, one of the participants in the}

\section{study. Here is her quote that accompanies it:}

I did a presentation at a press conference one time and that was the theme of it. I was shocked how many people came. But what I found interesting, there's a lot of, lot of good science books written about what we already do, but there aren't as many that are written about the other side of it, and one of the most amazing speakers I ever heard - actually two of them - talked about that side of leadership. One was a Marine Corps colonel, retired. He teaches at Annapolis. He was an amazing speaker. I should send you his speech..... It's just, it's a great - it's called "What's Love Got to Do with It," and here's this guy who was a big-time Marine colonel really talking about leadership from the heart, and he is 
absolutely amazing.

P. Cross (personal communication, January 27, 2015)

THE VICE ADMIRAL JAMES B. STOCKDALE CENTER FOR ETHICAL

LEADERSHIP

UNITED STATES NAVAL ACADEMY • ANNAPOLIS, MARYLAND

Colonel Arthur J. Athens

Leadership: What's Love Got to Do With It?

1/C Capstone Seminar

sponsored by The Vice Admiral James B. Stockdale Center for Ethical Leadership

U.S. Naval Academy

Chesapeake/Severn Room

January 11, 2008

Colonel Arthur J. Athens, USMCR

Colonel Athens is the Naval Academy's first Distinguished Military Professor of

Leadership. He has a diverse background, spanning the military, higher education, and the non-profit sector.

Colonel Athens has also served as the Commandant of the U.S. Merchant Marine Academy; the Executive Director of OCF, a worldwide non-profit organization helping military personnel integrate their faith and profession; a White House Fellow under President Ronald Reagan; the Special Assistant to the National Aeronautics and Space Administration (NASA) Administrator following the Space 
Shuttle Challenger accident; and a U.S. Marine Corps Officer with more than 29 years of combined active duty and reserve service in significant command, staff, and instructional positions. In his current Marine Corps Reserve assignment as the Special Assistant to the President, Marine Corps University, Colonel Athens led the effort to establish the Marine Corps' General John A. Lejeune Leadership Institute. In 2005, while fulfilling his other professional responsibilities, Colonel Athens volunteered to coach the Northern High School boy's lacrosse team and led the team to their first regional championship and a third place finish in the Maryland state championships. The Washington Post selected him as their Coach of the Year. Colonel Athens holds a bachelor's degree in operations research from the Naval Academy where he lettered in lacrosse, served as the Brigade Commander (the senior ranking midshipman at the Academy), and received the Alumni Award for overall academic, athletic, and leadership achievement. He also earned masters' degrees from the Naval Postgraduate School, where he stood first in his graduating class, and the Army's School of Advanced Military Studies.

Colonel Athens currently serves as the Director of the Admiral James B. Stockdale Center for Ethical Leadership at the U.S. Naval Academy.

He is married to the former Mistina Root of Williamsburg, Virginia, and they have ten children.

Leadership: What's Love Got to Do With It?

Introduction

Lieutenant Nick Rogers, USN 


\section{Lecture}

Colonel Arthur J. Athens

The 1/C Capstone Seminar program is supported through the generosity of the family of John R. Elliott.

This is an edited, abridged version of the original lecture transcript.

\section{Introduction}

\section{Lieutenant Rogers}

I have the distinct honor and privilege of introducing our guest speaker today. Colonel Athens is the Naval Academy's first distinguished military professor of leadership. He has a diverse background that spans the military, higher education, and the nonprofit sector. Colonel Athens has served as the Commandant of the U.S. Merchant Marine Academy and as the Executive Director of OCF, which is a worldwide, nonprofit organization that helps military personnel integrate faith in their profession. He has also been a White House fellow. He has served the United States Marine Corps for more than 28 years of combined active duty and reserve service, in significant command staff and instructional positions.

His current Marine Corps Reserve billet is Special Assistant to the President, Marine Corps University. He also serves as the director of the Stockdale Center for Ethical Leadership here at the Naval Academy.

In 2005, Colonel Athens volunteered to coach the Northern High School boys' lacrosse team and led the team to their first regional championship and third-place finish in the 
Maryland State championships. The Washington Post gave him the newspaper's Coach of the Year award.

Colonel Athens holds a bachelor's degree in operations research from the Naval Academy, where he lettered in lacrosse and received the Alumni Award. He has masters' degrees from both the Naval Postgraduate School and the Army School of Advanced Military Studies.

He is married to the former Mistina Root of Williamsburg, Virginia, and they have 10 children.

1

Lecture

\section{Colonel Athens}

That doesn't worry you, does it, that I have 10 children? Are you wondering, "Man, what is wrong with this guy?" Just in case there are a couple of questions rolling through your mind, yes, they're all mine. They're all with the same wife, and yes, we know how it happens.

\section{(Laughter)}

We drive a 15-passenger van. Unfortunately, it's white, so it looks just like a GSA vehicle, one right out of the motor pool. My children continue to remind me, "Dad, if we have to have one of these huge cars, couldn't we at least get something that has color to it?" But the cheap ones are the big white ones that you can get used. As a matter of fact, when I was Commandant up at Kings Point, which is in a fairly wealthy area of New York, and one of our sons was a high school student, the school's parking was filled with 
BMWs, Jaguars, and Land Rovers. Every once in a while, Arthur would drive his 15passenger van, and the thing that always amazed him was all the kids saying, "Look at that! Can we drive your 15-passenger van?” And he's thinking to himself, "How stupid. I want to drive your BMW - that's what I want to drive." He actually used the van at one of the proms there. They put up a disco ball inside and had it spinning. It was pretty cool. That son of mine, Arthur, just got married on the 29th of December, so it was a pretty big, exciting holiday time for us. We just picked him up from Dulles Airport on Wednesday night from his honeymoon, and then he got on a plane at BWI to fly back to his duty station in Germany. He is actually an Army first lieutenant now, a combat engineer. Let me tell you something about him, because it ties with what we will focus on today. Arthur went to James Madison University over in Harrisonburg, Virginia. He actually went there to play football, and I think probably after his second season there, even though he had done pretty well, he thought to himself: "I'm probably not going to the NFL, so maybe I need to think about what's next in my life." He ended up getting an Army ROTC scholarship. He graduated from JMU in May 2006, and he had five days off before he went to Fort Leonard Wood, Missouri. It's a combat engineer school for the Army. Then he went to Airborne School down in Fort Benning and then right to Schweinfurt, Germany, where his duty station is, to join the 9th Engineer Battalion, but they were already deployed to Iraq. So he dropped his personal goods and found himself by December — six months after he had graduated — in Ramadi, Iraq, leading a platoon. Before going to Germany, he anticipated what would happen, and he sat down with me. "Hey, Dad," he said, "We have talked a lot about leadership over the years, but could you 
give me a quick summary before I go do this for real?"

2

That's a tough thing to do, not just as someone who thinks a lot about leadership. How do you summarize it in just a quick discussion? It was also tough because he is my son, and I wanted to say the right thing for his benefit before he would lead soldiers in combat. So I had a flashback to when I became a platoon commander out of the Naval Academy, and a mentor of mine, Lt. Col. Tom Hemingway, sat down with me after I graduated. "I'd like to tell you a story about leadership," he said, "that I'd like you to remember as you go out and lead Marines." This is Tom Hemingway's story.

He was a Citadel grad, and he came into the Marine Corps in the late 1950s. He graduates from Citadel, goes to the basic school, and then from there, shows up at his first infantry platoon. He hears about his platoon sergeant, who is a gunnery sergeant. That gunnery sergeant had served in the Pacific Theater in World War II, landing in places like Guadalcanal and Iwo Jima — just some of those minor skirmishes that occurred in World War II. This particular individual had been promoted to an officer rank. They had lost a lot of officers on the beaches, and they were promoting folks, but after the war ended, he was reverted back to enlisted rank. Then Korea comes, and he fights in places like Incheon and Chosin Reservoir. He gets another battlefield commission, and then reverts back to enlisted rank. Now he is a gunnery sergeant, and my friend Tom is about to take command of this platoon.

So Tom was humble enough and smart enough to go in and see this gunnery sergeant, and they were both standing up. Tom says, "Gunny, look, you know my background, and 
I know yours. I don't understand how I'm supposed to lead you and some of these other Marines with all their experience, for us to be successful."

The gunny looked Tom Hemingway in the eye and said, "Lieutenant, sit down."

Of course, that was a polite way for a senior enlisted person to tell a lieutenant: "I have something to tell you, and you need to listen."

The gunnery sergeant said to Tom, "Lieutenant, there are only three questions that I'm going to be asking about you, and your Marines are going to be asking about you. First question they're going to ask is: do you know your job, or are you striving real hard to learn it? We know you don't know everything, but we're going to be watching to see if you're paying attention, whether you're asking the right questions, whether you're humble enough to find out how to do your job really, really well. Second question we're going to ask is: are you going to make the hard but right decision even if it costs you personally? And the last question we're going to ask is: do you care as much about me as you care about yourself?

Now, as Tom thought about those three questions, in his own mind he said, "The three C's: competence, courage, and compassion." That's the story Tom Hemingway told me when I was a brand-new second lieutenant in the Marine Corps. When my son got ready 3

to go to Iraq, that's the story I told him. When he sent back one of his early pictures from Ramadi, with his little hooch where he was hanging out, he had the three C's posted on his board. He might have just put those up and taken a picture to send to his dad, but no, he really had them up there, and it really did help direct his thinking about leadership 
while he was in Iraq. Competence, courage, compassion.

I have spent a lot of my life leading, developing leaders, thinking and studying about leadership, and our tendency is to focus quite a bit on competence and courage. I think a lot of what the Naval Academy is about has to do with developing your competence and addressing this area of character and courage. I am not so sure we stop and think enough about the third C: compassion. Do you care as much about them as you care about yourself? That's what I'd like to turn to.

If I could take you back to 1984 , there was a billboard top hit that year. The person who sang the song actually won the Grammy award in 1984. The name of the song was “What's Love Got to Do With It?" Anybody know who the artist was for that one?

Participant

Tina Turner.

\section{Colonel Athens}

Tina Turner, right. That song took her to the top then, and I've thought about that title. I've thought that if we took the word "leadership" and the word "love" and brought them together, I wonder if we wouldn't ask the same question: "What's love got to do with it?" Now I'd do my Tina Turner imitation for you this morning, but it's a little early, and I don't want to overdo it. If she were here singing, here's what the refrain of that song would sound like:

What's love got to do, got to do with it? What's love but a secondhand emotion? What's love got to do, got to do with it? Who needs a heart when a heart can be broken? She would challenge us to say what love has to do with this relational piece. If we 
actually stepped back and thought about it, we would say, "Yeah, well- what does love have to do with leadership?" And I'm going to tell you I think it has everything to do with it. I'm going to tell you that I don't think you can be an extraordinary leader unless you love your people sincerely. Let me repeat that. I don't think you can be an extraordinary leader unless you love your people sincerely.

Now history shows us that you can win battles, you can accomplish the mission, you can make money, you can build buildings, and you can win games without loving your people, because a lot of people have done it that way. But I am convinced that you and your organization, your unit, your group will never be extraordinary in the long run without that kind of genuine concern for your people.

4

So what is this connection between leadership and love? Is it real? Let me tell you just a couple of stories. Let me take you back now to 1918, even further back than Tina Turner. General John Lejeune - you might have heard his name. His statue is out there in front of Lejeune Hall. For Marines, he is the epitome of leadership. When we had to name a leadership institute in the Marine Corps, we named it the Lejeune Leadership Institute. In his autobiography, Lejeune told a story about when he was the second division commander in World War I. He had both Army and Marine units under him, and they were fighting at the very end of the war, in November 1918. The war was drawing to a close, and if you remember your history, the armistice was actually signed in November of 1918. The battle ends in France on that November 1918, and the next day after the armistice is signed, Lejeune is visiting one of his division field hospitals. He's walking 
through the hospital and happens to see this one particular Marine who has an amputated leg, and he decides he is going to ask what happened.

So Lejeune walks up to that Marine and says, "Sergeant, tell me about it. Tell me what occurred."

"Yesterday," the sergeant said (yesterday being the day the war ended) "I was crossing a bridge on the Meuse River with a mission. There was heavy mortar fire. There was smallarms fire, and the shrapnel seriously injured my leg. They decided they needed to amputate it to save my life."

Lejeune said, "Sergeant, did you know that the war was about to end when you went across that bridge?"

"Sir," the sergeant said, "That was common knowledge amongst the troops. Everybody knew it was just about over."

Then Lejeune looked at the sergeant and said, "So what induced you to go across that bridge, knowing that it was almost just about over, that the fighting was going to be done?"

The sergeant said, "Sir, Our battalion commander Capt. Dunbeck gathered us on the friendly side of the Meuse River, and he said to us, 'I've received a mission, and I'm going across that bridge, and I expect you to come with me."” With slight tears in his eyes, the sergeant looked at Lejeune. "Sir, what could we have done? We certainly weren't going to let him go across that bridge by himself. We loved him too much for that."

Lejeune in his book then writes: "I have always felt that the incident I have just narrated 
gives one a better understanding of the meaning and practice of leadership than do all the books that have been written and all the speeches that have been made on the subject." When I read that in Lejeune's book, it really struck me. All the leadership books, all the speeches that have been made — and Lejeune believes that little snapshot of the love 5

between a Marine commander and his Marines represents leadership better than anything else?

On my Marine Corps Reserve side, I was involved with the establishment of the Lejeune Leadership Institute, so I read all the things that Lejeune wrote, not just his autobiography, but all his speeches and all his correspondence in the archives down at Quantico. The thing that struck me about Lejeune was how often he used the words "affection" and "love." I would have never expected it, but it was constantly in his communication while he was a Marine and after he retired from the Marine Corps. Let me tell you another story. Between 1974 and 1983, there was a young man by the name of Jeffrey Marx. He was the ball boy for the Baltimore Colts. As you probably know, they left Baltimore and are now in Indianapolis. Jeffrey Marx eventually became a journalist, and he decided to write a book about the Baltimore Colts when he was the ball boy and find out what they did after they left professional football.

So Marx got the old roster, and he decided to call them one at a time, interview them, take notes, and write the book. The first guy he calls is Joe Ehrmann, who used to be a lineman, all pro, for the Baltimore Colts. He called Ehrmann and said, "Hey, do you remember me, Jeffrey Marx? I used to be the ball boy." 
Oh, yeah," said Ehrmann. "We used to call you 'Brillo,' didn't we, because you had that curly black hair?"

"That's me."

“Okay. Hey, what do you need?”

"Well, I'm writing this book," said Marx, "and I want to find out what you did after you left professional football."

"I'd love to tell you about that," said Ehrmann. "I had kind of a strange transition out of pro football, because when I left, my brother died of cancer. It really affected me, and so I ended up going to seminary. I started a church in Baltimore, and I worked with primarily young men. But let me tell you what I really like doing. I'm the assistant football coach for Gilman High School outside of Baltimore. That's where my real passion is. As a matter of fact, Jeffrey, why don't you come to one of our practices and see what goes on there? It's pretty unique."

Marx was curious. He's a journalist. He showed up at Gilman High School for the practice. Joe Ehrmann has the team gathered around him before the practice starts. He asks the football team: "What's our job as coaches?"

All the players in unison reply, "To love us."

Then he asks, "What's your job as players?"

6

And all the players shout out in unison, "To love each other."

Okay, I've been around athletics a long time. I've coached at a lot of different levels. I've assisted teams, collegiate level, even. I hate to admit it, but I even worked with the New 
York Jets, not as a player, but to assist them in some other areas. I'm not sure I did very well as I look at their record, but I'm going to tell you that's not sort of the standard way that people start practices. I don't care what your sport is.

Marx was fascinated by this. He changed the direction of his book. Rather than writing about all the Baltimore Colts, he decided to focus on Joe Ehrmann and this Gilman football team. Gilman has won seven out of the last nine Maryland Independent Athletic Association Division-A football titles. Often they're ranked in the top 25 of USA Today's top high school football teams. This is not a pushover team.

One of my sons, who is a junior, just transferred to St. Mary's of Annapolis this year, and he's the quarterback for St. Mary's. They played Gilman, and I can tell you they're not pushovers. This is a team that plays hard, works hard, but there is a bond of love there. Jeffrey Marx came here about two years ago, and I had a chance to chat with him. I asked if he ever went back to see what happened afterward.

"I've been back there plenty of times," he said. "It's real. One time I watched when Gilman lost to McDonough, which is one of their chief rivals, and in the end zone at the end of the game, the coaches were there. All the players on the team were there except for two guys that were separate from the team, a captain and one of their star players. They had just lost probably the biggest game of the year, and those two guys were crying. So one of the coaches looked at the team and those two guys, and he said, 'Look at those two players over there."”

Now, most coaches would then say, "Look at those wimps. Hey, you two wimps, get over here with the rest of the team." That's not these coaches said. 
They said to the team, “They are our family. They're hurting. We need to go over there and encourage them, because we're a team."

Pretty incredible stuff. I watched this football team come out on the field. I watched how they worked with each other, how they cared for each other, and how they were winners. Let me tell you another leadership love connection story. It's about me when I coached this high school team. In 2005, two of my sons played on the Northern High School lacrosse team down in southern Maryland. Two weeks before the season starts, the head coach transfers. The assistant coach disappears, and another assistant coach gets pretty sick, so they have no coaching staff. The season is about to begin, so the principal and 7

the athletic director come to me, knowing my lacrosse background, and say, "Hey, how would you like to take the team this year?"

I said, "Well, you know, I have a couple things going on at the Naval Academy. I'm a Marine Corps Reserve guy. I have a big family. I can't really fit in being a voluntary head coach of a high school varsity team."

So I go home, and I tell my good old wife.

"Gosh," she says, "that sounds like a wonderful opportunity. Are you sure you don't want to do that? You would be with your sons, and we'll all pitch in."

As a matter of fact, the Washington Post did a feature story on us that year, because our oldest daughter is a physician assistant, so she was like the team doctor, and then our next son was Arthur, who was going to school at James Madison. He was a communications major, so he would come over to announce the games when he could break away from 
school. Our next two sons were playing. The next one warmed up the goalies all the time. The next one was the statistician. Then we had two water boys, a water girl, and a cheerleader, all in the family. We had the whole thing. (Laughter)

But I couldn't picture that at first. My wife could though, so she said, "I think this is fantastic.”

So I go back to the principal and say, "Okay, I guess I'm going to take this team." Three days before the season begins, I become the head coach of this team on a voluntary basis. I had to rush down from the Naval Academy for practice and all this kind of stuff. It's about 50 minutes south of here.

The first thing I did was interview all the seniors and ask them about their future plans. What do you think your strengths and weaknesses are as a lacrosse player? How can I help you? Blah, blah, blah. So I'm going through each of the seniors one at a time, in about 15-minute interviews, and Houston shows up. Now, when Houston walks in, the easiest way to describe him is to say he is not exactly dressed like I am today or you either. Very, very different. Really, really baggy shorts. I mean, really baggy shorts, with a T-shirt that probably had, as I remember, some kind of derogatory comment about life on it. He had earrings all the way up his ears, across his eyebrows, and in his nose. Now is there any problem? No, I can get over that stuff. But my initial reaction was, "Wow, I have nothing in common with this guy." I'm not sure how we are going to get along. It got worse, because Houston, before I said anything, asked, "Hey, Coach, do you remember me from last year?" 
"Well, Houston," I said. "I didn't coach last year."

"Oh, no, I know," he said. "But you came to all the games. You were up in the stands one time when we had that big fight with Patuxent High School, and you actually came out of the stands, and I was like pummeling this guy, and you dragged me off."

"I guess I do remember you, Houston."

I'm thinking to myself about how I help people with how to prepare for interviews at different types of venues. That's normally not how I suggest you meet your new boss, but to Houston, that made no difference. At that moment in time, I realized that I needed to love that young man. He was part of the team. I was the leader, and it was not going to be natural for me. It wasn't going to be easy for me, but I needed to love him.

The next day, before the season actually begins, before our first practice, I ran into the principal of the high school, who said, "Oh, by the way, I forgot to mention there is one guy who is going to be on your team, his name is Houston, and the guy is a bum. I would kick him off the team right now."

"Well," I said, "I need to give him a chance."

He said, "No, no. The guy is terrible. He'll miss practice. You just watch."

Okay, so Houston is showing up for practice, not only showing up for practice, but is trying really hard. He's not a great lacrosse player, but I am investing myself in this guy, because I want him to know that I really do care about him.

Then one day, Houston doesn't show up for practice. It's interesting how human nature works. My first reaction was: maybe the principal is right. I left the practice field, and 
there was Houston standing by the locker room.

By the way, this is always a good lesson: rather than flaming on someone right away, it's always good to ask a question first.

So I didn't say, “Where the heck were you, Houston? You know my policies.” No, I didn't say that. I said, "Houston, you doing all right?"

“Coach, could I talk to you for a minute privately?” he asked.

I said sure. So we go off to the side, and Houston said, "Coach, you've gotten to know me. I just want to swear to you that there were no drugs involved, no alcohol, but I was driving my car, and I was driving really fast, and I was driving so fast that when I touched my CD player to change the CD, I looked up, and I realized I was heading right through a red light, and I hit a car at an intersection."

9

While I was taking this in, Houston said, "Coach, I killed the driver in the other car. I don't know what to do."

So you're the leader-what do you say? I'm convinced that, if you already love that person, you are in a much better position to figure out what to say. Basically, I told Houston, "I don't know how this will turn out, but I can tell you this. I'm going to walk beside you as we do this, however it turns out." This was a hurting young man. As the season went on, and other legal things occurred as well, he then broke his collar bone in a game. He was absolutely dejected, because lacrosse was beginning to be the centerpiece of his life. It was a refuge for him. Old Houston would come to practice every day with his broken collarbone. He didn't have to practice. He would do whatever he 
could, but every day, he would come to practice and say, "Coach, I bet I'm going to be good in about two days."

I knew how long it would take to heal a collarbone. He wasn't going to be ready in a couple days, and I kept telling him, "Houston, you have to be patient with this."

Well, all of a sudden, unexpectedly, this team that had never won much of anything wins a regional championship. We go into the state playoffs, and Houston is just chomping at the bit to play. Now I have my daughter involved as the physician's assistant, and I'm saying, "Christina, you have to let me know when I can pull the trigger with this guy, because I need to get him in if I can.” It's the state semifinals, and I don't need Houston in there. As a matter of fact, part of me is saying he may even be a detriment if he goes in, but I knew that young man had to get into that game. Christina said he was going to be okay.

Houston goes into the game. He doesn't do much of anything, but I know to this day, because I have run into him a number of times, that it was probably the highlight of his life to play in a state playoff game as a high school player. I don't think I would have figured out how to walk with Houston through his situation. I wouldn't have put Houston in the state semifinal if I hadn't learned to love him as his leader early on.

So what really is this connection between leadership and love? Why is it so important? What I have learned is, people want to feel special and valuable, every single person. Every single member of your platoon or division or section or whatever it is who's standing in front of you, they want to feel special and valuable. I celebrate birthdays when I am in a leadership position. When I am in class, I get the 
roster so I know when people's birthdays are, and then I plot it into my calendar. When a birthday comes up, I buy the person just a little book, some cheap thing, and then we sing "Happy Birthday" in class, and I present the gift. It's almost a little corny, but you know what, the person who is on the receiving end thinks it's pretty darn special. Even the ones that say, "I don't care if anybody knows my birthday or not"-I'm not so sure they don't care. I find that people like to be recognized on their birthday, because it's a special day to say someone is valuable. I make the effort to figure out when it is and 10

recognize the person in some way, even if it's just shaking his or her hand and saying happy birthday.

When I was at the Army-Navy game this past fall, I was trying to get to my seat, and Admiral Mullen, who is the Chairman of the Joint Chiefs of Staff, also happened to be walking. Out of the corner of my eye, I saw him stop and walk over to me with this huge entourage behind him. Admiral Mullen comes over and says, “Art, how are you doing? How is that new position and everything? How is Misti?"

Now, how does Admiral Mullen know any of that? Well, when Admiral Mullen was a lieutenant, he was the executive assistant to the Commandant when I was a midshipman. I happened to serve as the brigade commander, and so I would interact with Lt. Mullen every day, but I hadn't seen him in years. He knew Misti because I was dating her at the time. The Chairman of the Joint Chiefs of Staff stops to come over and say hello to me? Does that change how someone looks to you? Absolutely. And that's how your people are looking to you to see if you are communicating in some way that you and you and 
you and you are special and valuable.

The second thing I've noticed is that people like to receive feedback in an atmosphere of genuine concern. All of you have experienced this. You know, I could bet my life- -I'd bet my 15-passenger van on this one- that you have been given feedback by someone who you are convinced couldn't care less about you. Your reaction to that feedback is what? Okay, great. Yeah, right. Because we want to get feedback from people we think care about us, and one of the most important things leaders do is provide feedback to people, both good and bad. You have to give feedback to folks. They have to know how they're doing. If you give that feedback, and they're convinced you don't really care, then they're not going to listen to your feedback. They're most likely not going to take action on it either, which is what you're hoping to see happen.

Once, I had a Marine, who at the time was a major, and I was a lieutenant colonel. He was an AV-8 Harrier pilot, and he was a pretty good officer, but he was really, really arrogant. I knew that I needed to sit down with this guy and tell him, "You're a really good marine officer, but you're too full of yourself, and it's hurting you." Now, try telling an arrogant person he's arrogant. You find out that's a really tough mission. I called Bob in. I said some good things about him, because they were all true, and then I said, "But Bob, let me confront you with something. I think you're kind of arrogant, and I think that arrogance is hurting you, not only just as a professional officer but as a person."

I gave him some ideas of about how he could change that. Man, he was angry. Now he was respectfully angry just because I was of a higher rank, but he was mad, and he was 
mad for about a year.

(Laughter) 11

But after a year, he came to me and said, "You know what, you were right about me. I know you have noticed I've made some changes."

I said that I had.

"Let me tell you," he said, "the only reason I made those changes is that I thought you really did care about me. It wasn't about making the office better. It wasn't about you becoming Commandant. You cared about me enough to tell me this thing that was a problem, and that's why I took action on it."

I think people want to feel special and valuable, and love enables us to make them feel that way. We want to receive feedback in an environment of genuine concern. I also think people want to know they have a leader they can come to when they're hurting. You are going to have people who work for you with a lot going on below the surface. Some of it you will never find out. But some of it every once in a while percolates to the top. When I was Commandant at Kings Point, a midshipman made an appointment and came in to see me. We were chatting, and then I say, "So how is everything going?" He said, "Sir, to be honest, not very good. My father was murdered last night." Now I have had people come and say: my father has cancer, or my father died, but not this. His father had been murdered, in a gang-style type of murder, in New York City. We talked about it for a long time, and then he said as he left: "Sir, would you be willing to come to my dad's memorial service in a couple of days?" "Sure," I said, "I'd be honored." 
A few days later, my wife and I went to the Merchant Marine Academy Chapel for a 1900 service. I'm looking around, and I don't see anybody who looks officially religious. I knew all the chaplains. They weren't there. It's just starting to make me think.

About two minutes before the service was to start, this young midshipman came up to me and said, "Sir, whenever you're ready to start."

"What do you mean start?"

"Do the memorial service," he said.

I didn't want to say, “What are you talking about?” I just started a memorial service for a person I had never even met. Why did that young midshipman come and see me? Why did that young midshipman in his own mind trust that I was going to do his father's memorial service in this chapel at the Merchant Marine Academy? He was convinced I cared.

12

A sergeant major worked for me one time, who was the poster Marine physically. I mean, he was unbelievable. Never saw an emotion out of the guy. It always reminds me of the movie We Were Soldiers Once, where the sergeant major has no emotion. An enlisted man always walks by the sergeant major, hoping the sergeant major will cheer up a little bit.

He always says, "Good morning, Sergeant Major."

“What's so good about it?" the sergeant major replies.

That was my sergeant major until one day when he asked to see me. He closed the door and just broke down, sobbing, because he had found out his mother had been diagnosed 
with cancer, and his mother was the center of his life. People need to know they have a leader they can approach, and they're only going to feel that if they sense that you love them.

Does that mean you bring the platoon around, all hold hands, and sing "Kumbaya"? Is that what I'm talking about? No, I'm not talking about that. I'm talking about real love, because if you ask the people that were on my lacrosse team, or the people that I led in the nonprofit organization, or my Marine Corps units, they are going to tell you we worked hard. We had a vision of where we were going.

I think about that movie Miracle, where the coach, after the exhibition game, says, "Again, again, again, until you get it right." You can ask my lacrosse team about the hills that are near our field. I knew one thing — our team was never going to be outrun by any other team. The only way you get there is by working really, really hard. It also doesn't mean you have an undisciplined mob. It also doesn't mean that you don't confront people. Sometimes, love also means saying, "You're gone. This isn't going to work out." But it all starts with an atmosphere of love.

So how do you do this? Okay, love, yeah, I think I know what that is. I'm not so sure we do sometimes in the leadership context, but I will tell you, it comes down to just one word more. When it comes down to leadership and love, that word is "sacrifice." If we are going to love our people, it's going to cost us. It's going to cost us to sacrifice for our people.

Lance Corporal Madsen was one of my Marines in my first platoon, and he was a terrible Marine. Looked terrible, didn't know his job. It was a disaster. I was at Marine Corps 
Station Yuma, Arizona at the time. Phoenix is about three hours away. Madsen called me up on a Sunday night at 2200, and Madsen always talked really fast. I think he was hoping that he could deny whatever someone said that he said, because it was hard to follow him, he talked so fast.

So he's on the phone, saying, "I'm at the bus terminal, and I don't have enough money to get back, so I know I can't be back for formation, and I know we have a deployment, so I just want to make sure you don't run me UA."

13

“Okay, wait a minute, Lance Corporal, man," I said. "Let me get this straight. You talked to your squad leader, couldn't get a hold of him. You tried the platoon sergeant, so you talked to me. Okay, that's good. Now where are you?" "Well, sir, at the bus terminal up in Phoenix."

I'm not sure he really was at the time, but he got there eventually.

So I said, "You are not going to be back for our movement tomorrow, and you don't want me to run you UA? Well, you are going to be UA. It's not my fault you don't have the money to get back."

He went into this big, long story about why he didn't have money. He flew in from leave, and all this kind of stuff.

There was something that clicked inside of me that said, "This is a Marine I need to demonstrate my love for." So I said, "Hey, Madsen, you said you were at the bus terminal, right?"

"Yes, sir." 
"Okay, I'm going to drive there and pick you up and bring you back so that you are on time for your formation on Monday."

Now there was a big silence. That's why I thought he maybe really wasn't at the bus terminal. He might have been somewhere else, but in three hours, no matter where you are in Phoenix, you can probably find your way to the bus terminal.

So I get in my car, and I drive the three hours, pick Madsen up, and drive the three hours back. I get to know Madsen pretty well in the three hours in the car. By the way, I didn't go pick up Marines all the time. There were just certain times where I realized I had to sacrifice so they knew that I really did care about them. What I learned from driving with Lance Corporal Madsen was that he didn't have anybody in his life who would go ten minutes out of the way to pick him up, let alone three hours. He had never had anybody care about him.

So what happened to Madsen after he got back? He became a model Marine. He would do anything, anything that needed to be done, because one person said, "You know what, I need to demonstrate love.”

That love meant sacrifice. That drive took a lot out of me when we were getting ready to go on a deployment. So it takes sacrifice.

I love a story that Lou Holtz tells. Lou Holtz coached at Notre Dame, coached at South Carolina, coached at Windermere, but he is probably most famous for Notre Dame. By 14

the way, if any of you ever get a job, and you say, "I have a really hard job," think about the Notre Dame football coach and how much pressure that person is under. 
Anyway, Holtz is in his first season, and he has four wins and five losses, and he is thinking to himself: "I have to win this last game. We have to win this last game, because if I come out 500 my first season, the alumni will probably be off my back."

They are playing USC and losing by four points. It's late in the fourth quarter. USC has their ball in their own territory pretty deep, and it's fourth down, and Holtz is thinking to himself: "This is great. They're going to punt. Even if it's a good punt, we are going to be in good field position. The momentum is in our direction. We can win this game. I can be five and five. I might even have a pretty decent summer. This will be all right." The punting team comes out from Notre Dame. USC gets ready to punt. Lou Holtz had a son on that team. His name was Skip Holtz. Skip was on the punt return team, so as Lou Holtz describes the story, he says, "I'm down on my knees with my hands on my knees, and I'm looking at the punt, and it goes off, and I'm thinking, 'Wow, that's a terrible punt.' I mean, it's flopping all over the place, that's great." He looks out of the corner of his eye and sees a yellow penalty flag. He immediately looks over to where the punter was, and there is his son, Skip Holtz, sprawled out on top of the punter. The referee is signaling a roughing-the-punter call, which means USC will get a first down. It will be their ball, and they will continue on.

Lou Holtz continues with, "As my wife's son comes off the field-" (Laughter)

"All I could think about was strangling him and picking him physically up and throwing him into the bench." Fortunately, he remembered what someone had once said to him: sometimes the people who need love the most deserve it the least. So as Skip Holtz came 
off the field, Lou Holtz gave him a quick hug and said, "It's going to be okay," and Skip went to the sideline.

Notre Dame came back and won that game, and Lou Holtz got his five and five season in a miraculous turnaround, but he says, "You know, the reason I think we won that game is that every player on Notre Dame was watching me to see how I would react to what just happened, and because I reacted the way that I did, I think they were convinced that my love for each of them was unconditional. They could play with that kind of freedom." Lou Holtz went on to have many, many successful seasons there at Notre Dame. As a matter of fact, when I was a midshipman here, there was a guy named Josh McDowell who was speaking at different college institutions, and his theme was maximum sex. That was the title of his presentation, and when I was here as a plebe, which is when he came, it was still an all-male institution. You can imagine the big posters all around the Naval Academy, with big black letters, reading: "Maximum Sex." Very small letters explained that the presentation was about true love. You normally had 15

maybe 50 people or so in Mitchell Auditorium for events like these, but that night, it was packed.

(Laughter)

Just standing room along the walls and spill out into the open area beyond that. I'll always remember what Josh McDowell said that night. He said: "A lot of us base our love on 'love- if.' I'll love you if you do it my way. Sometimes we love 'because-of.' I love you because of the way you look or the things you do. Real love" he said, "is love 
'in-spite-of,' in spite of your quirks, in spite of the thing you just did, I'm going to still love you."

That's what real love is. That's what real sacrifice is too. It's interesting that in the book Gates of Fire, which the movie 300 was based on, there is a little section that I think captures this idea of sacrifice and love very strongly. Now, my last name is Athens. My original name was Athenasiades. I come from the old country, not personally, but my family comes from Greece, so of course, I was thrilled to see this movie gain such notoriety for the Spartans. In Gates of Fire, a Spartan slave is captured by the Persians, and this slave is up there with the Persian ruler Xerxes. Xerxes keeps looking down at these Spartans and can't understand why they are following Leonides. He asks, "Why is this? How can this king have that kind of following?"

And the slave says: "I will tell his majesty what a king is." He then explains to Xerxes: A king does not abide within his tent while his men bleed and die upon the field. A king does not dine while his men go hungry nor sleep when they stand watch upon the wall. A king does not command his men's loyalty through fear nor purchase it with gold. He earns their love by the sweat of his own back and the pains he endures for their sake. That which comprises the harshest burden, a king lifts first and sets down last. A king does not require service of those he leads but provides it to them. He serves them, not they him. Wow. That captures it.

Let me close with this final story. Corporal Jason Dunham, United States Marine Corps, grew up in Scio, which is in upstate New York. He graduates from high school and enlists in the Marine Corps in the summer of 2000. In 2004, Corporal Jason Dunham is a 
squad leader on the border of Iraq and Syria. As you probably know, squad leaders are typically sergeants, but in Dunham's case, he was a corporal, much loved by his people, much respected by all those above him. In 2004, Dunham is a squad leader at a checkpoint near the Iraq-Syrian border.

While he is at that checkpoint with his squad, he hears rocket-propelled grenade fire, small arms-fire, a distance up the road. A U.S. convoy had just gone through their checkpoint, so they were sure that this convoy had been ambushed. He mounts up his 16

17

squad. They move out in their Humvees to where the convoy was ambushed. He then turns his squad toward the village that's adjacent to this ambush location, and they move through the village. They finally come to this place where there are a couple of vans parked, and Dunham is convinced this is where the insurgents probably came from. Dunham carefully brings his squad up to these vans. In an instant, an insurgent jumps out of one of them. Dunham notices he has a grenade in his hand. The pin is already pulled, but he is holding the hand grip on it, and they begin to wrestle, Dunham and this insurgent. The insurgent breaks his arm free and throws the grenade towards the squad. Dunham is able to break loose from the insurgent, push him away, and tells his squad to hit the deck. Dunham takes his helmet off, puts it on top of the grenade, and the rest of his body and the grenade explodes. No squad members are injured. Dunham dies of his injuries seven days later. In January of 2007, the President of the United States presented the Medal of Honor to 
Corporal Dunham's family for conspicuous gallantry and intrepidity at the risk of his own life, above and beyond the call of duty. Corporal Jason Dunham sacrificed it all for the people he loved.

I have thought about this, and I think about you as a group, how many of you would be in that kind of situation in your lifetime, maybe none of you. Maybe a very small handful would be in that kind of situation where you need to throw yourself on a grenade, but here is what I am convinced of. I am convinced that all of us as leaders have to have the willingness to throw ourselves on grenades daily for the people we work with. We need to be ready to sacrifice for them, and our ability and our willingness to do this and our motivation to do it that's going to make us extraordinary is the motivation of love. If you ask Jason Dunham what leadership and love have to do with each other, he would say they have everything to do with each other. If you ask General John Lejeune what leadership and love have to do with each other, I think General John Lejeune would say they have everything to do with it. I believe if you ask any extraordinary leader what does leadership and love have to do with it, they would tell you everything. My great hope is that all of you that are about to go out as leaders, some of you will take command of units much earlier than others, but all of you will be involved in leadership, that you will go out with a desire to be extraordinary, but if you want to be extraordinary, it's not just about competence, and it's not just about courage. That third $\mathrm{C}$ is part of the foundation, the $\mathrm{C}$ of compassion. Love your people, and you will see amazing things occur. “To promote and enhance the Naval Academy's development of ethical leaders for service in the Navy and Marine Corps and to advance the practice of ethical leadership in 
the naval service and the nation."

"Morality lurks in all the shadows surrounding our profession. To not only ignore it but fail to embrace it will ultimately ensure your failure in the service."

—VADM James B. Stockdale

The Vice Admiral James B. Stockdale Center for

Ethical Leadership

U.S. Naval Academy

Annapolis, Maryland

tel (410) 293-6085

fax (410) 293-6081

www.usna.edu/ethics 


\section{Appendix E}

\section{Interview Protocol}

\section{Research Questions}

R 1: How did principals of high poverty elementary schools live and experience the phenomena of reduced resources and the expectation of increased student achievement?

a. At the time of the initial reductions, what was going through your mind? What were your initial thoughts and feelings?

b. What initial steps did you take when you learned that resources would be reduced?

c. How did data play a role in your decision making? What data did you consider?

d. Did your strategic use of resources (people, time and money) change?

e. How did you nurture hope and maintain energy with yourself and your staff?

f. Did you engage teachers in problem solving at the school wide level? Perhaps at the level of teacher teams? How did you do this?

g. What skills and experiences were/are priorities?

g. Did the perceptions of the following groups play a role in your work over the years? How so?

1. Students, teachers, parents, community members, district office personnel, supervisors, evaluators.

h. How did you affirm the work of teachers?

i. If this happened, how did you help staff members deal with the negative labels 
attached to school performance such as school report card ratings- unsatisfactory, focus school, needs improvement etc?

j. Did you buffer the staff from unnecessary pressure from the district level, especially when resources were being reduced? Is there such a thing? Does a principal absorb this pressure without passing it along to the staff? How is that done?

$k$. How is or was teacher leadership distributed to effect change when resources were taken away?

1. What was the hardest thing you dealt with?

$\mathrm{m}$. What kept you up at night?

n. What metaphor would you use to describe your work as a principal? Why?

o. Sometimes words are difficult to use when describing an experience. Please share an object or artifact that represents your experience and explain how this is so.

p. Did you consult with anyone over decisions that you made? What did that look like?

q. End of Interview Now, looking back, would you have made any decisions differently? 


\section{Appendix F}

\section{Example of Member Checking Email Conversation Pseudonyms were used for the name of the participant and locations.}

Hi Tricia,

I hope all is well! I have attached the transcripts from our interview. Could you read through them and let me know if any changes need to be made?

The company I worked with shared these guidelines when reading the transcripts:

Any words that we were able to phonetically spell, but were not $100 \%$ sure of the spelling on we put in RED text the first time they are used. This allows you to go back and do a find and replace feature later if you happen to be more familiar with the word itself.

Any words we were not able to distinguish at all are indicated with a

I may need to get back to you for more clarification after more analysis on my part, but things seem clear to me after the first read when looking at your answers in relationship to the questions.

I will be back in touch at least one final time to let you know when I will be proceeding with my defense of the final product. I am extremely grateful for your time and energy on this project!

Kevin

Hello,

I have attached the picture I told you about that represents my experiences to me. In reviewing the notes, on page 3, the apartment complex was the Broadfoot Terrace and the nickname 'The water'. I would prefer not publishing the info that I replaced a principal in early in the school year (I wasn't sure if you would mention it or not). Other than that just let me know if you need any further clarification. 
Good luck,

Tricia

Hi Tricia,

Thank you so much for sharing the picture! That is really precious!

In terms of the Cherrie Heights experience, are you okay if I refer to the work that you did there without mentioning how or why you were hired? I am using pseudonyms for school district names as well as the names of the people in the study. So, Cherrie Heights school district will not be named.

I can take that whole section out if you would prefer. Let me know.

Take Care,

Kevin

Hello,

Thanks for understanding on Cherrie Heights. No problem if you mention my work there.

Tricia 